\title{
SOURCE ROD FAILURE AND SUBSEQUENT DECONTAMINATION
}

\author{
F. B. LONGTIN \\ Works Technical Department \\ Savannah River Plant
}
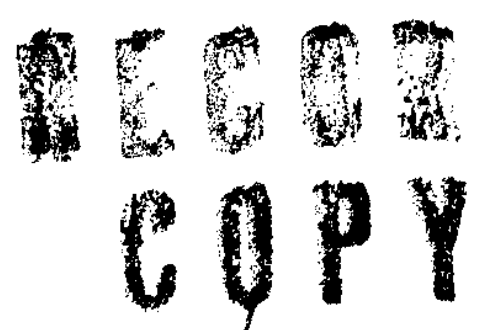

DO NOT RELEASS

BROM FILE
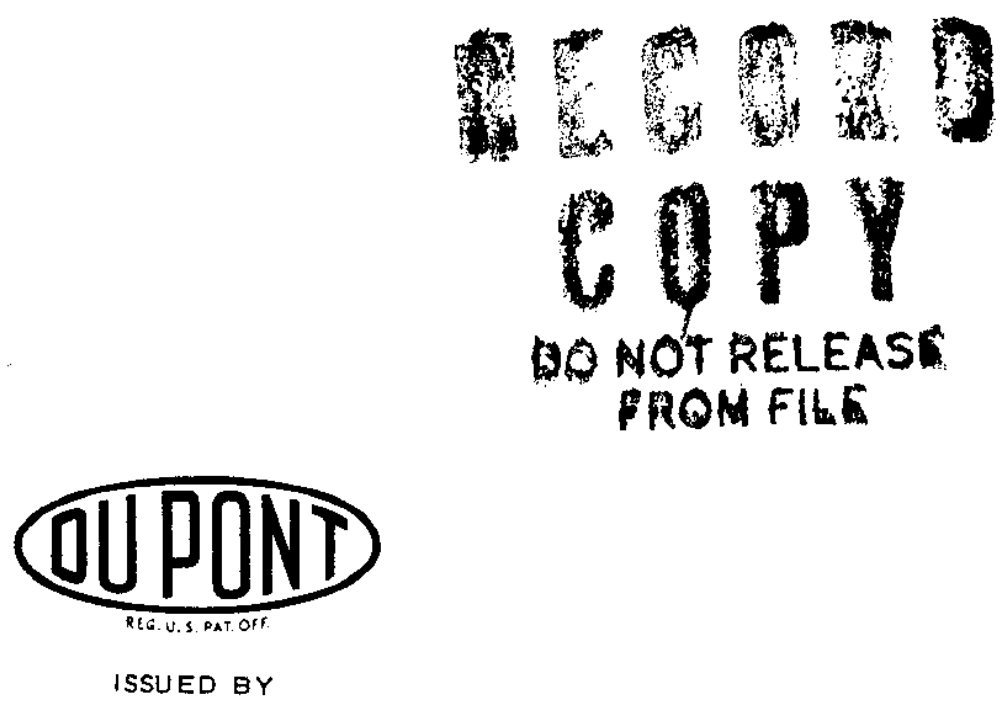

Savannah River Laboratory

Aiken, South Carolina 


\section{NOTICE}

This report was prepared as an account of work sponsored by the United States Government. Neither the United States nor the United States Atomic Energy Commission, nor any of their employees, nor any of their contractors, subcontractors, or their employees, makes any warranty, express or implied, or assumes any legal liability or responsibility for the accuracy, completeness or usefulness of any information, apparatus, product or process disclosed, or represents that its use would not infringe privately owned rights.

Printed in the United States of America

Available from

National Technical Information Service

U. S. Department of Commerce

5285 Port Royal Road

Springfield, Virginia 22151

Price: Printed Copy $\$ 3.00$; Microfiche $\$ 0.95$ 
DP-1305

General, Miscellaneous, and

Progress Reports

(TID -4500, UC-2)

\title{
SOURCE ROD FAILURE AND SUBSEQUENT DECONTAMINATION
}

\author{
F. B. Longtin
}

\begin{abstract}
Approved by
L. W. Fox, Superintendent

Reactor Technology Section

Works Technical Department

Savannah River Plant
\end{abstract}

April 1973

Issued by

E. 1. DU PONT DE NEMOURS \& COMPANY

SAVANNAH RIVER LABORATORY

AIKEN, S. C. 29801

CONTRACT AT(07.2).1 WITH THE

UNITED STATES ATOMIC ENERGY COMMISSION 


\begin{abstract}
On November 9, 1970, an antimony-beryllium source rod failed while suspended in air on the charge machine over the Savannah River Plant K Reactor.

This failure released 80,000 curies of radioactivity into the Reactor Process Room, and an additional 39,000 curies remaining in the failed rod was deposited in the Disassembly Basin before the nature of the failure was recognized. Very little of this radioactivity was released outside the reactor building. The atmospheric release was about $0.003 \mathrm{Ci}$, and liquid releases were about $7.4 \mathrm{Ci}$ to the $\mathrm{K}$ containment basin and $0.52 \mathrm{Ci}$ to a plant stream. None of the activity has been detected outside the plant perimeter fence.

Nearly all of the $80,000 \mathrm{Ci}$ released to the Process Room remained adhering to or lying on the charge machine, and was by far the major source of radiation preventing personnel entry in to the Process Room. It was removed by remote vacuuming and by manually removing parts of the machine with extension tools while the machine remained in the Process Room. The removed parts and debris were temporarily stored underwater in the Disassembly Basin. Remote vacuuming of the reactor top surface and floor by equipment carried on the discharge machine reduced radioactive contamination of those surfaces only slightly. Manual cleaning with wire brushes, vacuum cleaners, and chemicals was necessary to reduce radiation to levels at which normal reactor operation can be resumed.

Cleanup of the radioactive contamination took 3 months with the participation of 850 people, none of whom received excessive radiation exposure.
\end{abstract}




\section{CONTENTS}

INTRODUCTION

K REACTOR ROOM

INCIDENT DESCRIPTION 1

ANALYSIS OF FAILURE 3

INITIAL DISTRIBUTION OF RADIOACTIVITY 4

CLEANUP

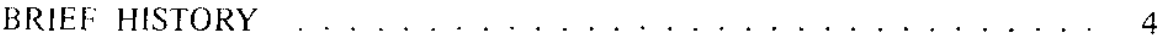

RADIATION MEASUREMENT (Task 2)

Methods ............................ 5



CHARGE MACHINE (Task 1) $\ldots \ldots \ldots \ldots \ldots \ldots \ldots$

Remote Vacuuming . . . . . . . . . . . . . . . . 8

Parts Removal . . . . . . . . . . . . . . . . . . . . . . 10

Manual Decontamination .................. . . . . .

REACTOR PROCESS ROOM (Task 3)

Remote Decontamination of Reactor Room . . . . . . . . . . . . 12

Manual Cleaning of Floor and Walls . . . . . . . . . . . 12

Manual Cleanup of Plenum Top . . . . . . . . . . 13

CONFINEMENT SYSTEM FILTERS (Task 4)

Description of the System . . . . . . . . . . . . . . 15

Confincment System Performance . . . . . . . . . . . . . 16

Filter Compartment Replacement . . . . . . . . . . 16

REACTOR WORK (Task 5)

Discharging . . . . . . . . . . . . . . 18

Ant imony in Reactor . . . . . . . . . . . . . 18

D\& $\&$ CANAL (Task 6)

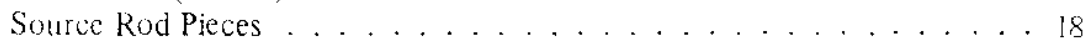

Material from Process Room . . . . . . . . . . . . . . . . 19

DISASSEMBLY BASIN (Task 7)

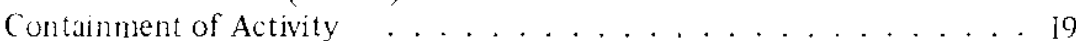

TECHNICAL SUPPORT (Task 8)

Understanding the Failure ............... . . 21

Assistance in Cleanup Operations . . . . . . . . . . . 22

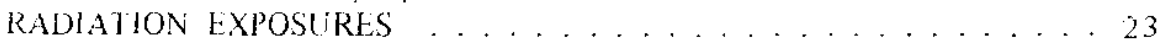

PROBLEMS IN CONFINING THE RELEASE

AND (I.EANUP OF RADIOACTIVITY



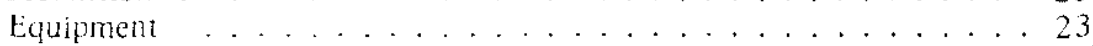

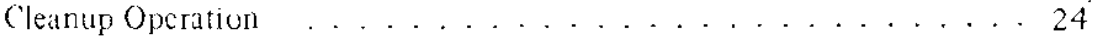

PROCRAM

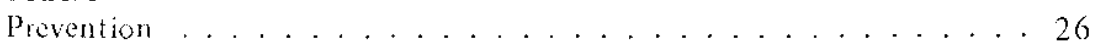



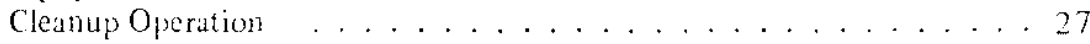

CONCLUSIONS 28

$\begin{array}{ll}\text { ILLUSTRATIONS } & 30\end{array}$

GLOSSARY 69

$\begin{array}{ll}\text { REFERENCES } & 72\end{array}$ 


\section{INTRODUCTION}

On November 9, 1970 an antimony-beryllium neutron source rod failed at about 5:00 a.m. while suspended in air over $K$ reactor. Failure of the source rod released activity to the Reactor Process Room and to the confinement filter compartments. The resulting levels of radiation and radioactive contamination were sufficient to prevent normal work in the Process Room without decontamination. Cleanup of the Process Room to the point that normal work could be resumed extended through early February 1971. Cleanup was completed with only minor releases of radioactive material to the environs.

\section{K REACTOR ROOM}

The K reactor Process Room (figure 1) is about 130 feet long by 58 feet wide at the floor. The ceiling height is 61 feet directly above the reactor and 43 feet elsewhere. Concrete haunches, 31 feet above the floor, support the rails of the charge and discharge machines. Wall, floor, and ceiling surfaces of the room are concrete. The floor and walls below haunch level are painted.

The reactor is located near the center of the Process Room (figure 2) and mostly below floor level. The stainless steel reactor plenum extends about 20 inches above floor level in the reactor room and is about 17 feet in diameter. A variety of reactor components extend above the surface of the plenum; these include permanent plenum tubes (which locate components in the reactor), component latches, probe pins for the charge and discharge machines, and leads for pressure and temperature sensors. Six inlet pipes rise through the floor and enter inlet nozzles around the plenum.

Reactor components are handled during charging and discharging by either the charge or the discharge machine, both of which operate on the same rails supported by the haunches. The charge machine picks up new components from the presentation point near one end of the room and the discharge machine deposits discharged components in the discharge and exit (D \& E) canal at the opposite end of the room. A remotely operable conveyor in this canal transfers irradiated reactor components from the reactor room to underwater storage hangers in the storage area outside the Process Room. The charge and discharge machines (cranes) can be moved from the process room through a doorway into the cranc wash and maintenance areas; the doorway is normally sealed by a 26-foot wide shield door.

\section{INCIDENT DESCRIPTION}

The incident occurred early in a normal reactor discharge. A cluster of six control rods and the source rod (which was in the center of the cluster) had been removed from the reactor to permit replacement of the septifoil housing which normally encloses them when in the reactor. During the replacement operation they were left suspended in air on the $\mathrm{C}$-mast of the charge machine (usually referred to as the "C machine"). This operation (including recharging the rods to the reactor) had already been successfully completed with five other rod clusters, one of which also contained an 
antimony-beryllium source rod. Because of difficulties in seating the septifoil, this particular cluster of rods was held in air ten minutes longer than the previous clusters, for a total of about 22 minutes before an attempt was made to recharge it to the reactor. It was then found that the $\mathrm{C}$-mast waterpan, which was located below the rods to catch drainage of $\mathrm{D}_{2} \mathrm{O}$ from them, could not be moved out of the way to allow the rods to be recharged to the reactor. Observation showed that the source rod had separated about four feet from the bottom; the lower part of the rod was supported by the waterpan, while the upper part of the rod was still held by the $\mathrm{C}$-mast chuck. The charge machine was moved to a position over the discharge and exit (D \& E) canal, into which discharged reactor components are normally deposited for transfer to the Disassembly Basin. It was left in that position until a procedure could be developed to discharge the failed rod into the canal.

The fact that radioactivity had been released to the Process Room as a result of the failure was not recognized immediately. The "High Radiation - Near-Far Side Filter Area" alarm came on sometime between 5:00 a.m. and 5:30 a.m.; this alarm was silenced but was not investigated until early on the 8-4 shift. Late on the 12-8 shift, Health Physics investigated high activity indications on the Kanne chamber which monitors tritium activity in the -40 exhaust air. Only later was it realized that this signal was caused by high gamma radiation $f$ rom the confinement filters, which are near this Kanne chamber. At about 8:00 a.m. the need to investigate the "High Radiation - Near-Far Side Filter Area" alarm was recognized and Health Physics was requested to survey the filter area as required by procedure ACC-519.

While the survey was in progress, development of a procedure for depositing the rod in the canal was completed. The cluster of rods in the $\mathrm{C}$ machine was raised to leave the bottom half of the rod free, but still resting on the waterpan. The waterpan was then moved; this motion dislodged the source rod section and caused it to drop into the canal. The upper half of the rod was then lowered into the canal and released. The remaining control rods were recharged to the reactor.

The existence of a radioactivity problem in the Process Room was first recognized when the radiation level in the room remained high after the control rods had been recharged to the reactor. At about this time the Health Physics survey showed a radiation level of $3.5 \mathrm{R} / \mathrm{hr}$ about $1 \mathrm{in}$. from the number 6 compartment and more than $70 \mathrm{R} / \mathrm{hr}$ about $1 \mathrm{in}$. from the number 2 compartment. Other alarms had been received and it was found that at 5:00 a.m. the radiation levels recorded by installed instruments which monitor the filter compartments had increased from $0.2 \mathrm{R} / \mathrm{hr}$ to $3.8 \mathrm{R} / \mathrm{hr}$ for compartments 5 and 6 and from $0.2 \mathrm{R} / \mathrm{hr}$ to $7.5 \mathrm{R} / \mathrm{hr}$ for compartments 2 and 3 over a period of about 15 minutes. It was also found that the Process Room radiation level (as read by HM chambers) had remained high after the rods were recharged. One chamber at the D \& E canal end of the Process Room indicated about $220 \mathrm{R} / \mathrm{hr}$.

By this time it was apparent that the source rod had failed and released radioactivity. Small bits of metal were observed in the waterpan and on other surfaces of the charge machine. The reading of HM chamber No. 40 (nearest the D\& E canal) increased from 170 to $288 \mathrm{R} / \mathrm{hr}$ when the charge machine was moved 10 feet closer, to a distance of 19 feet from it. High intensity Cerenkov radiation from both pieces of the source rod was observed from the Disassembly Basin side of the D \& E canal. Several areas of low intensity Cerenkov radiation were observed on other nearby sections of the canal floor. It was determined by radiation surveys and smears that, except for the pieces of the source rod in the canal, the radioactivity was confined to the process room and the confinement filters. At the time the source rod was deposited in the D\&E canal, that portion of the Disassembly Basin consisting of the canal and the vertical tube storage section (VTS) was isolated so that any radioactivity introduced by the rod was confined to that section. 


\title{
ANALYSIS OF FAILURE
}

\author{
DESCRIPTION OF SB-BE SOURCE ROD
}

Antimony-beryllium sources arc used as neutron sources within the reactor to check the response of instrumentation primarily for startup operations. During reactor operation the antimony is converted by $n, \gamma$ reaction to the radioactive isotopes ${ }^{122} \mathrm{Sb}$ and ${ }^{124} \mathrm{Sb}$, which act as a gamma source. The gamma rays from this source are absorbed in beryllium by the reaction ${ }^{9} \mathrm{Be}(\gamma, \mathrm{n}) 2{ }^{4} \mathrm{He}$ to provide the neutron source.

The Sb-Be source which failed consisted of three 3-inch long sections in an aluminum can (figure 3). Fach section contained a hot-pressed hollow cylinder of beryllium metal powder ( 0.81 in. OD $\times$ $0.42 \mathrm{in}$. ID) and a cast antimony metal rod core slip-fitted into the beryllium. The three sections were stacked in an 1100 alloy aluminum can $(0.86 \mathrm{in.}$ OD $\times 0.81 \mathrm{in.}$ ID). Thick end plugs were welded to seal the source. This source slug was swaged into a hollow 18 -ft long control rod "raincoat" made of 1100 athy alumirum $(0.94 \mathrm{in}$. OD) so as to be in the high flux portion of the reactor.

The source slug contained 112.000 curies of radioactivity (primarily ${ }^{122,124} \mathrm{Sb}$ ) at the time of fallue. The calculated isotopic and chemical distribution at the time of reactor shutdown is shown in table 1. The tellurium content, buit in primarily as $\beta$-decay products of $122.124 \mathrm{Sb}$ and activated to $123.125 \mathrm{~T}$ by neuren capture. Was calculated and measured to be $26 \mathrm{wt} \%$

\section{CALSE OF FAILLRE:}

Some observations at the time of the failure pointed to possible forceful separation of the rod such as 10 propel the separated end of the rod energetically. Subsequent analysis showed that the failure was caused by overheating and meiting of the aluminum cladding at the center of the source length. Brittle intergranula separation of aluminum was effected by grain boundary melting of silicon-enriched aluminum at about $600^{\circ} \mathrm{C}$. The appearance of the aluminum indicated that failure was not calised by overpressurization. Post failure examinations, engineering analyses, thermodynamic judgments, and differential thermal analyses indicate that no large energy releases (excepl selfthating on gatedses occured during the rise to $600^{\circ} \mathrm{C}$.

About $x 0.000$ ( $\mathrm{i}$ were released from the rod. The radioactive $\beta$-Sb 3 Te core melted at about $536^{\circ} \mathrm{C}$. splaticred upon rod separation, and fumed $\left(\mathrm{Sb}_{2} \mathrm{O}_{3}\right)_{4}$ and $\mathrm{TeO}$ or $\mathrm{TeO}_{2}$ gas while exposed 4 hours to ait over $400^{\circ} \mathrm{C}$ in the control rod chuster.

Figure 4 gives the results of calculations of rise in temperature of the source suspended in air, based on estimated power generation from self-heating and ${ }^{6}{ }^{\circ} \mathrm{Co}$ gamma rays from adjacent sources. At the time of fiathe (atter about 14 minutes in air) the temperature had risen to or slightly above the melting point of the irtadiated aluminum. Iradiation of the aluminum had converted enough of it to silicon to lower its melting point from an original $640^{\circ} \mathrm{C}$ to about $588^{\circ} \mathrm{C}$. Other evidence indicates that meling of the aluminum occurred at about this temperature. The second $\mathrm{Sb}$-Be source rod and the control rods did not fail because, in the twelve minutes or less that they hung in air, the temperature did not rise high enough. 


\section{INITIAL DISTRIBUTION OF RADIOACTIVITY}

Insufficient data were obtained to provide an accurate estimate of the distribution of radioactivity from the failed source rod immediately after the failure. However, with a few assumptions it is possible to make a rough estimate of this initial distribution, as shown in table II. Several days after the failure, pictures of the reactor process room were taken from above with a pinhole X-ray camera to assess the distribution of radioactivity. The estimate given in table II agrees qualitatively with the X-ray results, which indicated more than $90 \%$ of the total released activity remained on the $\mathrm{C}$ machine. From this estimate it is seen that:

- The $\mathrm{C}$ machine retained much more radioactivity than any other location.

- Most of the released activity not on the $C$ machine was on the top of the reactor tank where it had fallen from the suspended source rod.

- About 6364 curies of activity became airborne as fumes, of which $98 \%$ reached the confinement filters and was retained by them. Nearly all of the remainder settled on the process room floors, while less than $0.06 \%$ of it settled on the process room walls.

- An undetermined small amount was deposited at the edge of the D \& E canal where the C machine stood while awaiting disposal of the failed rod. It is not certain whether this deposit occurred at that time or later when the $C$ machine was at about the same location for cleanup operations.

\section{NATURAL DECAY}

While about $60 \%$ of the initial radioactivity was short-lived ${ }^{122} \mathrm{Sb}$ (half-life $=2.8 \mathrm{~d}$ ), the remaining $40 \%$ was long lived (mostly 60-day half-life or longer). Figure 5 shows the natural decay of radiation from such a source giving an initial radiation level of $100 \mathrm{R} / \mathrm{hr}$ (typical of initial radiation levels in the process room at positions more than a few feet from the $\mathrm{C}$ machine). Limited work on a nearly normal basis might begin when a level of $100 \mathrm{mR} / \mathrm{hr}$ is reached; figure 5 shows that with only natural decay this level would be reached in about two years. Consequently, some cleanup effort would be necessary.

\section{CLEANUP}

\section{Brief History}

On November 9 through November 11 efforts were directed at ensuring containment of radioactivity and assessing the magnitude of the cleanup problem. By November 12 it began to be evident that a major cleanup program would be necessary. This program was broken down into eight major tasks, each assigned to a separate committee, as shown in tables III and IV.

Because it already appeared from readings of installed radiation monitoring instruments that most of the radioactivity remained on the charge machine, the first objective (Task 1) was to decontaminate it to the point that it could be removed from the process room. If the radioactivity remaining in the process room were small enough, this would allow personnel entry to facilitate cleanip of the remainder either manually or remotely.

Of almost equal importance was to determine the location and intensity of radioactive contamination (Task 2). This would show where cleanup efforts should be concentrated and measure the effectiveness of each effort. 
The period from November 13 to November 23 was spent in planning the cleanup program, in designing, fabricating and procuring equipment, and in making radiation surveys. The first actual decontamination work was done on November 23.

The major phases in the decontamination process were:

- Removal of loose debris from the C machine by an eductor type vacuum cleaner mounted on the D\& E conveyor .................. Nov $23-$ Dec 28

- Remote vacuuming of the process room floor by an eductor mounted on the D machine ............ Dec $10-$ Dec 25

- Removal of contaminated parts from $\mathrm{C}$ machine ........ Dec $15-$ Dec 28

- Removal of the C machine to the Crane Wash

(first piece off Dec 22)

Area (between heavy shield doors) . . . . . . . . . . . . Dec 30

- Manual cleaning of process room

floors and walls ................ Dec 30 . Jan 5

- Completion of reactor discharge ............... Jan 6 - Jan 12

- Final cleaning of reactor tank top

- mechanical .................. Jan 13 - Jan 18

- chemical ................. Jan 19. Feb 4

- Decontamination of C machine Jan 16-Jan 20

in Crane Wash Area Feb 1 - Feb 5

A detailed chronology of cleanup operations is given in figures 6,7 , and 8 . The effectiveness of the major operations is summarized in table $\mathrm{V}$ and figure 9 , which give percents of the original radioactivity with the effect of radioactive decay eliminated.

Each reading in $\mathrm{R} / \mathrm{hr}$ at time of reading was multiplied by the ratio (radiation at zero time)/(radiation at time of reading) from figure 5 . The

results were then expressed as percent of the readings for November 9.]

Cleaning of the $\mathrm{C}$ machine removed at least $94 \%$ of the originally radioactive material. Some of the additional material removed in floor cleaning may have been dislodged from the $\mathrm{C}$ machine in the process of cleaning it or of moving it about the Process Room. Thus the results of radioactivity removal were in substantial agreement with the estimate of initial distribution of radioactivity given in table II.

\section{Radiation Measurement}

\section{METHODS}

A major factor in planning and monitoring the progress of cleanup efforts was the ability to locate and measure the intensity of radiation sources. Four remote reading ion chambers (HM chambers) mounted on the walls of the Process Room were part of the normal operating equipment for Health Monitoring purposes. Their locations are shown in figure 2. Throughout the cleanup period they provided a measure of the overall radiation level. They needed to be supplemented by additional remotely operated means of pinpointing the location of the major radiation sources, as well as by the usual manual surveys (see figures 17 and 18) which could not be used extensively until the radiation level had been brought down low enough to permit prolonged entry of personnel into the Process Room. 
The three principal remote methods used for locating major radiation sources were:

- A pinhole X-ray camera to photograph the distribution of radioactivity over the entire process room.

- An ion chamber with amplifier to survey the distribution of radioactivity on the $\mathrm{C}$ machine.

- A gamma radiation detector carried by the D machine for detailed surveys of the distribution of radioactivity on the Process Room floor and reactor tank top.

Pinhole Camera. The design of the pinhole camera is illustrated in figure 10. It consisted essentially of a lead box with a conical aperture in front and a film holder in back. To obtain a picture, it was loaded with X-ray film and placed over one of two holes that were available in the Process Room ceiling above the rim of the reactor tank, with the aperture pointing downward. It was left in that position long enough to obtain a suitable exposure and then the film was removed and processed. With this camera it was possible to locate with some accuracy the most intense radiation sources (see figure 11). Sources whose intensities were less than one-tenth that of the most intense source could not be distinguished.

C Machine Survey. Both the charge machine and the discharge (or D) machine have the built-in capability of being accurately positioned anywhere in the Process Room (within their limits of travel) by remote operation from the Crane Control Room. This capability was used as the basis for making detailed surveys of the distribution of radioactivity on the $\mathrm{C}$ machine. An ion chamber suitable for detecting and measuring the radiations was positioned in the Process Room in one of three different ways and the $\mathrm{C}$ machine was then moved past it in small steps to obtain a radiation profile.

In the first method the ion chamber was lowered into the Process Room on a rope through one of the ceiling holes (see table VI for results). In the second method the ion chamber was pushed into the Process Room on a cart. In the third and most accurate method, use was made of the facility by which unirradiated fuel assemblies are moved from the Final Storage section of the Assembly Area into the Process Room to be picked up by the $\mathrm{C}$ machine at the Presentation Point. The fuel assembly is suspended in a hanger from a trolley which carries it through a narrow slot in the concrete shielding wall to the Presentation Point where it is accurately positioned for pickup by the $\mathrm{C}$ machine. In this method the collimated ion chamber was suspended from the hanger at a measured elevation while it was in the Assembly Area. It was then carried to the Presentation Point and the $\mathrm{C}$ machine was moved past it to obtain a profile at one elevation. The ion chamber was then returned to the Final Storage area where it was repositioned at a different elevation. This process was repeated for a series of elevations to pinpoint the location of major radiation sources on the $\mathrm{C}$ machine (for typical results see figure 12).

The instrumentation used for this purpose was a portable Health Monitoring Cart designed in 1960 for special surveys requiring remote control. The ion chamber was supplied with 20 feet of cable and an extended range amplifier which provides a range from $\sim 50 \mathrm{mR} / \mathrm{hr}$ to $\sim 10^{7} \mathrm{R} / \mathrm{hr}$.

While these methods were very helpful in the early stages of planning and carrying out decontamination of the $\mathrm{C}$ machine, the best results were obtained by radioautography. This could only be used after the radiation levels had been lowered enough to allow personnel entry to place the $\mathrm{X}$-ray film on the $\mathrm{C}$ machine.

D Machine Probe. A portable gamma survey meter was developed by the Engineering Assistance Section which could be carried either by the $C$ or $D$ machine and read remotely; it was used only on the $\mathrm{D}$ machine. This self-contained battery-powered instrument provided a logarithmic range from 0.1 
to $1000 \mathrm{R} / \mathrm{hr}$. It consisted of an ion chamber shielded from lateral radiations by $1 \frac{1}{2} \mathrm{inches}$ of lead, a power supply and electronic circuit, and a meter mounted so it could be read with the Crane Control Roon periscope or with binoculars, as shown in figure 13. It was built without power switch, to operate continuously in order to maintain the best calibration; when operated this way the battery had a life of about 45 days. The entire unit was supported from a standard top filting which allowed it to be handled by the $C$ or D machine chucks in the same way as reactor components. Maintaining proper urientution of the meter for reading proved difficult.

To conduct a survey, the D machine carrying this probe was positioned serially at each point of it grid covering a designated portion of the Process Room. A coarse grid was used to locate regions of high interisity which could then be surveyed to finer detail using a fine grid to locate hot spots (for typical results see figures $14,15,16$, and 19).

\section{I:ITIAL SURVEYS}

Charge Machine. On November 9 the charge machine was moved from the D\&E canal to within about 20 feet of HM chamber 40 ; the reading on this chamber increased from $173 \mathrm{R} / \mathrm{hr}$ to $288 \mathrm{R} / \mathrm{hr}$. This increase gave the initial indication that a major part of the released radioactivity still remained on the C machine. This conclusion was further confirmed by a reading of $500 \mathrm{R} / \mathrm{hr}$ at 10 feet from the C machine obtained on November 11 with a Health Physics instrument inserted into the Process Room through the Wild level hole, and again by the first $X+r a y$ film cxposures with the pinhole camera on November 20.

Process Room. Some indication of the extent to which radioactive contamination was distributed over the process room flocr and walls was obtained as early as November 11 by instrument probe readings and by smears taken through the Presentation Point door and the wild level hole. The first extensive surveys were made on November 16 from doors 313 and 320 , which provide access to opposite ends of the Process Room. These doors are close to the locations of HM chambers 41 and 40 respectively. Reddings and smears could be taken only out to about io feet from the doors because of limititions un persomel exposure. Readings with portable survey instruments were close to the values recomed by the corresponding HM chambers Nos. 40 and 41 . Smears taken through these two doors and the presentation point door had radiation levels of 0.2 to $5 \mathrm{rad} / \mathrm{hr} / \mathrm{ft}^{2}$ at 3 inches; those closest to the reator were generally lighest. Tests done in connection with these surveys and on November 18 showed that most of the material on the floor could be easily removed either by damp mopping or by vacumming.

Smedrs of radioative contamination on the process room walls showed a much lower level of contuminition than on the floors. These smears ranged from very low at the far end of the process room to 0.05 w $0.5 \mathrm{rad} / \mathrm{hr} / \mathrm{ft}^{2}$ at 3 inches at the end nearest the reactor.

The first $X$-raty films showed, in addition to the major concentration of material on the ( machine, at small concentration of activity on the reactor top, one beside the D \& E canal (cf. figure 11) and a cluster of weak radiation sources in front of the observation window.

This information played at major part in determining priorities and methods of attack in the clesnup program.

\section{Charge Machine}

First priority in cleaning up the relcased radioactivity was decontamination of the $\mathrm{C}$ machine to the point that it could be removed from the process room. The primary requirements were to 
conduct this decontamination in such a way as to avoid breaching containment of radioactive contamination within the reactor building and to avoid making final decontamination of the process room more difficult. [In particular it was necessary to maintain a pressure below atmospheric pressure in the process room so that airborne contamination would not be carried out of the process room.] Because of the high radiation levels the initial work was done remotely.

The D \& E conveyor provided the basis for the initial remote operations. This machine normally receives discharged components in the $\mathrm{D} \& \mathrm{E}$ canal, and carries them underwater beneath the separating wall between the Process Room and the Disassembly Basin. It can also be used to carry components or equipment from the Disassembly Basin into the Process Room without breaching containment of radioactivity. It can provide a limited amount of vertical motion to equipment carried by it, relative to the $\mathrm{C}$ machine. Use of a remotely operated robot was considered, but entry of the robot into the Process Room would require breaching of containment, and procuring a suitable robot or reconditioning and adapting the existing general purpose robot would have entailed unwanted delay.

From visual observation by periscope from the Crane Control Room, much of the debris of the source rod on the $\mathrm{C}$ machine appeared to be loose chips and spatters (figure 20). The method of approach chosen was therefore as follows:

- Remove loose debris with an eductor vacuum system mounted on the D \& E conveyor.

- Remotely remove $\mathrm{C}$ machine parts having firmly attached, high radiation level contamination.

- Wash remaining lower parts of the $\mathrm{C}$ machine with a water spray.

- Remove the $\mathrm{C}$ machine to the Crane Wash Area.

- Complete decontamination manually.

The broad outlines of this program had been established by November 12 and firmed up in detail by November 18. Some development and testing of equipment was necessary; this was underway on November 13 and nearing completion by November 18 . Actual decontamination work started November 23.

\section{REMOTE VACUUMING}

Equipment. Vacuuming was selected as the most effective means of removing loose particles since the particles could be contained and would not be spread over the floor of the Process Room nor the D \& E canal. An air eductor, which was a Stores stock item, was chosen as the vacuum source. The suction leg of the eductor was provided with a screen, trap and absolute filter to prevent discharge of particles larger than 5 microns. Remotely operated air inlet and suction valves were provided to contain collected material after vacuuming was finished (figure 21 ).

This eductor system was mounted on the $D$ \& $E$ conveyor as shown in figure 22 . The conveyor consists of a boom which can be rotated either manually or under power in a vertical plane. The boom carries, on a pivot at its outer end, the "golf bag" receptacle into which discharged components are deposited. The lower end of the golf bag travels on a track which guides and correctly positions travel of the discharged component under the process room wall and into the Disassembly Basin. The eductor system was mounted on the upper end of the golf bag, with a compressed air supply via an underwater hose from the Disassembly side of the D \& E canal. Manual operation of the conveyor boom to move it through a small angle could be used to move the eductor vertically over a limited range in the process room. A special shielding cask was provided in which to store the eductor system in the Disassembly Basin after its use had been completed. 
Operation. The eductor system was installed on the D \& E conveyor in the Disassembly area and then moved into the process room. Because of mechanical limitations of the conveyor it was necessary to have the suction nozzle aligned in the plane of the boom and pointed torward the boom axle while travelling underwater. In use it needed to be $90^{\circ}$ away from this position. A rotary joint was provided (as shown) and the $\mathrm{C}$ machine was used to nudge it into the correct position. The inner chuck of the $\mathrm{C}$ machine A-mast was used to open the valve on the suction nozzle.

Each mast is provided with one or more chucks to grip reactor components of different designs. The A-mast inner chuck grips a knob of special design. The valve on the suction nozzle was supplied with a knob of this design so that the A-mast inner chuck could grip it. The valve could then be opened or closed by raising or lowering the A-mast.

The nozzle was then brought to the proper elevation for a particular vacuuming task by manually moving the conveyor boom. Then the $\mathrm{C}$ machine was moved into position and vacuuming was started by operating the air supply control valve in the Disassembly area. These operations were under constant observation through the Crane Control Room observation window and periscope, and were controlled by the window observer. Constant communication between the observers, the crane operators and the D\&E conveyor operators was essential, requiring use of a special headphone communication system.

Throughout this work there was close surveillance to detect any spread of radioactivity through the process room or any change in process room pressure which could allow escape of radioactivity. Vacuuming was to be discontinued if the process room pressure was not more negative than 0.4 inch $\mathrm{H}_{2} \mathrm{O}$ relative to the outside air, or if the particulate activity in the process room exhaust air increased by a specified small factor.

The effect of each major vacuuming operation was monitored by lowering the D \& E conveyor until the filter of the eductor system was shielded from the HM chambers by the concrete walls of the canal. The HM chamber readings were observed both with the $\mathrm{C}$ machine in its current position and again in the standard location.

Results. Photographs from the Crane Control Room periscope had shown presence of apparently loose debris in the waterpan (which collects drips from the components held in the C-mast), with smaller amounts on the clamshell plate and the support plate between B- and C-mast (figure 23).

The eductor system was first used on November 23 to clean the clamshell plate and waterpan (figures 24 to 26), with the result that the radiation level as read by the HM chambers (Nos. 40 and 42) nearest the C machine decreased about $75 \%$. Further work on November 24 on the clamshell plate and on other areas shown by the photograph to have loose debris produced little apparent reduction in radiation reading. However, when the eductor was removed from the Process Room on November 25 , the radiation level dropped another $13 \%$. At that time a plan view from the +66 level and a profile picture of the $C$ machine through Door 320 (nearest the $C$ machine) were taken with the $\mathrm{X}$-ray camera to define the location of major remaining contamination. Again on December 3 an $X$-ray profile and an ordinary photograph were taken to better define the location of hot spots by comparison. Vacuuming done November 25 and December 8 (guided by the $\mathrm{X}$-ray results) resulted in only a small reduction in the radiation readings.

Vacuuming removed all visible particles and about $95 \%$ of the original contamination. The radiation level on the $\mathrm{C}$ machine after completion of this operation was about $20,000 \mathrm{R} / \mathrm{hr}$ at 3 inches (estimate only) as a result of vacuuming plus radioactive decay. On the fourth day of vacuuming there was evidence of breakthrough of radioactive contamination from the eductor system. This eductor was therefore retired from service. Altogether, three eductors were used in this phase of cleaning the $C$ machine and were stored in the special containers in the Disassembly Basin. 


\section{PARTS REMOVAL}

Method. Originally it was planned to remove heavily contaminated parts at the D \& E canal by cutting lighter parts such as cables, and burning off heavier parts with an electric arc. Equipment was built and tested satisfactorily for this purpose, but the method was discarded because of the risk of spreading contamination vaporized by the arc.

Instead, the $\mathbf{C}$ machine was moved to the Presentation Point, where work could be done either with power tools mounted on the Presentation Point hanger (cf. "C-Machine Surveys," previously described), or manually with extension tools. However, motion of the $\mathrm{C}$ machine toward the Presentation Point carries the machine's power supply and control-cables (bit by bit) out of the Process Room. This would lead to spread of contamination by the cables if no precautions were taken.

Cable Decontamination. A plastic hut was erected over each crane haunch in the Crane Wash area next to the inner shield door, where the cables enter the Crane Wash area from the Process Room. Each hut was built with tube-lock scaffold framing and with a plywood floor to cover the rail and cable rollers, as shown in figure 27 . Initially the huts were about 20 feet long but they were eventually extended from the inner shield door to the outer shield door and beyond.

Starting on December 5, the $\mathrm{C}$ machine (and later the $\mathrm{D}$ machine) was moved in steps toward the inner shield door. The distance traveled in each ste $p$ was short enough that no contaminated cable would pass beyond the plastic hut. After each move, cable within a hut was decontaminated manually with a vacuum cleaner followed by wiping with a cloth damp with soapy water. Although cables were contaminated to a maximum of $700 \mathrm{mrads} / \mathrm{hr} / \mathrm{ft}^{2}$ at $3 \mathrm{in}$., it was possible in all cases to reduce the level of contamination to less than $5000 \mathrm{cpm} / \mathrm{ft}^{2}$ at $1 \mathrm{in}$.

This process had to be repeated each time motion of the $\mathrm{C}$ or $\mathrm{D}$ machine carried cable into the Process Room (where it picked up some contamination) and out again. Early in this process a penny-sized piece of debris fell from the $\mathrm{C}$ machine to the floor and was later retrieved. For this reason all subsequent moves of the $\mathrm{C}$ machine were made at low speed.

Presentation Point Work. Removal of parts, begun on November 18, was done by cutting off the nut or other fastener or connecting piece either with a disc-grinding wheel or a chisel. An attempt to remove bolts remotely with a wrench and then by drilling was unsuccessful. The loosened parts were dislodged and dropped into buckets with the help of a 20 -foot pry bar operated manually through the presentation point slot. The buckets were later transported by the $\mathrm{C}$ machine to the $\mathrm{D} \& \mathrm{E}$ canal, where they were transferred to the Disassembly Basin for storage.

For the grinding operation the portable grinder was suspended from a fuel hanger at the requisite elevation in the Assembly Final Storage Area and then moved to the Presentation Point. $X$ and $Y$ motion of the $C$ machine brought the part to be cut in contact with the grinding wheel. Necessary fine motion of the wheel relative to the part was provided by moving the $\mathrm{C}$ machine in 1/64-in. increments.

Chiseling was effective only in removing nuts from bolts which lay at right angles to the Presentation Slot, and was of little use for bolts which lay parallel to the length of the slot. For this operation a 20 -foot chisel was supported by ropes from a hanger and was steadied at one point on a suitable rest. The edge of the chisel was guided into position with the aid of the periscope. Blows from a 15-pound sledge hammer by personnel stationed in the Presentation Slot could remove a suitably oriented bolt in about fifteen minutes. High radiation levels in the slot severely limited the working times for this job. 
After removal of parts, the C machine was returned to the D \& E canal where a water spray was used to wash off remaining loose or soluble contaminants. The spray system was mounted on the D\& $\mathrm{E}$ conveyor and operated in much the same way as the eductor system. Spraying reduced the radiation level around the ( machine some but left hot spots on some parts. At this point personnel entered the Process Room to remove these parts with tools on extension handles. Remaining hot spots were covered with bags of lead shot and the $\mathrm{C}$ machine was then removed from the Process Room to the Crane Wash Area between the shield doors.

From December 10 un, some work had also been done on remotely cleaning up radioactivity distributed uver the Process Room floor and reactor tank top. First physical entry by personnel was

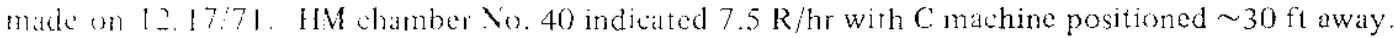
On December 30 when the ( mathine and all its parts had been removed from the Process Room, only about z perent of the or jginal radioastive contamination remained in the Process Room. General radiation levels were down to 1 to $2 \mathrm{R} / \mathrm{hr}$. permitting personnel entry for brief periods of work.

\section{WANUAL DLCONTAMINATION}

At this point a hot spot remained on the C-mast: its reading was about $2500 \mathrm{R} / \mathrm{hr}$ at 1 in. and whers were of weveral hundred $\mathrm{R} / \mathrm{hr}$ each. An enclosure of scaffolding and plastic sheeting was erected around the C machine in the Crane Wash Area to control contamination, provided with suitable entrance huts. The $2500 \mathrm{R} / \mathrm{h}$ hot spot at the lower end of the C-mast was shielded with lead to allow work on the other spots. These were first vacuumed and then sandblasted with a Vacublast unit shown in figure 28. This unit collects the used sand by vacuum, thus preventing spread of contamination. Filing and wire brushing were also used. Some small parts were removed, and finally the C-mast with its shielded lower end was removed from the $\mathrm{C}$ machine to be stored in a safe location in another building.

The lower part of the machine was then decontaminated manually with applications of Versene solution and of OPC ( $5 \%$ anmonium oxalate, $3 \%$ hydrogen peroxide, and $4 \%$ ammonium citrate) solution by brusl or absorbent pads. At this point the remaining hot spots had radiation levels of ahout lo $\mathrm{R}$ ha at it. The entire mathine was finally cleaned to a radiation level of a few $\mathrm{mR} / \mathrm{hr}$ by spay ing with at Versene-water solulion followed by a water rinse, working from the top (37-ft elevation) dentritide

Manual decontamination was interrupted at two points to permit use of the Cmachine in reactor charging and discharging. This work was completed on February 5 and a new C-mast and aciessories were installed to restore the machine to normal condition.

\section{Reactor Process Room}

Decontamination of the Reactor Process Room floor and reactor tank top (or "plenum"). beginning December 10,1971, was carried out in three stages concurrently with decontamination of the Compthine.

1. The thor and plentum top were vacuum-teaned remotely with an air eductor carried on the 1) milinine. This reduced the maximum radiation rate (on the plenum top) from $1,000 \mathrm{R} / \mathrm{hr}$



2. More rapid progress was made with manual cleaning beginning December 30, 1970. This included vacuuning and wire-brushing the floor, walls and plenum, and mopping the floor and walls with detergent. 
3. Chemical cleaning of the plenum top with OPC solution combined with mechanical cleaning, was begun on January 24, 1971. Stages 2 and 3 reduced the maximum radiation rate on the plenum top from $360 \mathrm{R} / \mathrm{hr}$ to $2 \mathrm{R} / \mathrm{hr}$ at $2 \mathrm{ft}$.

With completion of this work on February 5, 1971, radiation levels in the Process Room were low enough to allow preparations to resume normal reactor operation. (See also reference 1.)

\section{REMOTE DECONTAMINATION OF REACTOR ROOM}

To limit unnecessary personnel exposure, initial cleaning of the floor and plenum top was accomplished remotely using a specially designed air eductor carried by the discharge machine (figure 29). Air for the eductor was supplied by a portable compressor outside the reactor room via piping normally used to supply emergency cooling water to components in the discharge machine. The compressed air went through a venturi nozzle to create a suction pressure. Air coming from the nozzle passed through a 0.45 micron filter before being exhausted to the reactor room. The eductor could be taken into and out of the reactor room remotely using facilities normally used to handle reactor fuel assemblies. Several types of remotely replaceable nozzles were also provided.

A shielded survey meter, also carried by the discharge machine, was used to evaluate the progress of remote vacuuming. (See page 6 for details.) This instrument proved to be extremely effective and was used to provide radiation survey data throughout the decontamination program.

Vacuuming continued with some interruptions for charge machine decontamination and other activities from December 10 until December 30. During this time, the discharge machine was moved very slowly to cover the entire plenum top and the accessible floor area several times with different nozzle attachments. Manipulation of the nozzle around obstructions on the floor and plenum top proved to be slow. Several of the nozzles were knocked off in inaccessible locations and were abandoned until they could be retrieved manually. Survey results showed that remote vacuuming achieved decontamination factors of about 2 on localized hot spots but was essentially ineffective in reducing average radiation levels (table VII).

\section{MANUAL CLEANING OF FLOOR AND WALLS}

Decontamination proceeded more rapidly when large-scale manual cleaning of the reactor room was begun on December 30. During the following 5 weeks, about 1,000 individual entries were made into the reactor room. Approximately 350 personnel who normally are not exposed to radiation assisted to reduce exposure of reactor operating and service personnel. Use of these people, many of whom were unfamiliar with the reactor room and work in radiation fields, required careful briefing and surveillance by members of the decontamination task force. Health Physics monitoring was simplified by use of integrating dosimeters with alarms set at $400 \mathrm{mR}$. Workers also wore thermoluminescent dosimeters and self-reading pencils. Approximately $600 \mathrm{R}$ total exposure was accumulated by 850 workers during the 5 weeks of manual cleanup.

Commercial heavy-duty vacuum cleaners were purchased and were modified by installing absolute filters over their exhaust nozzles to protect against the further spread of activity if the two internal filter media should fail. Offset handles were also used to hold cleaner wands away from the operators (figure 30). Work with these cleaners initially achieved decontamination factors of about 10 on the floor; typical smear readings decreased from 2 to $3 \mathrm{rads} / \mathrm{hr}$ to 125 to $500 \mathrm{mrads} / \mathrm{hr}$ at $3 \mathrm{in}$. from the smear after several vacuum passes. Vacuum cleaner bags were removed frequently as they became significant radiation sources. Most of the cleaner bags read 5 to $10 \mathrm{R} / \mathrm{hr}$ at 1 foot and several read as much as $200 \mathrm{R} / \mathrm{hr}$ at $1 \mathrm{ft}$. The radioactive bags, and other similar material removed subsequently from the reactor room, were sealed in plastic bags and placed in a shielded transfer container for shipment to the contaminated waste disposal area. 
After the floor had been thoroughly vacuumed, crews continued the decontamination with wet mops. "Alconox" (Trademark of Alconox, Inc., New York) detergent solution followed by water was used on the mop heads. Walls were wet mopped using 10 to 15 foot extension handles on the mops without prior vacuuming. Typical wall smears were reduced from 20 to $300 \mathrm{mrads} / \mathrm{hr} / \mathrm{ft}^{2}$ at $3 \mathrm{in}$. before mopping to 10 to $40 \mathrm{mrads} / \mathrm{hr} / \mathrm{ft}^{2}$ at $3 \mathrm{in}$. after mopping.

Persistent hot spots on the painted concrete floor were reduced by scraping and wire brushing followed by vacuuming and wet mopping. Repeated applications were required to reduce many of these spots to background radiation levels.

\section{MANUAL CLEANUP OF PLENUM TOP}

Activity on the plenum top was reduced by decontamination and decay during a 25-day campaign which began on January 12 . An estimated 215 curies of activity remained on the plenum top when manual plenum cleanup began. Radiation levels above the plenum averaged $17 \mathrm{R} / \mathrm{hr}$ at 8 in. and the maximum reading of the remote survey meter was $360 \mathrm{R} / \mathrm{hr}$ at $8 \mathrm{in}$.

A closed circuit television monitor was installed in the reactor room prior to starting the plenum decontamination (figure 31). Vicwing screens were available in the reactor room and at the decontamination command post in a clean area. The camera could be positioned manually to provide either a close-up view of about 1 square foot of the plenum top or a general view of the reactor room. The close-up was useful for observing wire removal and mechanical cleaning methods. The general view was useful for briefing incoming personnel on their work assignments in the reactor room.

Temporary Shielding. The first phase of this campaign was to place temporary shielding over hot spots on the plenum to reduce personnel exposures during subsequent work. Several hundred bags were manufactured; each bag contained about 5 pounds of lead shot double-bagged in stapled "Fiberglas" cloth. The temporary shielding was removed gradually during the decontamination as radiation rates decreased. The bags were designed to be placed and removed by workers in relatively low radiation areas at the edge of the plenum using long-handled tools (figure 32). Experience showed that the bags were awkward to handle and that shielding effectiveness was limited by the inability to achieve high packing densities.

Wire Removal. Many instrument wires and tubing runs on the plenum top were contaminated when the suurce rod failed. These included thermocouple wires from moderator temperature sensors, special instrumented assemblies, and in-reactor flux sensors; instrument leads and detectors from the tank-top leak detector system; and leak collection tubing. In addition to being contaminated, these wires and tubing restricted access to the plenum top. The wires and tubing were removed up to the edge of the shielding using longhandied cutters and grippers. Additional wire and tubing were removed its it was exposed when temporary shielding was removed. An enlarged telephoto photograph of the plenum top was mounted in the command post with a plastic overlay on which cleamup progress could be recorded (figure 33 ).

Mechanical Cleaning. Mechanical cleaning of the plenum top began with the same type vacuum cleaners that had been used on the floor. Extensions were added to help workers position the wands from relatively low radiation areas at the edge of the plenum. Wire brushes on long poles were used to loosen adherent material for subsequent vacuuming. These tools were difficult to manipulate and were replaced with rotary wire brushes driven by $1 / 2$-inch drill motors. The motors were suspended from ropes stretched across the reactor room and were raised and lowered with an arrangement of ropes and pulleys (as in figure 34). Manipulation of these motor-driven wire brushes was awkward but they were more effective than manual ir rashes for scouring exposed horizontal surfaces. 
Results of calculations indicate that 11 days of mechanical cleaning and decay had reduced activity on the plenum top to approximately 26 curies. Decay alone would have reduced the activity to 187 curies. After mechanical cleaning the average plenum top radiation was $3.3 \mathrm{R} / \mathrm{hr}$ at $2 \mathrm{ft}$ and the maximum hot spot radiation was $41 \mathrm{R} / \mathrm{hr}$ at $2 \mathrm{ft}$ (see also figure 9).

Chemical Cleaning. Final decontamination of the plenum top was achieved with successive applications of OPC, a solution of ammonium oxalate, ammonium citrate, and hydrogen peroxide. The OPC solution was selected from several candidates known to be compatible with stainless steel and aluminum after tests at the Savannah River Laboratory indicated that it dissolved antimony particles in 16 hours at room temperature. OPC solution has been used for decontamination at other sites (references 2 and 3 ).

The reactor tank was sealed and helium gas pressure established to prevent diluting the moderator by inleakage of the chemical solutions. Water flow through the reactor and top shield was controlled to maintain the plenum temperature at approximately $35^{\circ} \mathrm{C}$. A dam about 1-inch high around the edge of the plenum top made it possible to pour about 20 gallons or more of solution onto the plenum top to form a puddle. Additional solution was sprayed on the latches, probe pins, outside of plenum tubes, and other surfaces that extended above the puddle. Spray units used building compressed air through a venturi to aspirate solution from 6-gallon bottles. The spray nozzles and extension handles were supported by the rope and pulley system (figures $34,35,36$ ). Spray rates of 2 to $4 \mathrm{gal} / \mathrm{hr}$ were achieved through each of the two sprayers. Excess solution was pumped off periodically to lower the level and avoid overflowing the plenum dam. Radiation rates from the bottles drawn off the plenum top provided useful indications of the effectiveness of the several treatments. After each chemical treatment the plenum top was thoroughly flushed with deionized water for several hours to remove residues.

A $1 \%$ solution of "Alconox" detergent in deionized water was used twice on the plenum top between OPC applications. The detergent was used to remove oil which had been observed on the plenum and was applied with the same tools and techniques used for OPC.

Five OPC and two "Alconox" treatments were applied during the 12 days of chemical cleanup. The OPC solution remained on the plenum top for 16 hours before flushing began in the first two applications and 32 hours for the final three applications. "Alconox" treatments lasted 4 hours before flushing began. The motor-driven wire brush was used during the second two OPC applications to agitate the solution and expose fresh material to chemical action. A steam lance replaced wire brushing during the final two OPC treatments. The lance utilized 175 psig building steam throttled to 60 psig. The insulated lance was very effective in scouring the plenum top.

Only about 3 curies remained on the plenum top after the chemical treatments. On February 5 , the average radiation field above the plenum was $260 \mathrm{mR} / \mathrm{hr}$ at $2 \mathrm{ft}$ and the maximum hot spot remaining was $1.75 \mathrm{R} / \mathrm{hr}$ at $2 \mathrm{ft}$. These levels were sufficiently low to permit reinstallation of equipment and resumption of preparations for reactor startup.

\section{Confinement System Filters}

The exhaust system for each reactor building (figure 37) includes five confinement filter compartments to contain released radioactivity in the event of a reactor accident or radioactivity relase in parts of the reactor buildings (reference 5). Exhaust fans maintain a negative pressure in the reactor room, the ducts to the filters, and the compartments containing the filters. At least four of the five compartments are on-line at all times. Fach compartment contains moisture separators, 
absolute titurs, wnd warcoal absorbers. The unshiclded aluminum filter compartments are located on the reactor building roof 55 feet above ground level and are designed for remote removal.

Four compartments were on-line with a total air flow of $86,400 \mathrm{cfm}$ when the radioactivity release ociured. The flow gradually decreased to $61,000 \mathrm{cfm}$ during the $31 / 2$-month cleanup period as the filters accumulated about three times their normal dust loading. The maximum radiation level at 1 in. from the side of the hist test lilter compartment was about $70 \mathrm{R} / \mathrm{hr}$ immediately after the release and $25 \mathrm{R}$ hor at $1 \mathrm{in}$. by the time of replacencul. Preliminary data indicate that activity was deposited predominantly on the moisture separators.

It was essential to maintain filter operation throughout the decontamination of the reactor room and equipment, to prevent relcase of airburne radioactivity. It was also evident in the earlicst planning

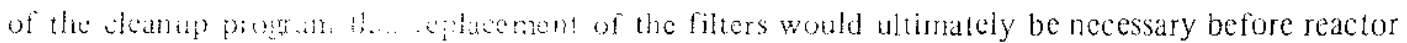
operation whild be romated

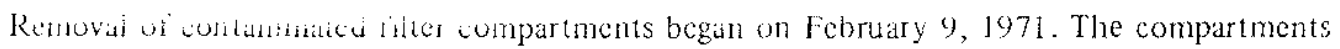
were lifted from the roof with a crane and placed on a special railroad flat car for movement to a storage localion niat ait out-of-service reactor building. Replacement filter compartments were installed. Following the lesting of new filters, the K-reactor confinement system was returned to thormal uri February $26,1971$.

\section{DESCRIPTION OH THE SYSTEM}

Savanmah River ractors were not originally designed with containment protection. Confinement facilitics for SRP ruators were installed in 1962 (reference 5). Airborne particulate and halogen contamination is collected by the confinement system (figure 37). Because it is not possible to make the building gastight, the ventilation system is designed so that the exhaust fans continuously matinain it regative pressure in the process areas, the ducts to the filters, and the compartments containing the filters. Air is exhausted from the reactor room, below grade process area and the purification allea and channeled into a common exhaust plenum before passing through the filter compartments. Because complete mixing does not occur in the plenum, unequal activity distribution occurs betwecr the companments depending on the building area in which activity is released. The

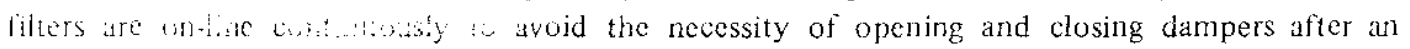
accident takes place. The filters are contained in five aluminum filter compartments on the reactor building rou! 55 leet above ground level. Lach compartment weighs 10 tons and is 8 feet wide, 22 feet long, and 25 feet high. The five compartments operate in parallel and each compartment contains three banks of filters in series (figure 38 ):

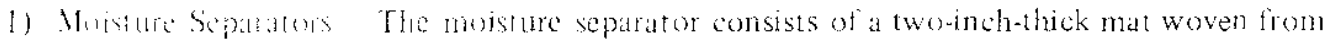

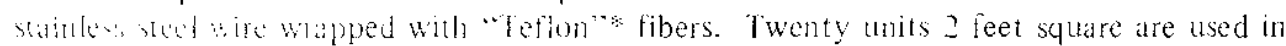
each complatrintist.

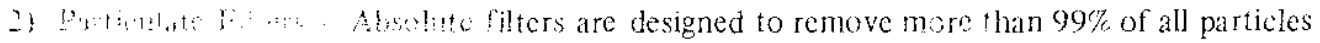

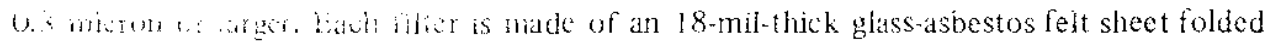
wer cortuated aluminum inserts into closely spaced pleats foming a unit 2 feet square by

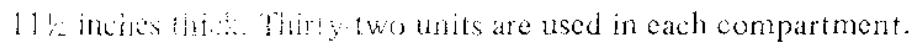

3) Carben Filters Carbon lilters consist of a one-inch-thick bed of 10 to 14 mesh crushed actialed sommeshell chamcolal enclosed between perforated metal sheets that are pleated to extend the surfice trea. The unc-inch-thick beds are stacked together to give an assembly 2 lect sputre 11'. inclues thick. Thit ty-two units are used in each compartment.

Each filter compartment sits on a rail dolly that can be positioned remotely by cables and pulleys. Both inlet and outet compartment nozkles are on the building end so that the unit can be attached to the vemitidion system by liting the compartment nozzles over nozzle extensions on the

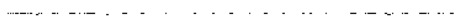

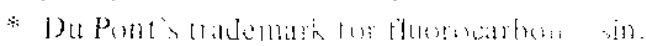


building. Inflatable seals at the nozzles eliminate leakage. A flapper door at each compartment nozzle seals the compartment when it is disconnected from the building ventilation system. When the compartment is delatched from the building a catch on each flapper door releases and allows the door to swing down and shut. The doors are held shut by two refrigerator-type latches. No shielding is provided for the compartments; therefore remote removal facilities were incorporated in the design. The latching and sealing controls and the positioning cables are located at ground level away from the radiation zone of the filter compartments. If a compartment becomes contaminated, it can be disconnected from the ventilation system remotely, pulled to the edge of the 55-foot elevation roof, picked up by a crane, placed on a railroad car and removed from the area.

\section{CONFINEMENT SYSTEM PERFORMANCE}

About 6250 curies were released in particulate form to the confinement filters. Only 3 millicuries of the activity released to the exhaust system escaped from the building exhaust stack. The confinement filters retained more than $99.999 \%$ of the activity. The initial maximum radiation level observed at the side of the hottest filter compartment was $70 \mathrm{R} / \mathrm{hr}$ at $1 \mathrm{in}$. This rate decreased by radioactive decay to $25 \mathrm{R} / \mathrm{hr}$ at 1 in. when the filter compartments were removed from the building.

Four of the five filter compartments were in use at the time of the accident (compartment $K-4$ was off-line for routine maintenance). The total exhaust air flow through the on-line filters was $86,400 \mathrm{cfm}$. The four contaminated filters remained in service during the three months following the source rod failure, during which time flow gradually decreased to $61,000 \mathrm{cfm}$. Table VIII shows the individual filter data prior to the incident and at the time the filters were removed.

The major filter pluggage was experienced in the moisture separators; however this pluggage was similar to normal moisture separator pluggage that has been experienced at SRP after similar service lifetimes and is not attributed to the source rod failure. Pluggage due to an accumulation of an oily substance and particulate matter on the upstream face normally limits moisture separator service to about 9 months. Plugged moisture separators are normally removed from the compartments and cleaned with steam jets to prepare them for continued service (reference 6).

Calculations made by Savannah River Laboratory personnel based on radiation measurements taken after the filter compartments were removed from the building indicate that the activity was not equally distributed among filter compartments (table IX). The two compartments nearest the reactor room exhaust duct contained $95 \%$ of the total activity released to the ventilation system. The activity distribution within the filter compartments indicates that the moisture separators retained about $82 \%$ of the activity while the particulate filters retained the remaining $18 \%$.

\section{FILTER COMPARTMENT REPLACEMENT}

Replacement of the contaminated fïters was desirable because continued use of the contaminated filters would result in radiation exposure for personnel working at ground level outside the reactor building and even higher exposure for personnel replacing contaminated, plugged filters and because continued radiation exposure to filter components could cause component damage.

Spare filter compartments are not maintained at SRP. The most rapidly available replacement compartments were located on the roof of a nonoperating reactor building. These compartments were removed from the roof, refurbished, pressure tested and equipped with new filters. The compartments were moved by truck to $\mathrm{K}$ Area. The height of the load required clearance of some overhead obstructions. These overhead obstructions were cleared by lifting the load over, removing or burying the obstructions, and by cutting new roads below grade level (figure 39 ). 
Removal of the contaminated compartments from K Area began on February 9, 1971 and was completed by February 12,1971. Individual compartments were moved remotely to the edge of the roof. An expanding urethane foam was sprayed into each of the compartment nozzles (figure 40) to fix any loose contamination an d provide a seal if a compartment flapper door failed to seal. Ten cubic feet "Insta-Foam FROTH PAKS" (Trademark of Insta-Foam Products, Inc.) were used. Application of the foam on the 56-inch diameter nozzles and flappers required approximately $1 \frac{1}{2}$ minutes in a maximum radiation field of $5 \mathrm{R} / \mathrm{hr}$.

The compartments were removed from the roof by a 75-ton motor crane equipped with 120 feet of boom (figure 41). A special remote handling lifting hook with long tag lincs was employed. The most critical crane operation was to lift the compartment straight up off the movable rail dolly. The crane operator located at the base of the building could not see the load. Two spotters with short-wave radios directed the crane operations; one spotter was located on an adjacent building roof and the second spotter was supported in a basket by a second crane. Once the compartment was clear of the rail dolly the compartment was lowered to a modified railroad car (figure 42). The maximum radianon dose rate for the crane operator was $200 \mathrm{mR} / \mathrm{hr}$. The railroad car supported frame supported the compartments so that no tie-downs were required. The train was made up of the modified car, three spacer cars and a locomotive (figure 43) for movement to the storage area. The spacer cars ensured adequate distance to reduce radiation dosage to personnel in the locomotive. The train was preceded by a track motor car with personnel to visually inspect the track, lines switches, spike faing switch points, and open security fence gates. The plant primary road crossings encountered by the train were blocked by Patrol personnel to eliminate the possibility of radiation exposure of their normal operating positions and to carry a Health Physicist who surveyed the track to ensure that no contumination was released. Movement of each load required one hour. The maximum radiation dose rate to the railroad crew was $30 \mathrm{mR} / \mathrm{hr}$.

The contaminated compartments were removed from the railroad train with a 100 -ton capacity crawler crane equipped with 65 feet of boom. The special remote-handling lifting hook with tag lines was alio used. The maximum radiation dose rate for this crane operator was $400 \mathrm{mR} / \mathrm{hr}$. The four contaminated compartments are now stored behind the out-of-service R-reactor building where they will remain until additional decay of activity makes reclamation operations feasible. The building provides some shielding against wind.

Replacement of the refurbished compartments was completed on February 12 and 14 . After leak testing the particulate filters and carbon filters, the compartments were connected to the building ventilation system on February 18 and 26. The K-reactor confinement system has been returned to nomal. (See reference 4 for further details.)

\section{Reactor Work}

All normal reactor maintenance work scheduled for this shutdown which did not requirc access to the Process Room or use of the $\mathrm{C}$ and $\mathrm{D}$ machines was completed (as time permitted) during the cleanup operation. In addition, decontarnination work with the $\mathrm{C}$ and $\mathrm{D}$ machines was interrupted several times for essential reactor discharge operations and special measures were taken to remove some antimony which had entered the reactor. 


\section{DISCHARGING}

On December 23, twelve highly contaminated upper plugs were discharged to remove one major tank top source of radiation. At the same time locking control cluster caps were installed on septifoil sleeves to keep contamination and other foreign matter from falling into the reactor. Between January 6 and January 12 the reactor was almost completely discharged, leaving only a few target housings and semipermanent sleeves. Special plug assemblies were charged to the empty positions. This both completed the delayed reactor discharged and removed additional radiation sources to reduce radiation levels to a point where manual decontamination of the tank top could be started. The possibly contaminated upper plugs for the remaining target housings were discharged on January 22 and 23.

\section{ANTIMONY IN REACTOR}

About $4 \mathrm{Ci}$ of antimony-122 and -124 was measured to be in the moderator at 9:30 a.m. November 19 . Nearly $100 \%$ efficient removal by the moderator purification system reduced this amount to $0.2 \mathrm{Ci}$ by November 29 . Between December 13 and 15 there was a relatively large release of antimony to the moderator, accompanied by a large increase in radiation level (to $1000 \mathrm{R} / \mathrm{hr}$ at 1 inch) in the septifoil cooling pipe loop (gooseneck) for the control rod cluster from which the failed source rod had been removed. Apparently, tank top work around this position either dropped material into the reactor or shook it loose from the recharged control rods in this cluster.

The control rods from this cluster were discharged late on January 11. The material in the gooseneck was flushed out on January 12-14 to reduce the radiation level in the monitor pin room. The flushed-out material was caught in a special trap designed by the Savannah River Laboratory. It consisted of a ball check valve and a 200-mesh screen inserted in a universal sleeve housing which was charged to the septifoil position (figure 44). Upflow cooling water to this gooseneck flushed material out of the gooseneck into the trap, which was subsequently discharged.

\section{D \& E Canal}

\section{SOURCE ROD PIECES}

The failed source rod, still containing about $40,000 \mathrm{Ci}$ of radioactive antimony and tellurium, was deposited in the $D \& E$ canal before it was recognized that the rod had failed. While most of this material remained in the two pieces of the rod, smaller amounts were scattered over the floor of the canal. A small amount came to rest on the upper surface of a concrete pedestal in the Process Room side of the D \& E canal. These pieces could be located from the Disassembly Room side of the canal by their blue Cerenkov glow. It was necessary to retrieve them for proper containment and storage without spreading contamination into other parts of the basin.

Normally water from the Disassembly Basin is circulated through portable deionizers to remove radioactive contaminants. As a first step in minimizing spread of contamination, flow was established from the D \& E canal to the deionizers with return of the deionized water to a remote point in the vertical tube storage (VTS) section of the basin.

A number of methods of retrieving pieces of source rod from the D \& E canal were tried or developed. The two most successful were tongs (of the type designated as Peters' tongs) and "Dux Seal" (Johns-Manville trademark) putty. The putty was pressed into an array of small holes drilled through one side of a short length of aluminum L-section bar. A long rod attached to the other side 
of the bar served as a handle with which to press the putty against the piece to be picked up. The putty containing the retrieved piece could then be scraped into a suitable container. The tongs were used to grip and pick up larger pieces, while the "Dux Seal" putty picked up pieces too small to be gripped by the tongs.

All of the retrieved pieces were stored in a failed-fucl-element container which was later shipped to RBOF for final disposill. Some of the smaller pieces were first placed in screw top cannisters, which were then dropped into the larger container.

By November 17 all of the easily retrievable pieces had been picked up and placed in the failed-fuel-element container. At this time it was decided to do no further retrieval work until it could be done either from the Process Room side or by using an underwater vacuum cleaner which was being developed. The only major remaining piece was that on the concrete pedestal, which was so located that any efforts at retricval from the Disassembly side were likely to dislodge it and spread it over the cinal floor.

\section{MATERIAL FROM PROCESS ROOM}

Initially all contaminated material to be deposited in the D \& E canal from the process room was placed in sealed containers. This included the eductors used in cleaning the $C$ machine, which were stored in special shielded boxes, and the eductors used on the D machine, which were stored in cannisters. When it came time to remove the $\mathrm{C}$ machine parts from the process room, a suitable means of storage was not immediately available. Because the amount of radioactive contamination on these parts was much less than was already in the basin, it was decided that they could safely be stored in open buckets.

None of the material deposited in the canal from the Process Room (other than the source rod itsell) contributed significantly to basin water activity. Whenever source rod pieces were removed from contact with basin water, a decrease in the rate of introduction of antimony activity into the water was easily detected. No increase in this rate was observed when any of the $C$ machine parts were deposited in the D \& E canal.

\section{Disassembly Basin}

The Disassembly Basin consists of two main sections which can be isolated from each other. These are the Vertical Tube Storage Section (VTS) in which freshly discharged components are stored, and the Machine Basin in which the disassembly operations are carried out. The D \& E canal connects directly with the VTS section, but can be isolated from it by installing stop logs if necessary.

Prior to the source rod failure, a sand filter system had been undergoing testing in the $K$ Disassembly Area. Use of the filter maintains basin water clarity, allowing the basin to be kept isolated for extended periods with no purging of water to the environs. Two portable mixed-bed deionizers. one of $60 \mathrm{ft}^{3}$ and the other of $30 \mathrm{ft}^{3}$ capacity, were available to remove ionic radioactive material from the water.

\section{CONTAINMENT OF ACTIVITY}

More than $95 \%$ of the radioactive material originally present in the source rod was deposited in the I) \& E Lind for temporary storage. Most of this material was stored in closed containers. Thus a major part of the responsibility for containing the radioactivity not stored in containers rested in the matragenent of the basin facilities. 
Method. Both deionizers were used, one on-line while the other was being regenerated. The VTS section and the machine basin were kept isolated. Feed to the deionizer was taken from the Process Room end of the D\& E canal and a skimmer in VTS in such a way as to avoid stirring up radioactive particles from the bottom. The water level in the VTS section was kept below that in the Machine Basin to limit leakage of contaminated water into the Machine Basin.

Basin Water Cleanup. The pieces of the source rod were dropped into the D \& E canal on the morning of November 9. By 2:00 p.m. of that day a nonuniform distribution of ${ }^{122} \mathrm{Sb}$ and ${ }^{124} \mathrm{Sb}$ activity was found in the VTS section of the basin. By November 11 the distribution of antimony activity in the VTS section was uniform. By early December the antimony activity was uniform throughout the entire basin because of slow leakage between the VTS section and the Machine Basin (figure 45).

Deionization of the basin water was started on November 9 and continued with minimum off-time until late January 1971. Intermittent deionization was continued thereafter. In a total of 51 deionizer runs, 207 curies of ${ }^{124} \mathrm{Sb}$ and 44 curies of ${ }^{122} \mathrm{Sb}$ were removed by the deionizers. An additional 66 curies of ${ }^{124} \mathrm{Sb}$ and 31 curies of ${ }^{12}{ }^{2} \mathrm{Sb}$ decayed to stable forms while dissolved in the basin water.

The antimony activity was present mainly in the form of anions, as confirmed by laboratory tests (figure 46). The capacity of the portable deionizer for anions was less than for cations at this time, resulting in early anion breakthrough. Breakthrough of antimony activity followed closely the anion breakthrough. Recognition of this fact was necessary so that the deionizer could be regenerated as soon as its ability to remove antimony activity dropped off.

Samples of basin water taken November 11 showed $75 \%$ activity retained on a 0.45 -micron membrane filter. Within a few days this decreased to $15 \%$ or less. The filterable activity was removed by the deionizer resins, whether ionically depleted or not. The sand filter showed essentially zero removal of antimony activity.

Activity Input. A source of antimony input to the basin water was evident throughout the cleanup program. From November 10 to November 15 the input rate was about $10 \mathrm{Ci}$ of ${ }^{124} \mathrm{Sb}$ per day. On removal of some source rod pieces from the $D \& E$ canal floor, this input rate dropped to $4 \mathrm{Ci} /$ day. This rate continued until late in December, when shipment of the harp containing the pieces of the source rod to RBOF resulted in a further decrease to about $1 \mathrm{Ci} /$ day. Since then the input rate has continued to diminish at a rate faster than the rate of radioactive decay, reflecting a steadily diminishing surface area of antimony available for dissolution. By May 15, 1971 the input rate was 0.1 to $0.2 \mathrm{Ci} /$ day. It is estimated by a material balance that 1.78 grams of antimony (containing 488 $\mathrm{Ci}^{124} \mathrm{Sb}$ on $11 / 8 / 70$ ) dissolved in the basin over the 7 -month period. The dissolution rates ranged from $40 \mathrm{mg} /$ day (11/10 to $11 / 15$ ) to $5 \mathrm{mg} /$ day (May 1971).

Basin Releases. No antimony activity was released to effluent streams from $K$ Area. There was a release of $0.52 \mathrm{Ci}$ of ${ }^{124} \mathrm{Sb}$ from C-Area basin caused by incomplete decontamination of a resin bed used in $\mathbf{K}$ Area, prior to using it to deionize the $\mathrm{C}$-Area basin water.

A total of $7.4 \mathrm{Ci}^{124} \mathrm{Sb}$ was transferred to the 50 -million-gallon containment basin in $\mathrm{K}$ Area through April 1971. This was the result of purges to reduce tritium content of the basin water or to correct high water levels which would otherwise have caused releases to the effluent streams. Transfer to the containment basin delays release long enough to gain roughly a 400 fold reduction in ${ }^{124} \mathrm{Sb}$ activity from radioactive decay. 


\section{Technical Support}

Extensive technical support in the form of calculations and experiments was needed to aid in planning cleanup work, to define the cause(s) of the accident, and to ensure that the source rod accident would not be repeated. The major part of this effort was directed at developing an understanding of the failure, its cause and its consequences. Other work was done as needed to aid in specific phases of the cleanup operation.

\section{UNDERSTANDING THE FAILURE}

Causes. The major effort by both the Reactor Technology Section and the Savannah River Laboratory was directed at determining the causes of the failure. The central problem was to determine the temperature of the source rod and surrounding control rods as a function of time that they were suspended in air. This required calculation of:

- Isotopic composition of the rods at time of discharge.

- Radioactivity of each isotope at time of discharge and radioactive decay thereafter.

- Rate of heat generation from radioactive decay.

- Heats required for meiting and other physical and chemical changes undergone by the rod materials on heating.

- Rod temperatures from the above heat data, plus heat transfer characteristics of the rods.

The results of this work have been summarized in the section on "Analysis of Failure" (page 3). This method was used to determine the potential for failure of irradiated source and control rods from other reactor charges; the results supplied the basis for measures to prevent recurrence of such an incident.

Distribution of Radioactivity. Methods of estimating the location and intensity of major radiation sources were needed as a guide in every stage of planning and carrying out the cleanup program. In the later stages the normal methods of radiation survey by portable instruments and smearing of surface contamination were used extensively, supplemented by radioautography, and the D machine radiation probe (as discussed in detail in the section on Radiation Measurement (pp 5-7). Greater ingenuity was needed in the earlier stages when only remote methods could be used.

Initially the only means available were readings of the four HM chambers, smears and radiation surveys of the limited areas accessible by extension tools from the two Process Room doors and the Presentation Point slot, and the cstimated total radioactivity of the source rod. The results presented in table II were obtained from these data plus the amount of antimony-tellurium remaining in the source rod pieces. The latter value was determined approximately by inspection of the recovered pieces.

The first estimates of the relative amounts of radioactivity in the various locations listed in table II were crude and inaccurate. Better estimates could have been obtained from the HM chamber readings provided they follow the inverse square law with respect to distance from the radiation source. Some measurements with portable instruments suggested that there was enough backscatter of radiation to invalidate the inverse square law. However, the HM chamber readings obtained when the $\mathrm{C}$ machine was first moved to the Presentation Point decrease with distance from the radiation source in good agreement with the inverse square law. On this basis, chamber readings can be used to determine source intensities and locations. This requires that the chambers be in good calibration and 
their locations accurately known. The readings of three chambers can be used to locate and determine the intensity of a single source. If the location of the major source (e.g., the $\mathrm{C}$ machine) is known, the readings of four chambers will determine the intensity of the major source and the location and intensity of one other source. If the $\mathrm{X}$-ray camera is available to locate all of the major sources, the HM chamber readings will serve to determine the intensities of up to four such sources.

From the inverse square law it follows that for a single source the product of the readings of two HM chambers is relatively insensitive to motion of the source over a wide area in the vicinity of the midpoint of the line joining the two chambers. For chambers HM 40 and 42 this includes most of the area accessible to the $\mathrm{C}$ machine in the vicinity of the $\mathrm{D} \& \mathrm{E}$ canal. This fact could have eliminated the need to move the $\mathrm{C}$ machine to a standard position to check the progress of decontamination. It was used in constructing figure 9 to allow inclusion of data from other than the standard location.

An early estimate of the extent of contamination of the crane haunches was desired as an aid in planning. A test of a model of the Process Room to determine the pattern of flow and deposition of fumes from the source rod was proposed. Such a test was actually conducted in the C-Area Process Room during a reactor shutdown, using a smoke generator to mockup the fuming rod. The results suggested that the haunches could be heavily contaminated. A later radiation survey in $\mathrm{K}$ Area show relatively low contamination of the haunches except for one hot spot.

Potential Consequences. The possible levels of radioactivity at the stack and at the plant boundary resulting from stack releases of ${ }^{124} \mathrm{Sb}$ were calculated by the Savannah River Laboratory. The maximum permissible concentration (MPC) for ${ }^{124} \mathrm{Sb}$ is $5 \times 10^{-8} \mu \mathrm{Ci} / \mathrm{cc}$. A 3-millicurie release (approximately the actual value) represented $2.1 \mathrm{MPC}$ at the stack and $6.3 \times 10^{-6} \mathrm{MPC}$ at the plant boundary. If the confinement filters had not been present $6250 \mathrm{Ci}$ would have been released, representing 4,375,000 MPC at the stack and 13.1 MPC at the plant boundary.

\section{ASSISTANCE IN CLEANUP OPERATION}

Storage of Radioactive Debris. The same calculations which established the distribution of radioactive contamination in the Process Room also served to estimate the source intensity of material transferred to the D \& E canal and the amount of shielding needed for safe storage of this material in the Disassembly Basin. Radiolysis of water to produce hydrogen and oxygen could build up a gas pressure in the storage container if it were gastight. Calculations showed that a pressure of several atmospheres could result from the $\mathrm{Sb}$-Be source present in the intact source rod slugs: thus storage of these pieces (or any debris containing both antimony and beryllium) would be safer in a container provided with relief rather than a sealed container.

Chemical Decontamination. Selection of a chemical decontaminating reagent for final cleaning depended on an understanding of the chemistry of antimony and tellurium, either as the elements or their oxides and possibly mixed or alloyed with aluminum and beryllium. Antimony and tellurium and their oxides do not dissolve readily in simple acids or basis. Their chemistry is such that both an oxidizing agent and a chelating agent would be necessary to ensure effective dissolution and removal of the contaminant. A number of available decontaminants which met this requirement were screened in laboratory tests by the Savannah River Laboratory. The OPC solution was selected as the most effective of these for removal of antimony and tellurium. 


\section{Radiation Exposures}

The entire cleanup operation was completed with a total radiation exposure of about 600 rem to over 8.30 employees. Most of this exposure was received in the manual and chemical cleanup of the reactor room floor, walls, and tank top.

The distribution of radiation exposures is given in table X. All work was done under controls which limited the exposure to any individual to about $1.5 \mathrm{R}$ if his normal work did not involve radiation, or to no more than he would normally receive in the same period if his normal work did involve radiation exposure. Only in one case did the exposure received exceed $3 \mathrm{R}$, which is both the plant annual exposure guide and the AEC quarterly exposure guide. In that case the man was working beside two other men whose exposures were much lower.

\section{Problems in Confining the Release and Cleanup of Radioactivity}

The cleanup operation was done without previous experience with this type of work on the part of either those responsible for planning and supervising it or the many people who came in from other areas to help do the work. However, in the light of expcrience, some problems can be pointed out which could be avoided in the future.

\section{PREVINTION}

The first problem arose in recognizing the possibility that these particular rods when suspended in air could heat up past the melting point of their materials. Similar operations with identical source rods hat been performed in the past but from reactors that had operated at lower neutron fluxes, hence with surce und with fower heat generation. The significance of recent reactor operation at much higher neutrun thuxes on the heat generation in these source rods was not recognized. Additional problems arose through delity in realizing the validity of the radioactivity alarms under the conditions obtaining, and in responding promptly.

\section{EQUIPMENT}

Difficultics were uncuvered in four major pieces of equipment which bear in a crucial way on our ability either on contain or clean up a large activity release.

Filter Compartment. In this incident with the ventilation system set up for shutdown conditions, distribution of radioactivity among the compartments was unequal. In a major release, one compart-

ment could be overloaded whte the capacity of others was underutilized. Subsequent overheating could result in at greater release of activity to the atmosphere than if the activity were equally distributed. However distribution might be more un iform for normal ventilating conditions. 
Conditions were found which impeded removal of filter compartments from the roof in the intended manner. Chief of these was interference of an added walkway with motion of the filter compartment dolly. The compartment could not be moved to the edge of the roof until the obstruction was removed (requiring extra radiation exposure).

VTS Isolation Gates. Leakage through the isolation gates reduced the effectiveness of the basin containment system.

C \& D Machines. It was the original design intent that remotely operated water sprays would accomplish partial decontamination. However, these machines provide a multitude of locations in which radioactive debris can lodge. Access to many of these locations is difficult or impossible without dismantling. Removal of contaminated parts was delayed because of inaccuracies in the drawings of the C machine.

General Purpose Robot. Considerable effort was spent unsuccessfully in trying to put this seldom used component retrieval machine into use in cleaning up the $\mathrm{C}$ machine and Process Room, for which it was not intended. Although partial operability was attained, the necessity to violate the containment of the Process Room to gain entry and subsequent control of the GP Robot precluded further consideration of use of this machine.

\section{CLEANUP OPERATION}

Some difficulties with tools and their deployment led to delays in cleanup or made it more laborious.

Spread of Contamination. Once the rod failure was recognized as such, the need to avoid spreading contamination was established as a primary requirement. This requirement was not entirely met, however.

At the outset the $\mathbf{C}$ machine was moved about the Process Room in trying to assess the nature of the problem. These moves dropped radioactive debris in front of the Observation Window and possibly elsewhere in the Process Room. The operation of depositing the failed rod in the D \& E canal dropped radioactive debris on the canal floor. Both operations made subsequent containment and cleanup of radioactivity more difficult. 
Radioactivity was also spread by abrasive grinding at the Presentation Point and by raising the outer shield door during work on the $\mathrm{C}$ machine in the $\mathrm{Cr}$ ane Wash Area. Oil sealed vacuum pumps for the educators sprayed oil in to the Process Room, making subsequent decontamination more difficult.

Tools. Some long-handled tools were difficult to use. These included in particular those used at the Presentation Point to dismantle the $\mathrm{C}$ machine, and the long-handled floor mops used on the Process walls.

While the D machine eductor reduced tank top hot spots, it had very little effect on the general radiation level over the tank top. Subsequent manual vacuuming of the same areas produced a greater reduction in general radiation level than did remote vacuuming with the eductor. This was because manual vacuuming could get into corners and around obstructions into places that could not be reached by the eductor.

The $\mathrm{D}$ machine radiation probe could not easily be kept in the proper orientation for reading from the periscope. The method of presenting eductor nozzles to the D machine on stands at the Presentation Point required excessive radiation exposure to personnel in positioning the stands. Tools carried by the D machine were frequently dropped.

Planning and Coordination. In several instances cleanup was delayed while waiting for a new approach to be developed when the previous method either proved unsuccessful or reached a point of diminishing effectiveness. The fewest such delays were encountered in Task 4 , which had the longest time available for planning and which brought in help of many people from outside groups in the planning stage. Most such delays occurred where the time and manpower available for planning were limited and where the people responsible for planning were also responsible for directing the cleanup work. Such delays also resulted from persisting with a method or tool after it had lost its effectiveness. An example is the diminishing effectiveness of eductor vacuuming once the major hot spots had been successfully removed.

Direct use of people in Process Room cleanup proved much more effective than remote operation. confirming decontamination experience at other sites. The willingness of people from outside the reactor area to work in the Process Room was helpful. It was important that their work be so directed as to use it in the most effective way. Full time shift-by-shift coverage by a technical coordinator in training workers before entry into the Process Room was excellent. On occasion, however, workers went to work at the wrong locations because they were not familiar with the Process Room as it looked from the inside. Control of the flow of supplies and manpower in and out of the Process Room and provision of supporting services was sometimes poor because the man responsible for coordination of work and services inside the Process Room had too many other outside duties and because he could not be present in the Process Room to coordinate the work effectively. While two-way communication between the workers and the outside coordinator was provided, it was not very effective because of the muffling effect of plastic suits. 
Radiation Exposure. At the outset, after the rod failure but before its nature was recognized, one man went on the roof of the reactor building near the filter compartments. If the "High Radiation Near-Far Side Filter Area" alarm had been investigated promptly, this area would have been roped off in accordance with ACC-519, thus preventing his entry. Fortunately he only received $15 \mathrm{mR}$ radiation exposure.

The entire cleanup operation was done under controls to limit annual radiation exposures well below the $3 \mathrm{R} /$ man plant guide. In only one instance was this guide exceeded. However, there were instances in which better use of manpower could have been made by measures designed to reduce unnecessary radiation ex posure. Examples are exposures received:

- From accumulations of radioactive material from previous work.

- During discussion and planning work while in the Process Room.

- Because handling of cleanup wastes interfered with entry to and exit from the Process Room.

- In making radiation surveys with some of the less effective methods.

\section{Program}

\section{PREVENTION}

The reactor Technical Standards are being revised to require that the heat generation and heat transfer characteristics of any reactor component be known before it is discharged. Operating procedures for reactor discharge have been revised to prevent discharging any component whose heat generation and heat transfer characteristics are not known. Methods of calculating these characteristics for source rods and control rods are now available in references in all reactor areas.

Measures have been taken to ensure that radiation alarms and other indications of activity release in the Process Room and ventilation system are investigated promptly.

\section{EQUIPMENT}

Filter Compartments. The confinement filter system will be reviewed to assure that filters will perform as intended and that they can be removed by renote operation after they have collected radioactive material from a major release.

Vertical Tube Storage. Isolation between the VTS section and the Machine Basin will be reviewed to determine what improvements can be made to provide greater confinement of radioactivity in the VTS section.

C \& D Machines. The design of the C \& D machines should be reviewed to determine what revisions can be made to facilitate cleanup following any future activity release. This review should be broad enough to assure that any changes made do not cither hamper decontamination of the $C$ or $D$ machine after a different type of release, or make more difficult some other phase of cleanup. Efforts will be made to keep piints of the C \& D machines up to date to assure that cleanup work can be planned from the prints successfully. 
Robot. The needs for special equipment such as the General Purpose Robot should be reviewed. The $\mathrm{K}$-Area experience shows that cleanup work is much more effective when the operator can see at close hand what needs to be done and can guide his operations at least in close simulation to direct manual uperation. Thus, in the event of a much larger activity release such that early personnel entry is impossible. some type of emotely controlled robot will probably be necessary. Some possibilities which the review could consider are:

- Assign responsibility for the (iP Robot to widen its capabilities, keep it in repair and periodically pracice operating it.

- Purchase a robot which is more effective than the GP Robot. One such unit costs approximately $\$ 50.000$.

- Desigil and construct cquipment to be carried by the C or D machine which would make either in effect a master-slave robot.

- Make use of arrangements with other sites to use such equipment on loan as needed.

\section{CLEANUP OPERATION}

The following actions should be taken to improve efficiency or capability of handling cleanup following any future activity release.

1. Develop guide lines to provide in advance sound answers to problems such as:

- when and how a C or D machine carrying a failed component should be moved,

- when to use flooding of the Process Room floors,

- wher to raise the shield doors,

- how soon to change from remote operation to direct use of people in the cleanup operation.

2. Select the best combination of radioactivity monitoring methods.

a. For general survey purposes.

(Cse of a radiation probe on a long cable could allow Health Physics personnel to work at lower radiation exposure behind a radiation shield.)

b. For locating major radiation sources.

(K-Area experience suggests that the combination of X-ray camera, HM chambers, and autoradiography is effective.)

3. Stock integrating dosimeters with alarm feature.

4. Consider improvenents of the D machine radiation probe to eliminate the problem of orientation for reading via the periscope.

5. Consider improvements to the D machine eductor to make it more effective.

6. Develop better means of two-way communication and test under actual working conditions. 
7. Consider ways of improving:

- tools for work at the Presentation Point,

- means of presenting tools to the C \& D machines and of holding them more securely in the chucks,

- tools for cleaning Process Room walls, to be less tiring to the operator than the long-handled mops.

In the event of a future activity release the following actions should be recommended.

8. Organization of Task Forces and Central Committee should stress:

- separation of responsibility for planning from responsibility for execution,

- planning with a view to overall effectiveness so that one operation does not make subsequent operations more difficult,

- contingency plans ready as soon as it becomes evident that the previous approach has become ineffective,

- prompt decision to abandon (or modify) a method whose effectiveness is diminishing.

9. Whenever direct work in the radioactive area (e.g., Process Room) is done by people not familiar with that arca:

- provide full time coordination inside the radioactive area,

- provide a shadow-shielded area in which to discuss and plan work inside the radioactive area.

\section{CONCLUSIONS}

1. An antimony-beryllium neutron source rod melted in the $105 \cdot \mathrm{K}$ Process Room when it was suspended in air in excess of 22 minutes, releasing about 80,000 curies of radioactivity which was deposited in various ways to the Process Room floor, walls, D and E canal, discharge machine, tank top, rcactor moderator, and confinement system filters.

2. Limits for the allowed time-in-air to prevent melting had not been calculated by the Reactor Technology Section, and no procedures existed to prevent this incident.

3. Insignificant amounts of radioactivity were released outside of the 105 reactor building; estimates are:

$0.003 \mathrm{Ci}$ Sb released from the stack.

$7.4 \mathrm{Ci} \mathrm{Sb}$ released to the $\mathrm{K}$ containment basin.

$0.52 \mathrm{Ci} \mathrm{Sb}$ released to $\mathrm{C}$-Area disassembly basin, and subsequently over the weirs to the plant stream.

None of the activity has been detected outside at the plant perimeter fence.

4. Cleanup of the 80,000 curies took 3 months; 850 people participated.

5. Total man-rem incurred in the cleanup, monitoring and filter replacement, was 600 .

6. Cleanup time included two weeks of planning and preparations, one month of remote cleanup operations, onc month of manual cleanup, and one week of reactor discharging. 
7. Concentrations of airborne $\mathrm{Sb}$ activity at the plant boundary were calculated to be about $10^{-5}$ Maximum Permissible Concentration (MPC), whereas if the contanment filters had not becn functioning the concentration would have been about $13 \mathrm{MPC}$.

8. The Task Force -- Subcommittee organizational approach was effective.

9. As a result of this incident the following programs have becn or are being carried out:

- A Technical Standard has been proposed limiting heat generation rates of material before removal from the reactors.

- Heat generating rates and cooling requirements have been calculated for source rods, control rods, targets and other miscellaneous materials. (Complete)

- Operating procedures regarding discharge of source rods and other rods have been revised to require knowledge of hear generation rates prior to removal.

- An alarm system is being installed at the +55 containment filter area to prevent personnel exposure in a similar incident.

- Various changes are being made to the confinement systems to improve operation, confinement capabilities, and remote removal after an activity release. 


\title{
ILLUSTRATIONS
}

\author{
Figures and Tables Arranged in
}

Order of Citation in Text

INTRODUCTION, etc.

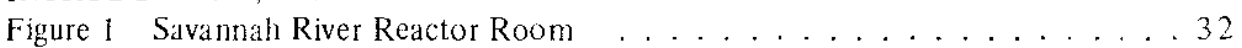

Figure 2 K-Reactor Process Room . . . . . . . . . . . . . . . 33

Figure 3 Schematic of Source Rod After Failure . . . . . . . . . . . . . 34

Table I Composition of Failed Source at Shutdown . . . . . . . . . . 35

Figure 4 Temperatures Calculated in Control Rod Source Cluster . . . . . . . 35

Table II Initial Distribution of Radioactivity . . . . . . . . . . . 36

Figure 5 Decay of Source Rod Radioactivity (Calculated) . . . . . . . . . 36

\section{BRIEF HISTORY}

Table III Cleanup Tasks . . . . . . . . . . . . . . . . 37

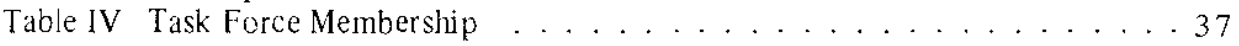

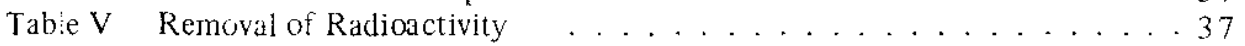

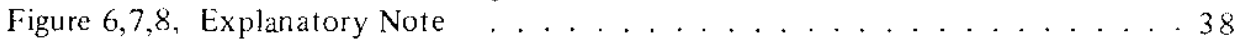

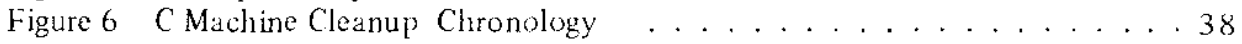

Figure 7 Tank Top Cleanup Chronology . . . . . . . . . . . . . . . . 39

Figure 8 Gencral Process Ruom Cleanup Chronology . . . . . . . . . . . 39

Figure 9 Chronology of Reduction in Contamination . . . . . . . . . . 40

\section{RADIATION MEASUREMENT}

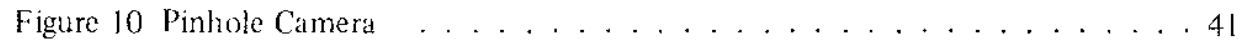

Figure 11 X-Ray of Process Room Overlaid on Scale Diagram of Room . . . . . 41

Table VI Radiation Profile of C.Machine 12-7-70 . . . . . . . . . . . . . 42 (Probe Lowered from +66 -ft Level)

Figure 12 Radiation Profile of C.-Machine at Presentation Point . . . . . . . . 42

Figure 13 Remote Survey Meter ("D-Machine Probe") . . . . . . . . . . . . . 43

Figure 14 First Coarse Grid Radiation Survey of Process Room 12-11-70 . . . . . . 4.3

Figure 15 First Fine Grid Radiation Survey of Reactor Top 12-11-70 . . . . . . 44

Figure 16 Coarse Crid Survey 1-22-70 (Tank Top After Manual Cleaning Finished) . 44

Figure 17 Radiation Survcy (Manua1) 1-31-71 (Process Room) . . . . . . . . . 45

Figure 18 Radiation Survey (Manual) 1-31-71 (Reactor Top) . . . . . . . . 46

Figure 19 Final Tank Top Radiation Survey 2-5-71 (Coarse Grid) . . . . . . 47

\section{CHARGE MACHINE}

Figure 20 Distribution of Debris on C-Machine . . . . . . . . . . . 48

Figure 21 C-Machine Eductor-filter System . . . . . . . . . . . . . . 49

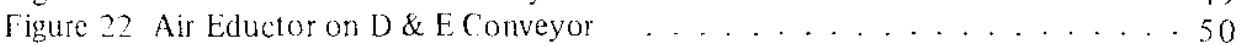

Figure 23 Debris on Clamshell Plate and In Water Pan . Nov 23 Before Vacuunitig . 5!

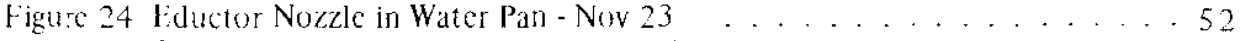

Figure 25 (-Machinc Clamshell and Waterpan After Vacuuming - Nov 23 . . . . 52

Figure 26 Chip Behind Clamshell Plate 12-2-27 (Before \& After Vacuuming) . . . . 53

Figure 27 Crane Haunch Plastic Enclosure . . . . . . . . . . . . . . . . 54

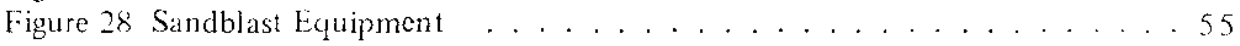

\section{PROCESS ROOM}

Figure 29 Dixcharge Machine Air Eductor . . . . . . . . . . . . . . 56

Table VII Initial Vacuuming of Reactor and Process Room, . . . . . . . . . . 56

Figure 30 Process Room Manual Vacuum Cleaner . . . . . . . . . . . . . . 57 
PROCESS ROOM, contd

Figure 31 Process Room TV Camera Dolly . . . . . . . . . . . . . . . . . 58

Figure 32 Placing Bags of Lead Shot on Tank Top . . . . . . . . . . . . . 59

Figure 33 Composite Photograph of Reactor Tank Top (used as guide in stripping wires) . 59

Figure 34 Tank Top Spray System $\ldots \ldots \ldots$. . . . . . . . . 60

Figure 35 Tank Top Spray Nozzle . . . . . . . . . . . . . . . . . 60 60

Figure 36 Tank Top Spraying $\ldots \ldots \ldots$. . . . . . . . . . . 6l

CONFINEMENT SYSTEM FILTERS

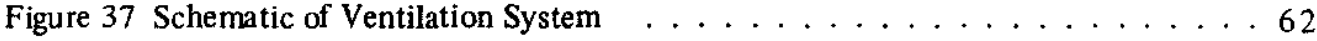

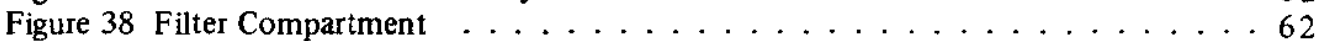

Table VIII Filter Behavior . . . . . . . . . . . . . . . . . 63

Table IX Distribution of Activity Among Confinement Filters . . . . . . . . 63

Figure 39 Moving Filter Compartments (From L Area) Under Power Line . . . . . . 63

Figure 40 Sealing Filter Compartment with Urethane Foam $\ldots \ldots$. . . . . . . 64

Figure 41 Lifting Filter Compartment from Roof . . . . . . . . . . . . . . 64

Figure 42 Filter Compartment Being Lowered Onto Flatcar . . . . . . . . . 65

Figure 43 Filter Compartment Train $\ldots \ldots \ldots \ldots \ldots 65$

REACTOR WORK

Figure 44 Filter Trap Insert $\ldots \ldots \ldots 6$. . . . . . . . . . 66

\section{DISASSEMBLY BASIN}

Figure $45{ }^{124} \mathrm{Sb}$ Activity in Disassembly Basin . . . . . . . . . . . . 67

Figure 46 Anionic Breakthrough of $\mathrm{Sb}$ in Basin Deionizers $\ldots \ldots \ldots 6$

RADIATION EXPOSURE

Table X Personnel Exposure Distribution $\ldots \ldots \ldots \ldots 8$ 







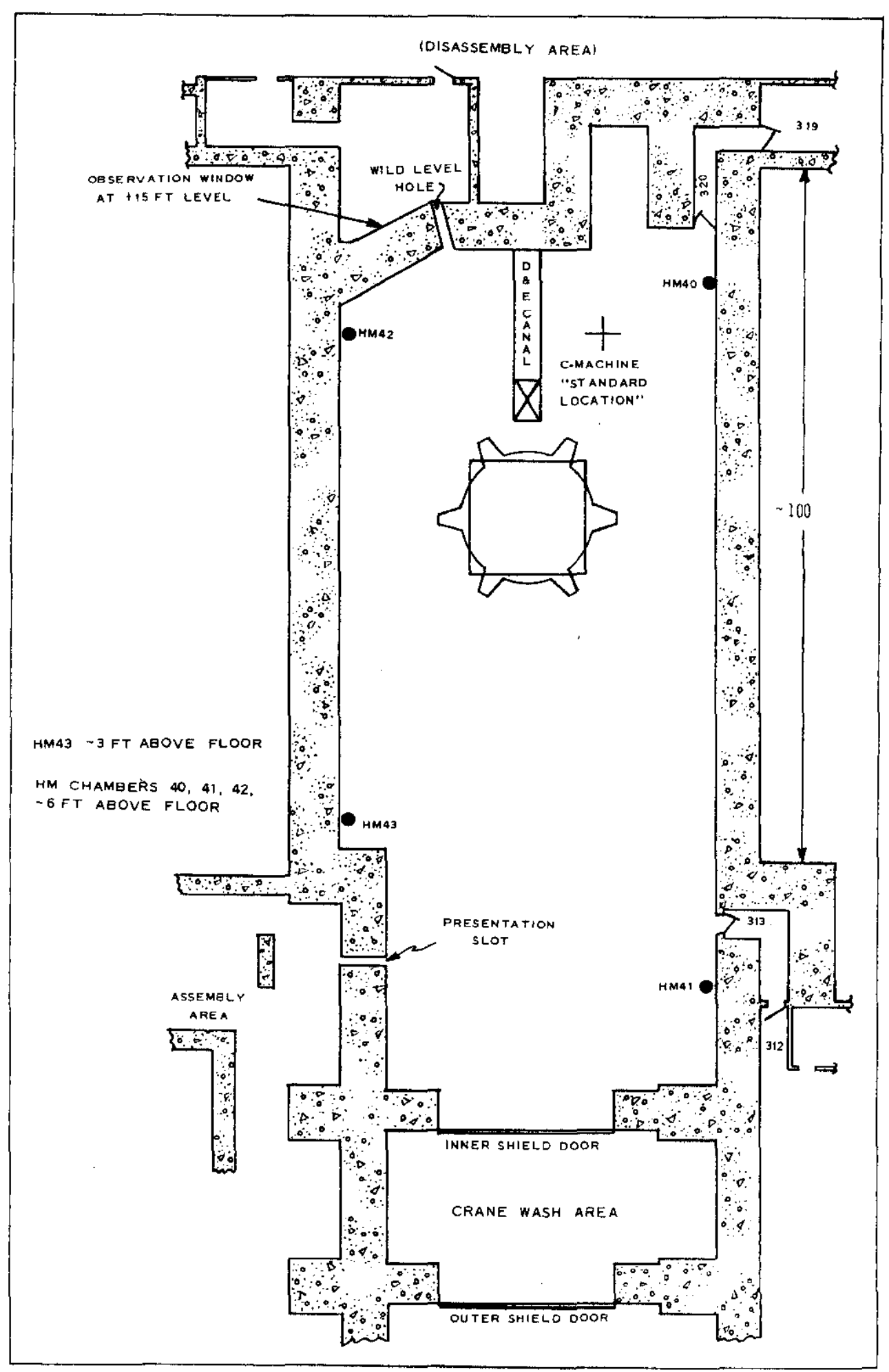

FIGURE 2. K-AREA PROCESS ROOM 


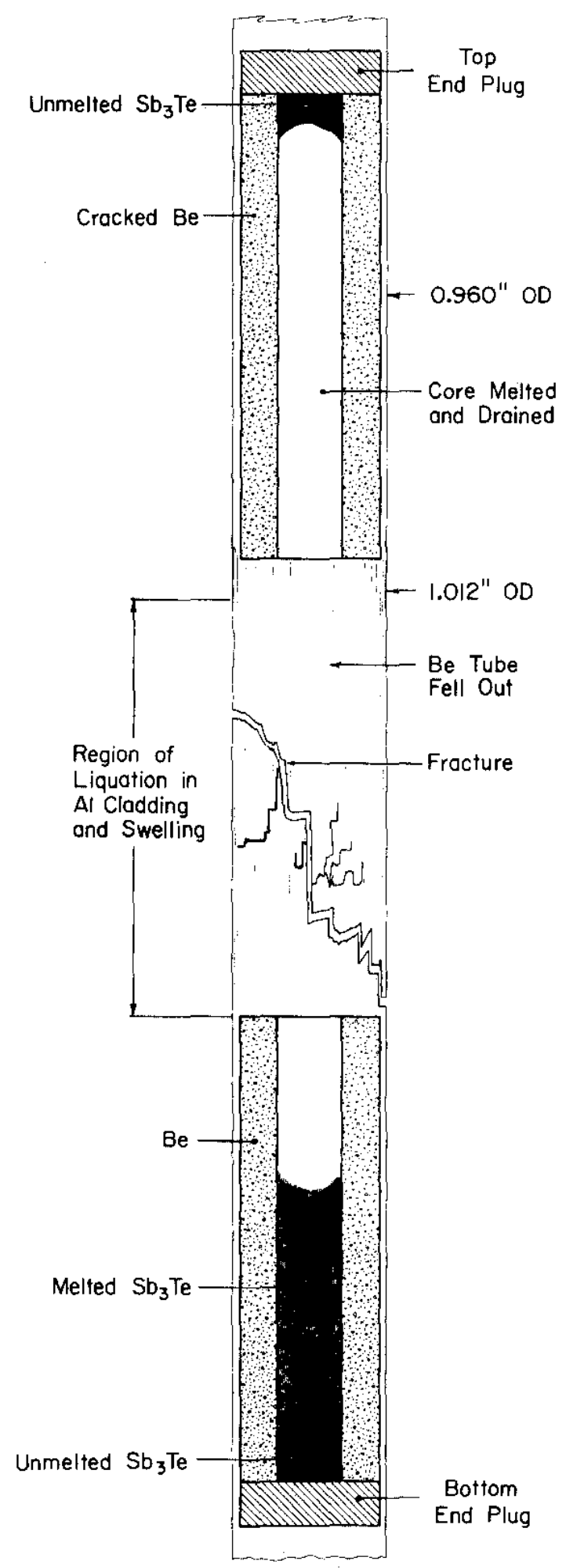

FIGURE 3. SCHEMATIC OF SOURCE ROD AFTER FAILURE 

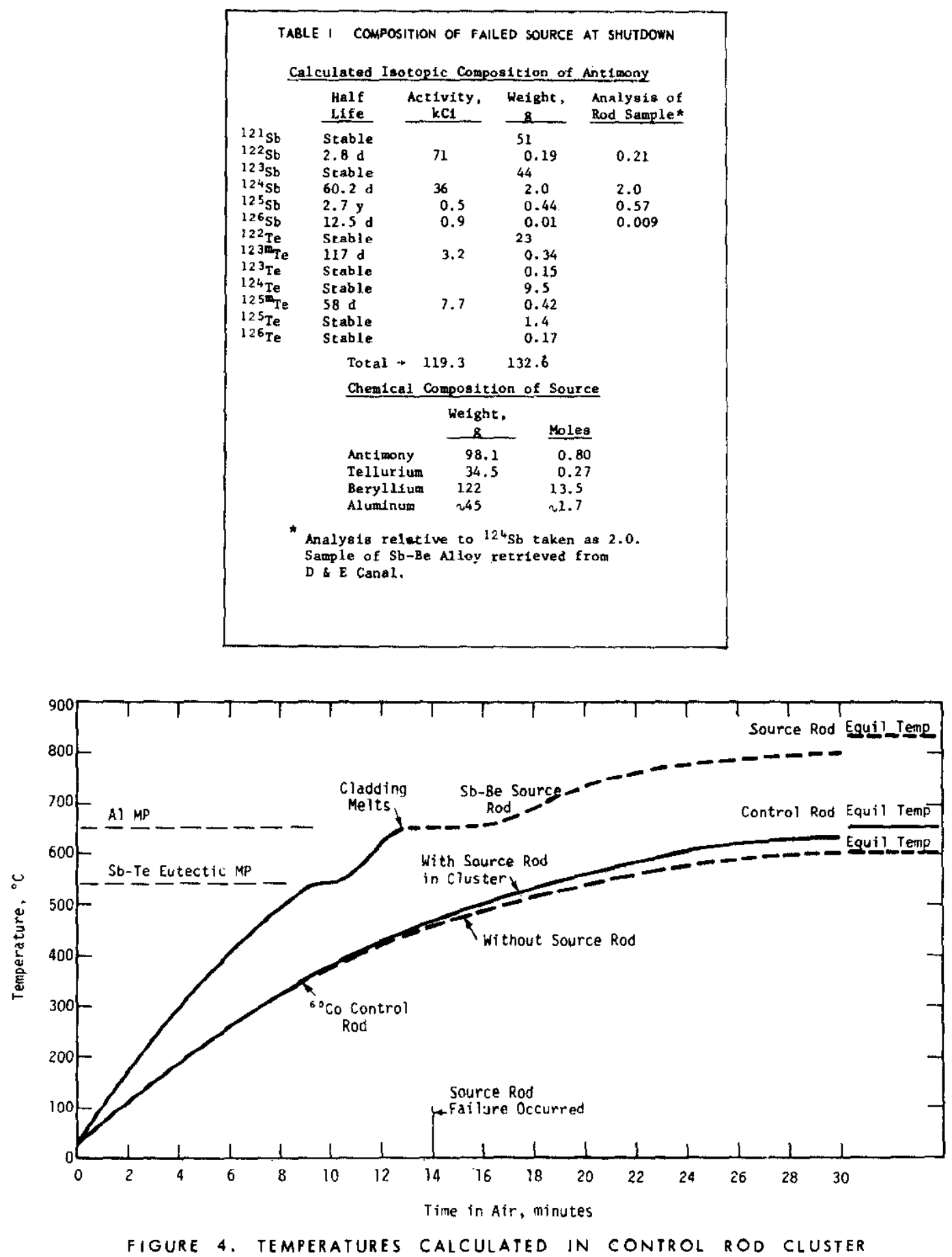


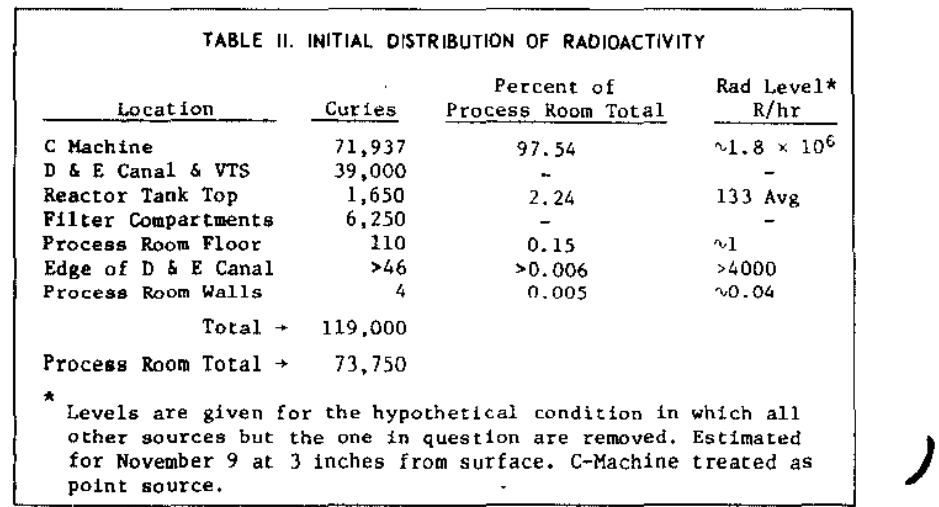

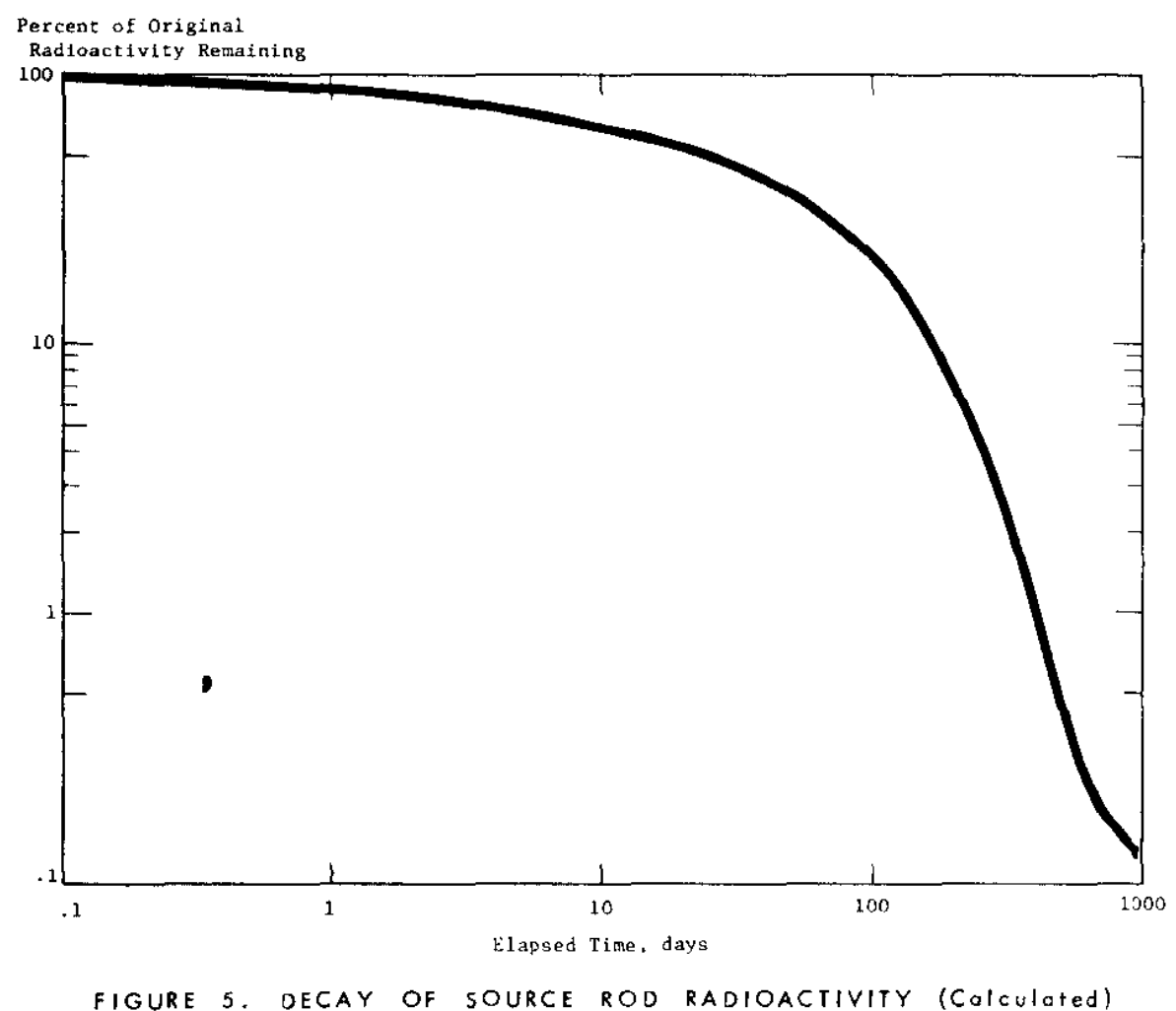

FIGURE 5. DECAY OF SOURCE ROD RADIOACTIVITY (COICUIGTED) 


\begin{tabular}{|c|c|c|c|}
\hline & Task No, and Ticle & objective & Means \\
\hline 1. & Charge Machine Cleanup & $\begin{array}{l}\text { Remove major source } \\
\text { of rad1ation }\end{array}$ & $\begin{array}{l}\text { - Remote removal of activity } \\
\text { - Move machine to crane wash } \\
\text { area } \\
\text { - Remove remaining activity } \\
\text { manually }\end{array}$ \\
\hline 2. & Process Root Survey & $\begin{array}{l}\text { - Assess problem } \\
\text { - Evaluate cleanup } \\
\text { progress }\end{array}$ & $\begin{array}{l}\text { Standard and special } \\
\text { radiation surveys }\end{array}$ \\
\hline 3. & Process Room Cleanup & $\begin{array}{l}\text { Reduce radiation to } \\
\text { tolerable level }\end{array}$ & $\begin{array}{l}\text { Mechanical and chemical } \\
\text { decontamination }\end{array}$ \\
\hline 4. & $\begin{array}{l}\text { Filter Compartment } \\
\text { Replacement }\end{array}$ & $\begin{array}{l}\text { Ensure containment } \\
\text { of airborne activi- } \\
\text { ty }\end{array}$ & $\begin{array}{l}\text { Replace nearly apenc } \\
\text { compartments after clean- } \\
\text { up completed }\end{array}$ \\
\hline 5. & Reactor Planning & $\begin{array}{l}\text { Prepare to complete. } \\
\text { discharge and } \\
\text { recharging }\end{array}$ & \\
\hline 6. & D \& E Canal Cleanup & $\begin{array}{l}\text { Recover and contain } \\
\text { pieces deposited } \\
\text { in canal }\end{array}$ & Mechanical recovery \\
\hline 7. & $\begin{array}{l}\text { Basin Activity } \\
\text { Removal }\end{array}$ & $\begin{array}{l}\text { Contain activity re- } \\
\text { leased to disassem- } \\
\text { bly basin }\end{array}$ & $\begin{array}{l}\text { Use installed basin } \\
\text { contalnment system }\end{array}$ \\
\hline 8. & Calculations & $\begin{array}{l}\text { - Analyze incident } \\
\text { - Aid in cleanup } \\
\text { - Prevent recurrence }\end{array}$ & $\begin{array}{l}\text { Data collection and analysis } \\
\text { plus theoretical calcula- } \\
\text { tfons }\end{array}$ \\
\hline
\end{tabular}

TABLE IV. TASK FORCE MEMBERSHIP

CENTRAL COMMITEE

I. R. Smith,* C. T. Axelberg, J. M. Boswell, E. O. Kigex, W. M. O1Ifff,

o. A. Towler, W. P. Walke

$\underline{\text { TASK }}$

J. M. Weibel, * E. C. Bertsche, G. F. Haase, P. M. Hankinson, R. S. Wingard

W. P. Walke, * G. W. McManaway, J. S. Petersen

J. S. Petersen,* J. W. Joseph, K. E. Kehr, E. S. Occhipinti, J. S, Murdock

J. W. Joseph,* J. W. Little, F. E. Urban

L. Galloway, * H. F. Allen, D. R. Becker

M. D. Moore,* B. S. Spangler

E. C. Bertsche, * L. Galloway, W. R. Jacobsen

E. O. Kiger, * J. M. Boswell, P. L. Roggenkamp, O. A. Towler

* Chairman. P. A. Dahien also chatred the Central Committee vice I. R. Smith.

\begin{tabular}{|c|c|}
\hline $\begin{array}{c}\text { TABLE V. REMOVAL OF RADI } \\
\text { Operation }\end{array}$ & $\begin{array}{l}\text { IOACTIVITY } \\
\% \text { Removed }\end{array}$ \\
\hline $\begin{array}{l}\text { C Machine } \\
\text { Vacuuming at D \& } E \\
\text { Removal of parts }\end{array}$ & $\begin{array}{r}91 \\
6\end{array}$ \\
\hline $\begin{array}{l}\text { Floor and Tank Top } \\
\text { Vacuuning by D Machine } \\
\text { Floor, manual cleaning } \\
\text { Tank top, mechanical } \\
\text { and chemical cleaning }\end{array}$ & $\begin{array}{l}1 \\
1.9 \\
0.1\end{array}$ \\
\hline $\begin{array}{l}\text { BASIS: HM Chamber readings } \\
\text { to undecayed values } \\
5: 00 \mathrm{am}, \text {, as shown }\end{array}$ & $\begin{array}{l}\text { corrected } \\
\text { at Nov } 9, \\
\text { In figure } 9 .\end{array}$ \\
\hline
\end{tabular}


FIGURES $6,7,8$ - EXPLANATORY NOTE

These figures include only items which were recorded in Log books or could be verified from other reliable sources. Additionol work may have been done which is not included in these figures becouse of lack of reliable or explicit informotion.

Information sources used were

- Senior Supervisor's Log Book

- Crone Control Log Book

- File of daily "105+K Building Cleonup Program"

(by C.T. Axelberg, et al)

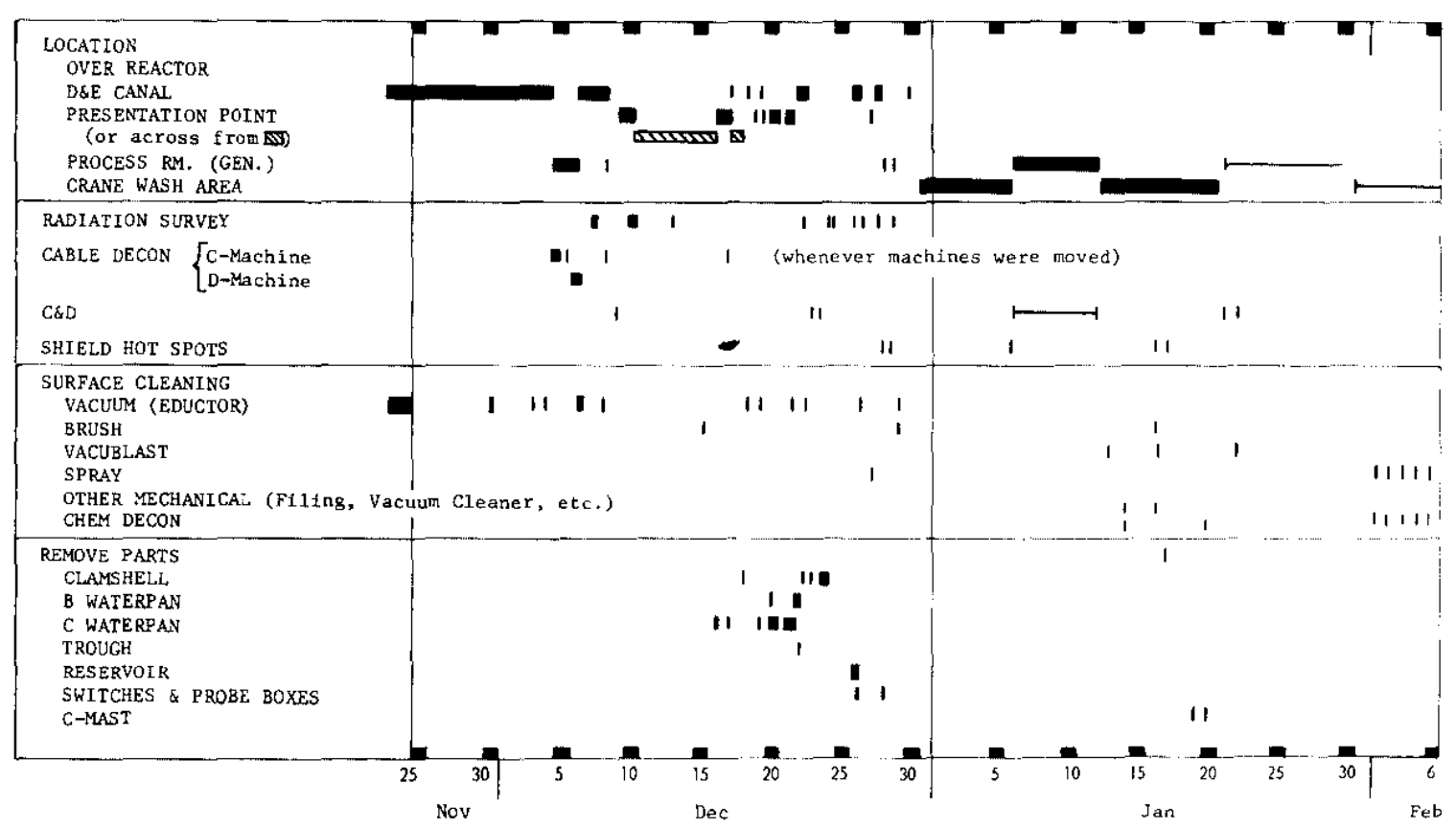

FIGURE 6. C MACHINE CLEANUP CHRONOLOGY 


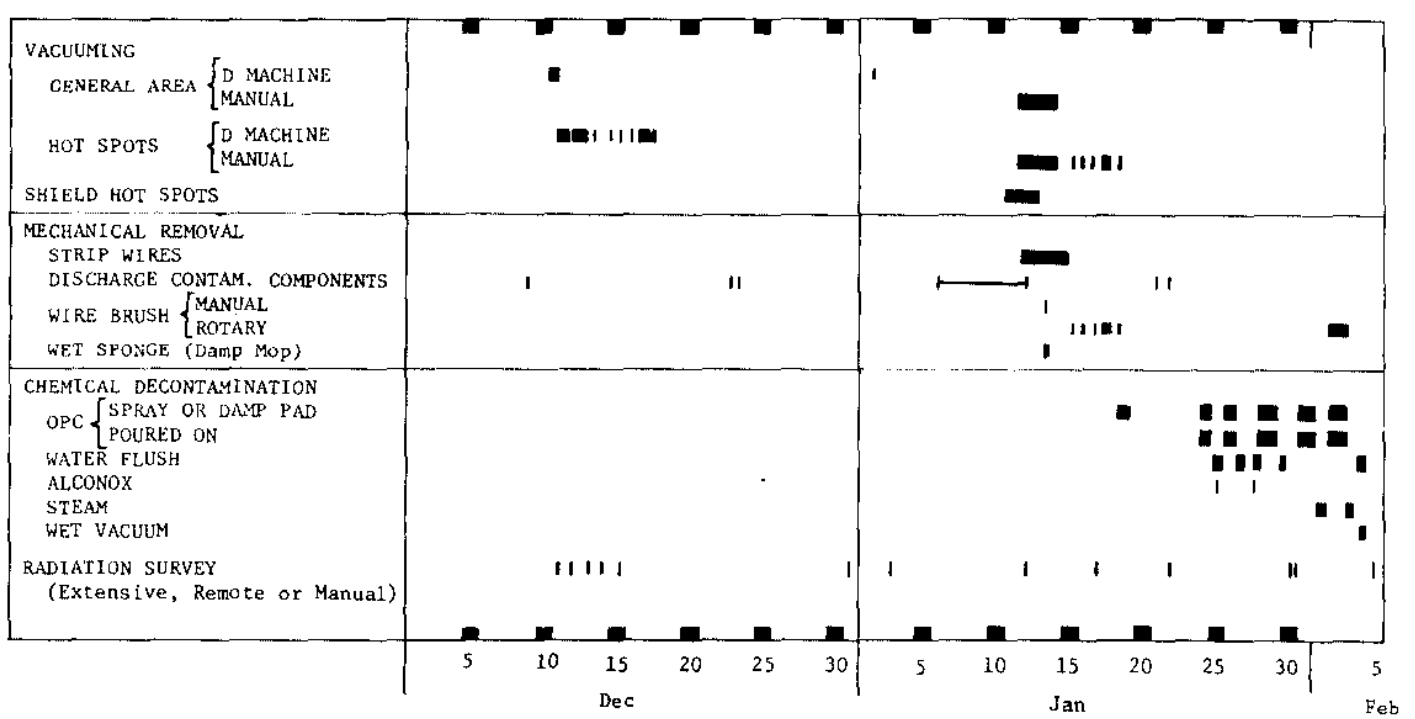

FIGURE 7. TANK TOP CLEANUP CHRONOLOGY

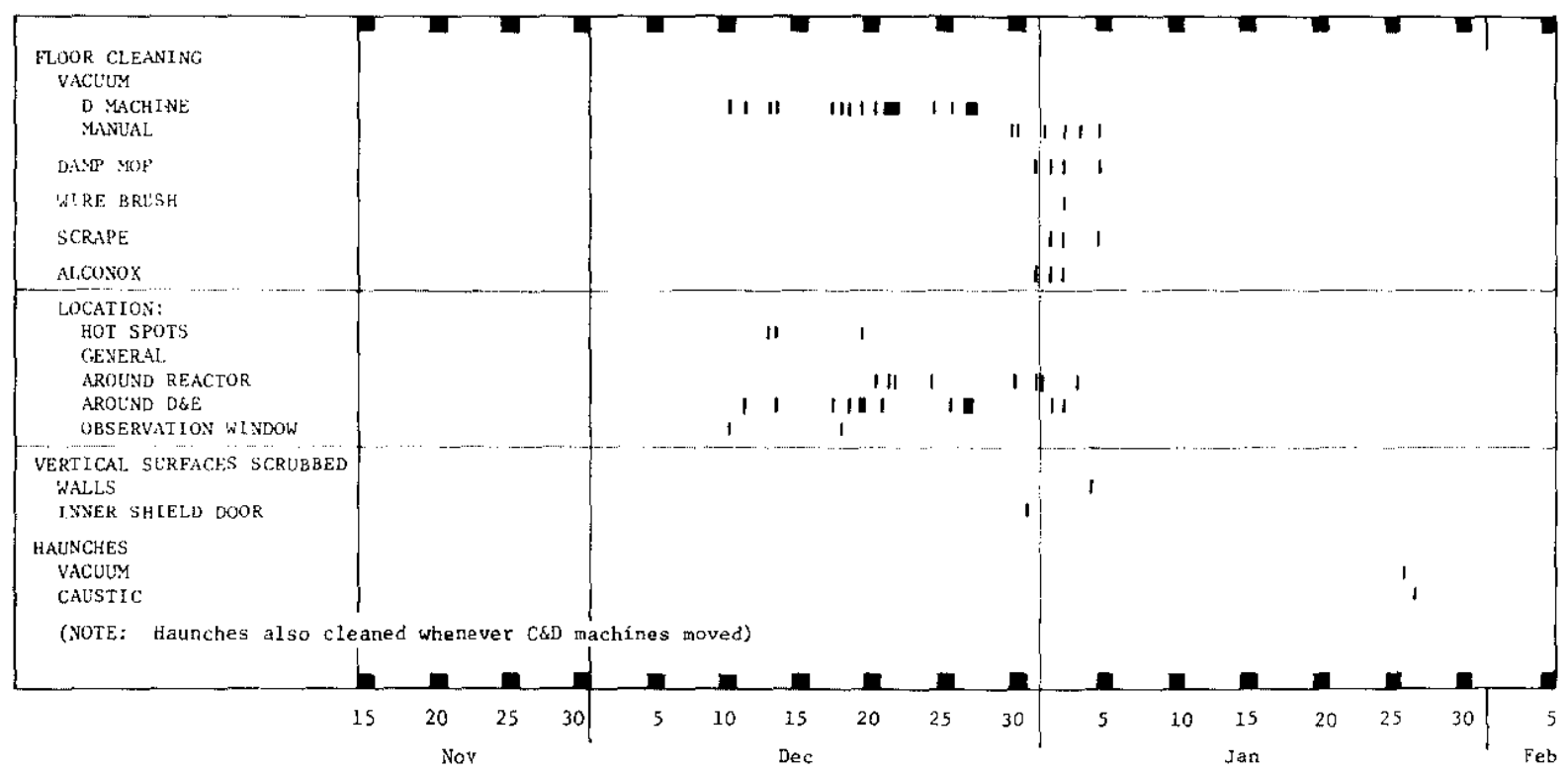

FIGURE 8. GENERAL PROCESS ROOM CLEANUP CHRONOLOGY 


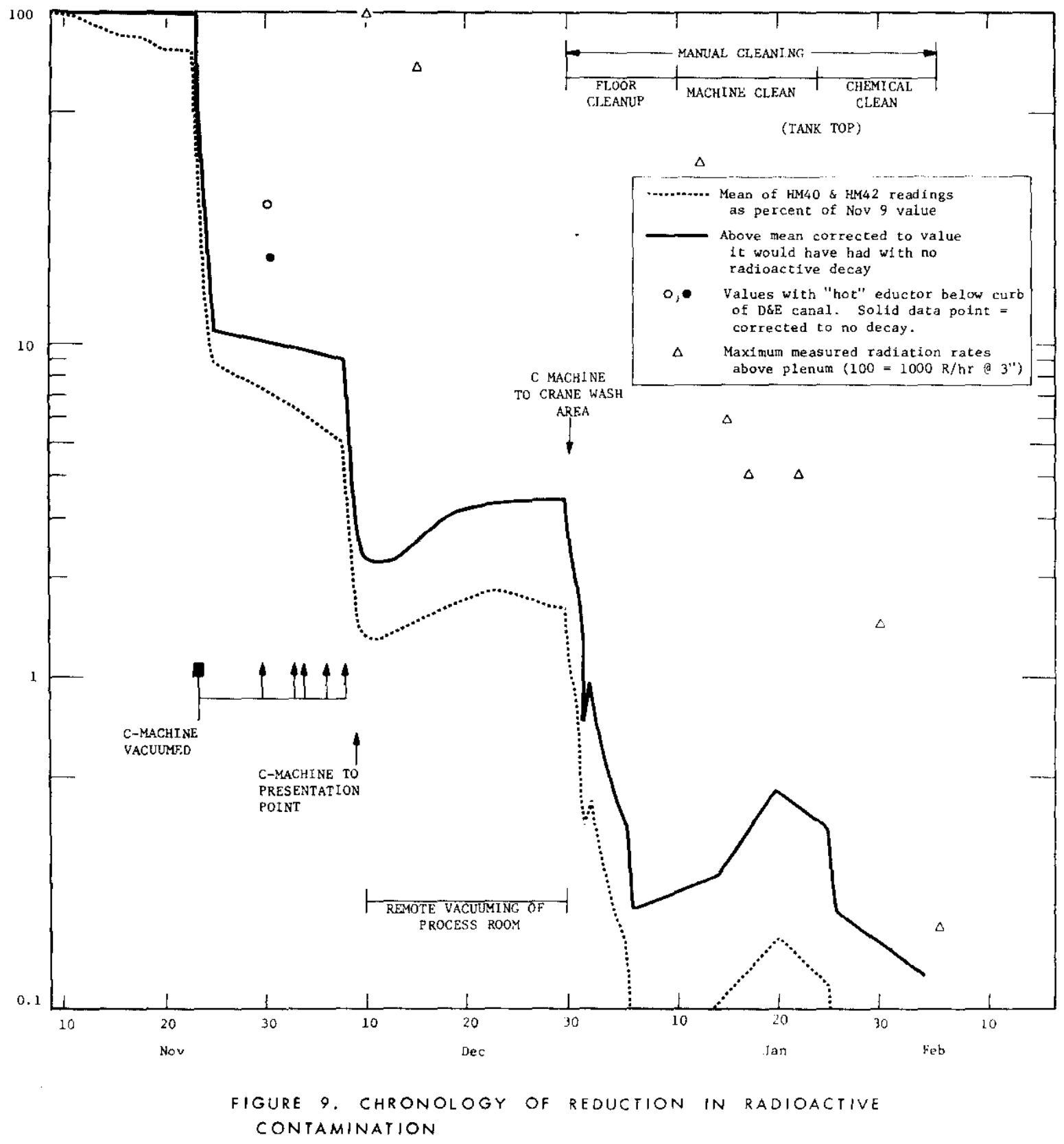



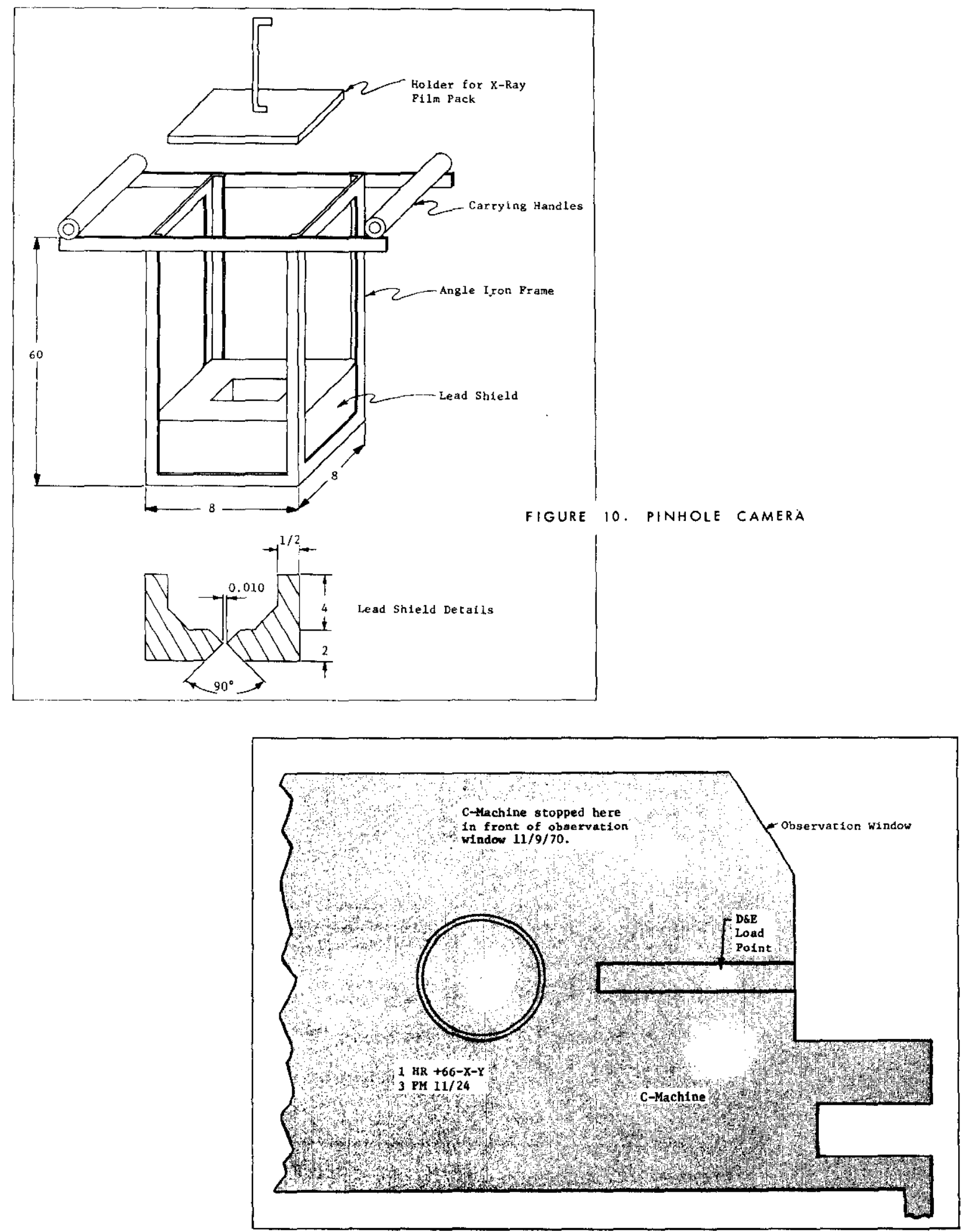

FIGURE 11. X-RAY OF PROCESS ROOM OVERLAID ON SCALE DIAGRAM OF ROOM (Shows major source on C-machine, minor source near center of tank top, cluster of foint sources in. front of observotion window) 


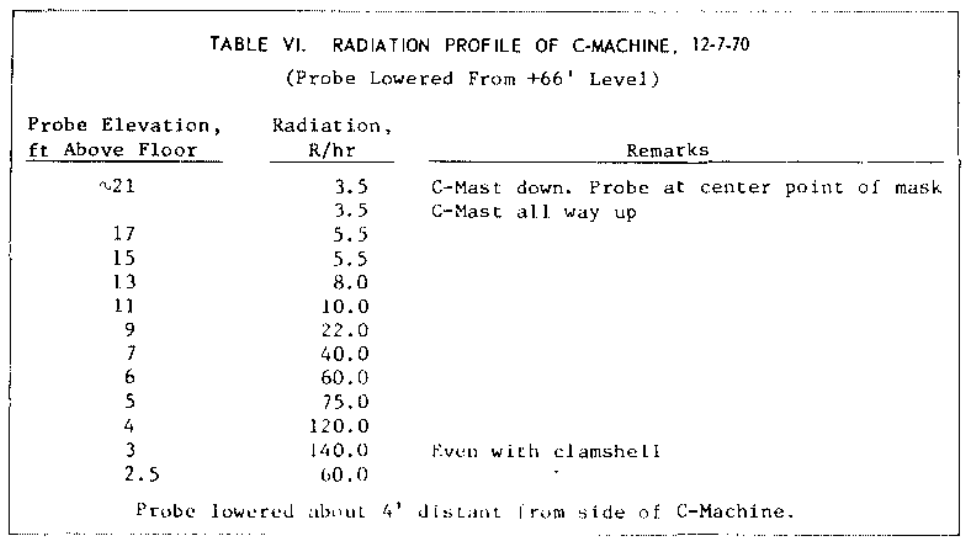

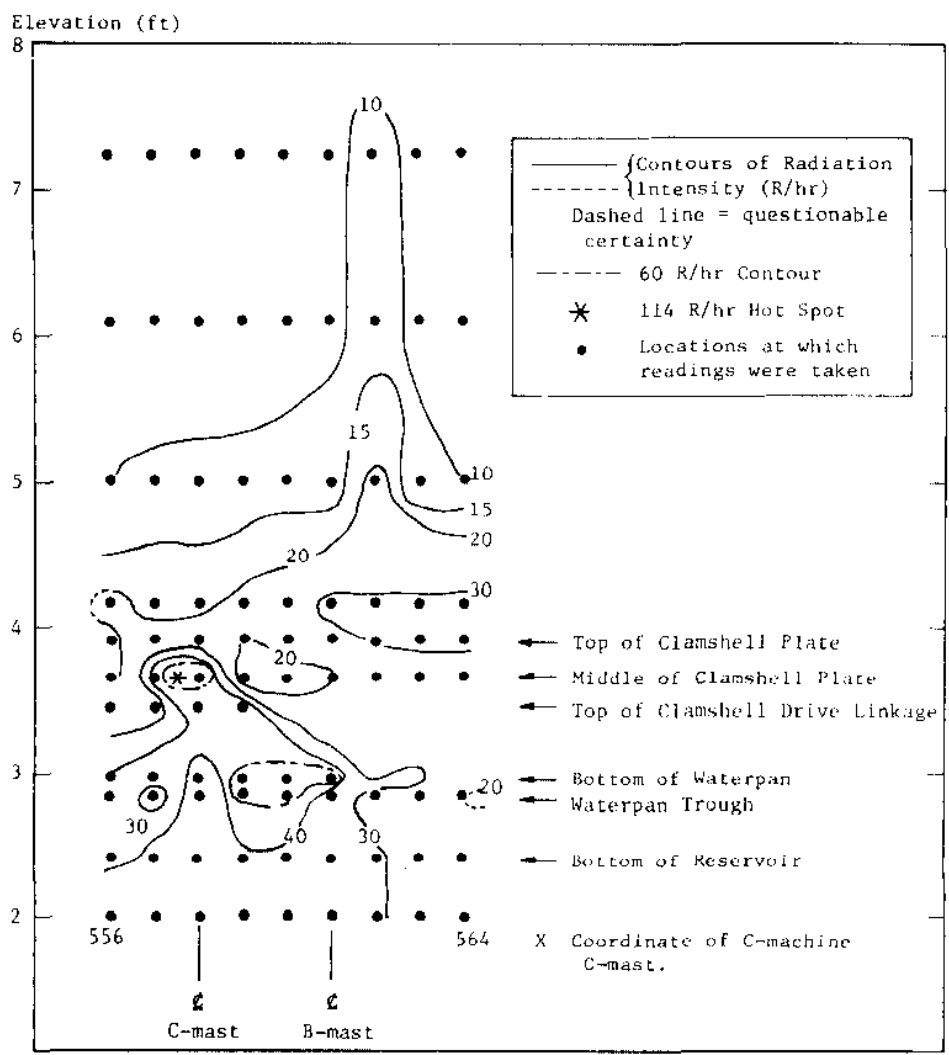

FIGURE 12. RADIATION PROFILE OF C-MACHINE AT PRESENTATION POINT 


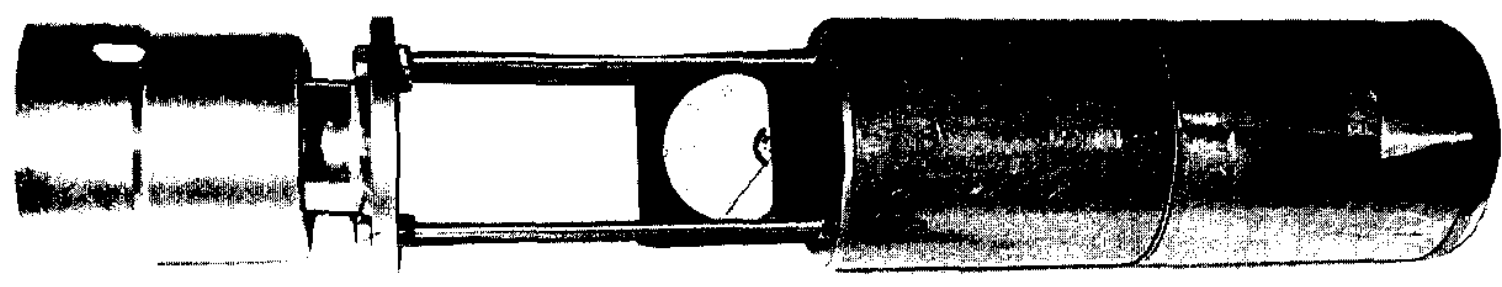

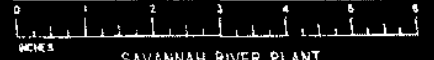 \\ SAVAghah River PLANT}

FIGURE 13. REMOTE SURVEy METER ("D-Machine Probe").

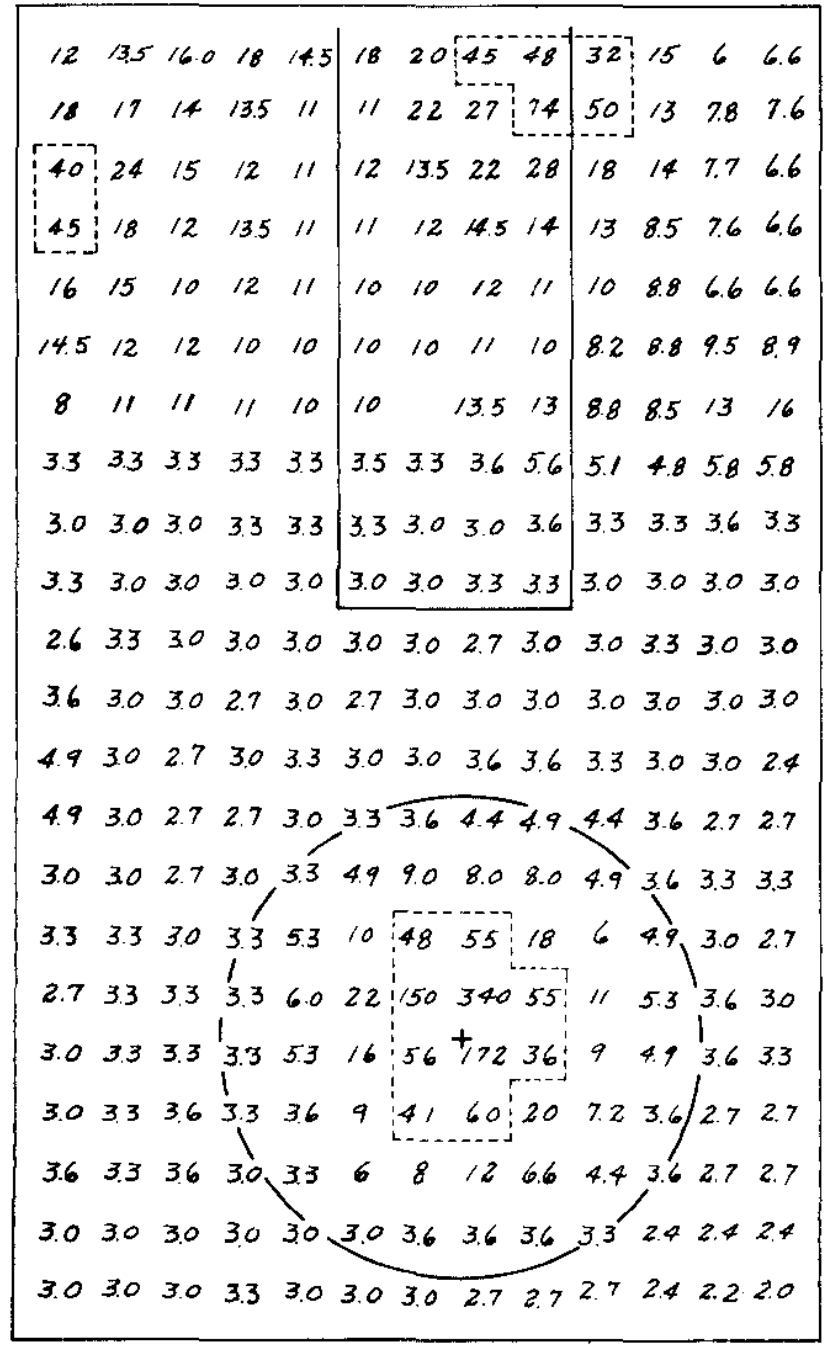

FIGURE 14. FIRST COARSE GRID $2 \mathrm{ft} \times 2 \mathrm{ft})$ RADIATION SURVEY OF PROCESS ROOM, 12/11/70 (Readings in $R /$ hr at about 8 in. from floor) BEFORE ANY CLEANING Note same hot spots shown by $x$-ray camero 


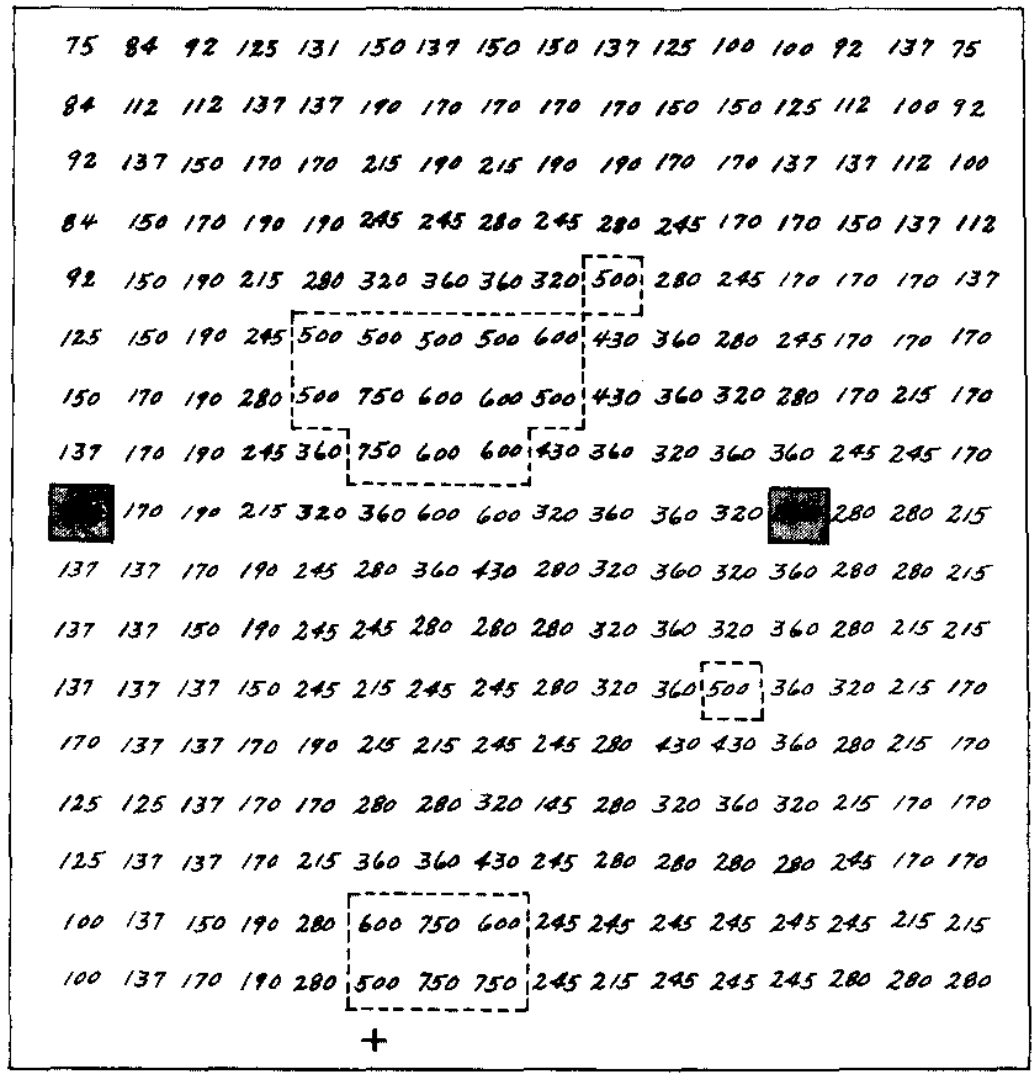

$\sum_{\text {Hot Spots }}$

Frid Points of Coarge Grid (See Figure 14)

+ Center of Reactor

FIGURE 15. FIRST FINE GRID ( 2 in. $x 2$ in.) RADIATION SURVEY OF REACTOR TOP, 12/11/70 (Readings in $R / \mathrm{hr}$ at about $12 \mathrm{in}$. from tank top; orientation as in figure 14) BEFORE ANY CLEANING

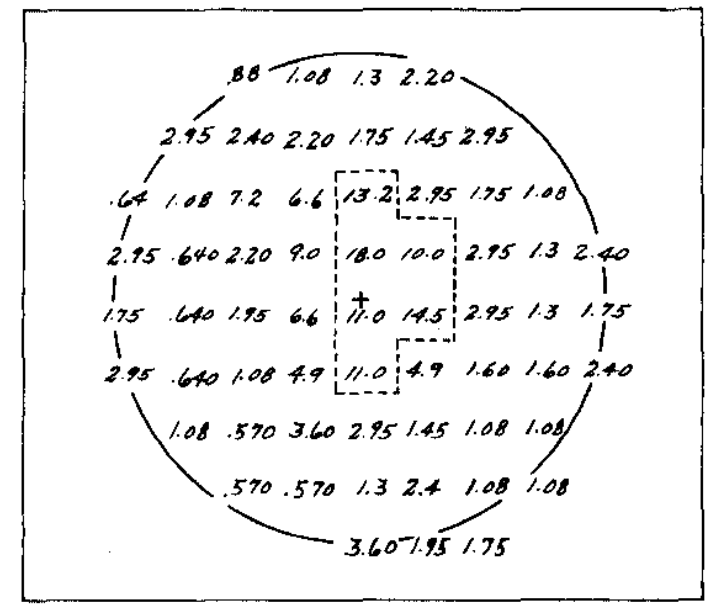

FIGURE 16. COARSE GRID SURVEY $(2 \mathrm{ft} \times 2 \mathrm{ft})$, $1 / 22 / 71$ Tank top after manual cleaning finished (Reodings in $R / h r$ of about 12 in. from tank top) 
L RADIATION READINGS IN $\mathrm{mR} / \mathrm{hr}$

Readings at 3 in. from smears taken to determine transferable contamination.

* Radiation level at $14 \mathrm{ft}$ above center of tank was $350 \mathrm{mR} / \mathrm{hr}$

All other radiation readings at 6 in. from floor.



Ao

然

$\begin{cases} & 0 \\ 0 & 0 \\ 0 & 0 \\ 0 & 0 \\ \hdashline & 0\end{cases}$

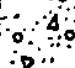

40

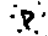

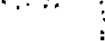

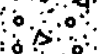
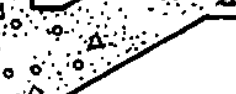

500

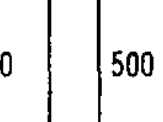

500

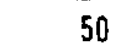

50

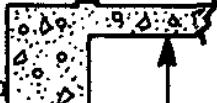

50150

500

300

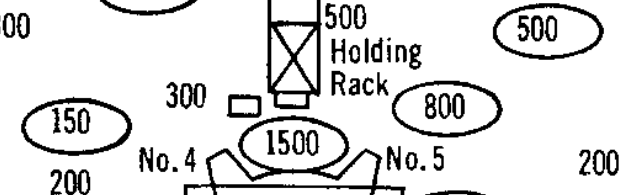

$\because$

$\therefore$

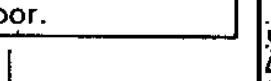

0

50

a

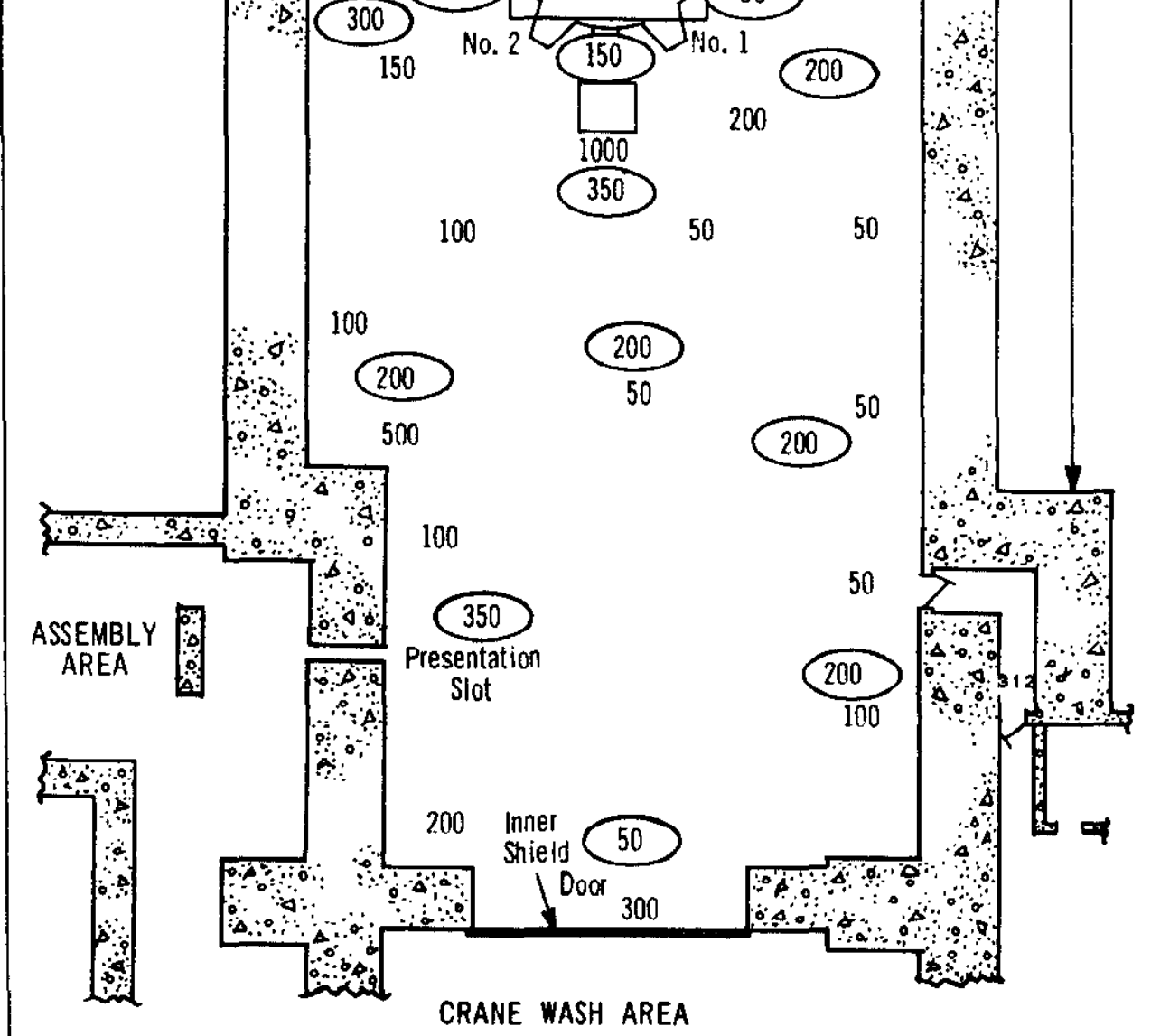

FIGURE 17. RADIATION SURVEY (MANUAL), $1 / 31 / 71$ PROCESS ROOM 


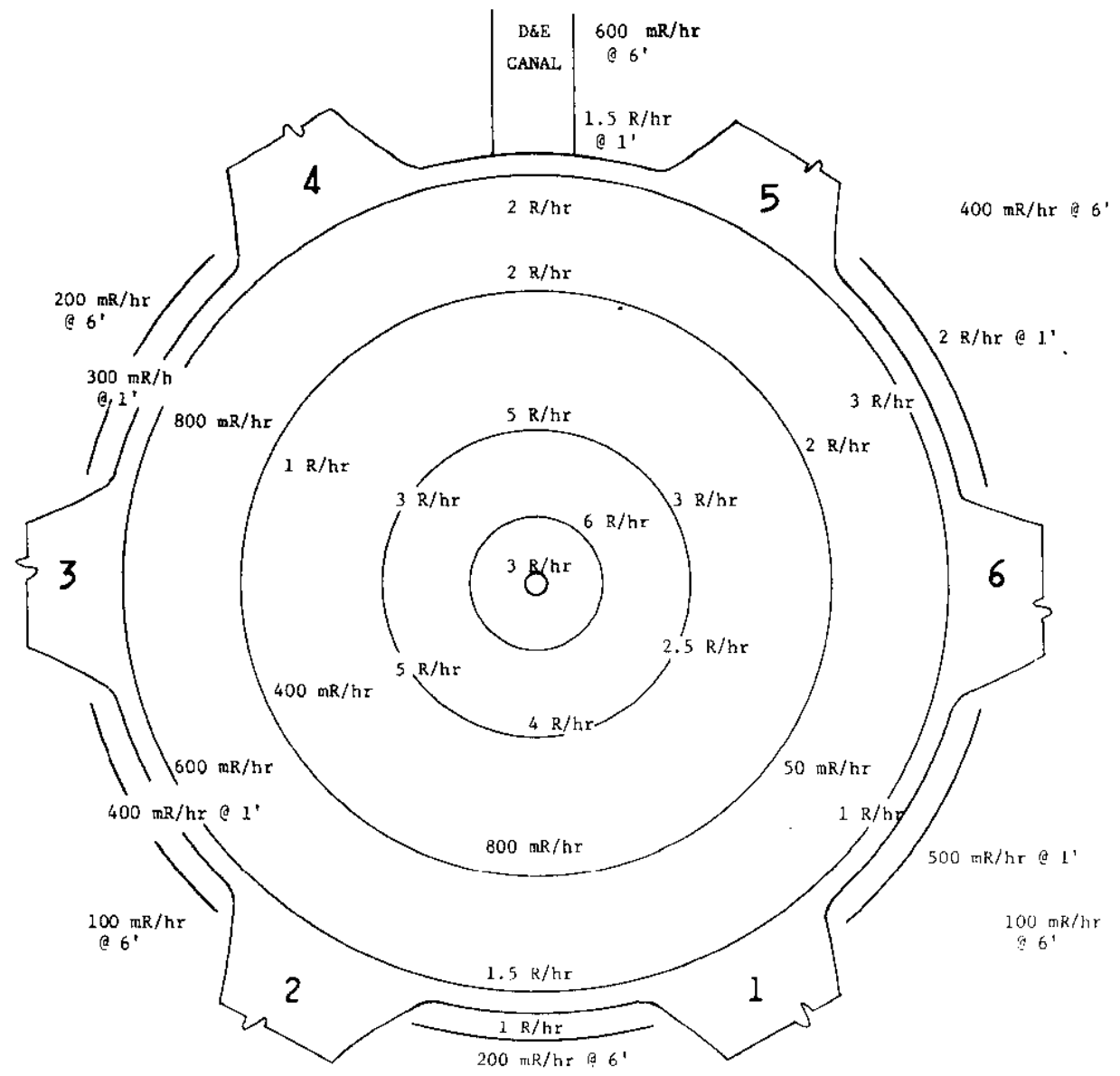

FIGURE 18. RADIATION SURVEY (MANUAL) $1 / 31 / 71$, OF REACTOR IOP (Radiation measurements over tonk lop were at probe pin height; i.e., obout $12 \mathrm{in}$. distance; other measurements as shown) 




\begin{tabular}{ll}
$>.8 \mathrm{R} / \mathrm{hr}$ & $\because$ Typical Grid Pattern \\
$1.2 \mathrm{R} / \mathrm{hr}$ (hottest spots) & $\because$ (Selected Actual Grid Points) \\
$.4 \mathrm{to} .8 \mathrm{R} / \mathrm{hr}$ & $\begin{array}{c}\text { Reactor Top Outline } \\
\text { (Approximate) }\end{array}$ \\
$0.2 \mathrm{to} .4 \mathrm{R} / \mathrm{hr}$ & $\begin{array}{l}\text { NOTE: X and Y scales unequal. } \\
\text { Radiation measurements at probe } \\
\text { pin height (about 12 1n.) }\end{array}$ \\
\hline$<.2 \mathrm{R} / \mathrm{hr}$ &
\end{tabular}

FIGURE 19. FINAL TANK TOP RADIATION SURVEY, $2 / 5 / 71$ (Coorse Grid: approx 9 in. $x 9$ in.) Same orientation as Figure 18 


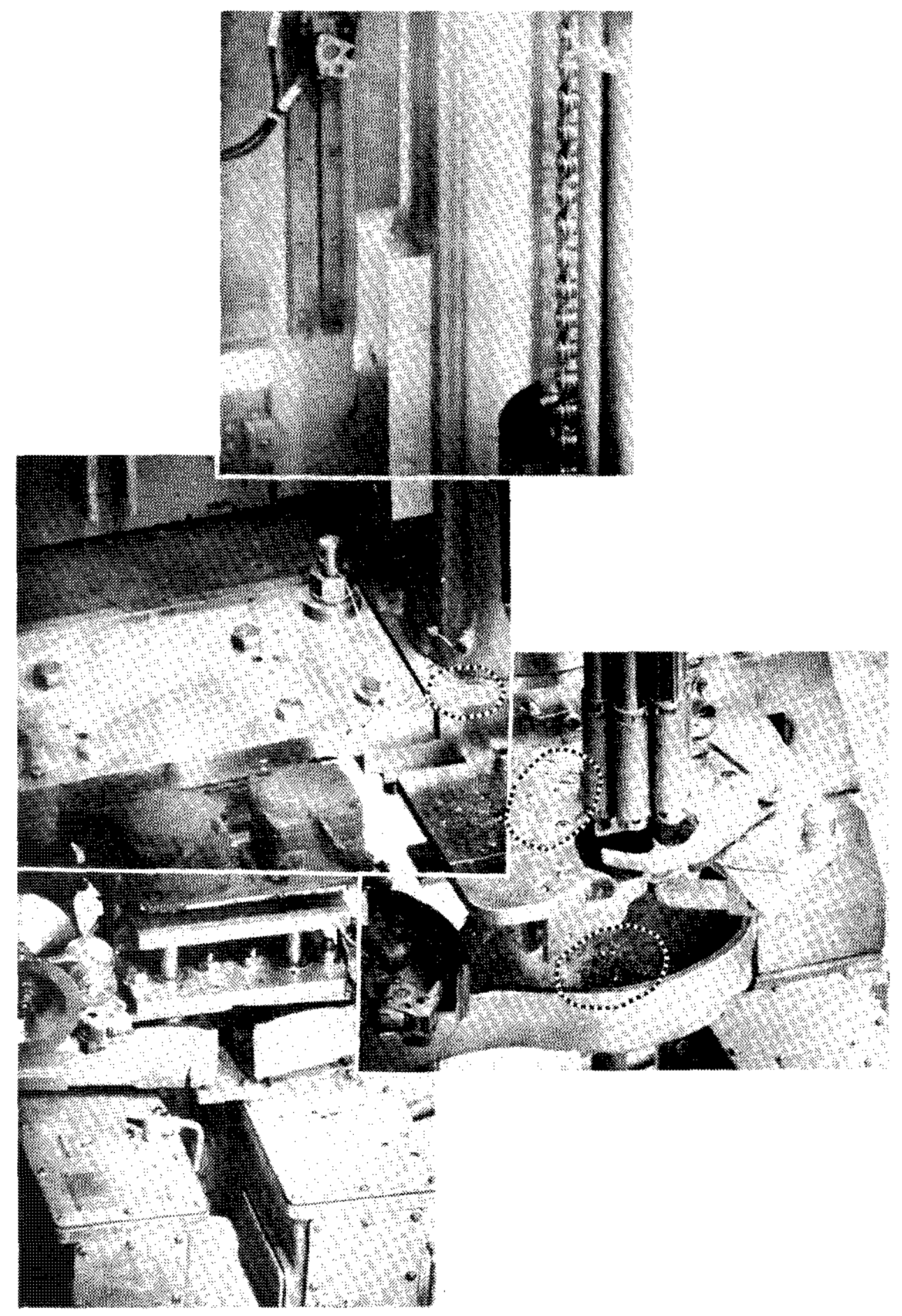

FIGURE 20. OISTRIBUTION OF OEBRIS ON C-MACHINE (COMPOSITE PHOTOGRAPH) Note small pleces of debris in citcled locations 


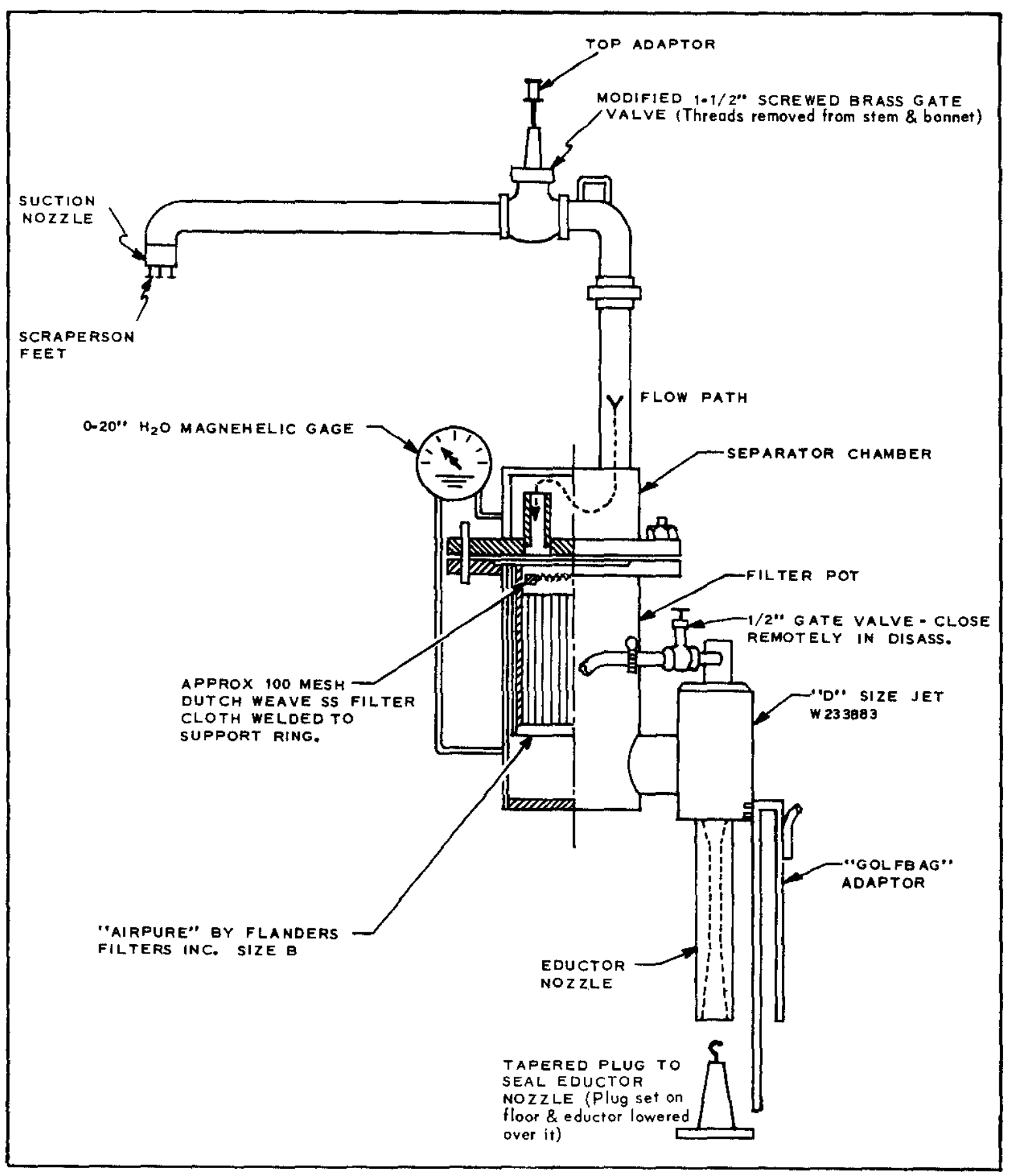

FIGURE 21. C-MACHINE EDUCTOR-FILTER SYSTEM 


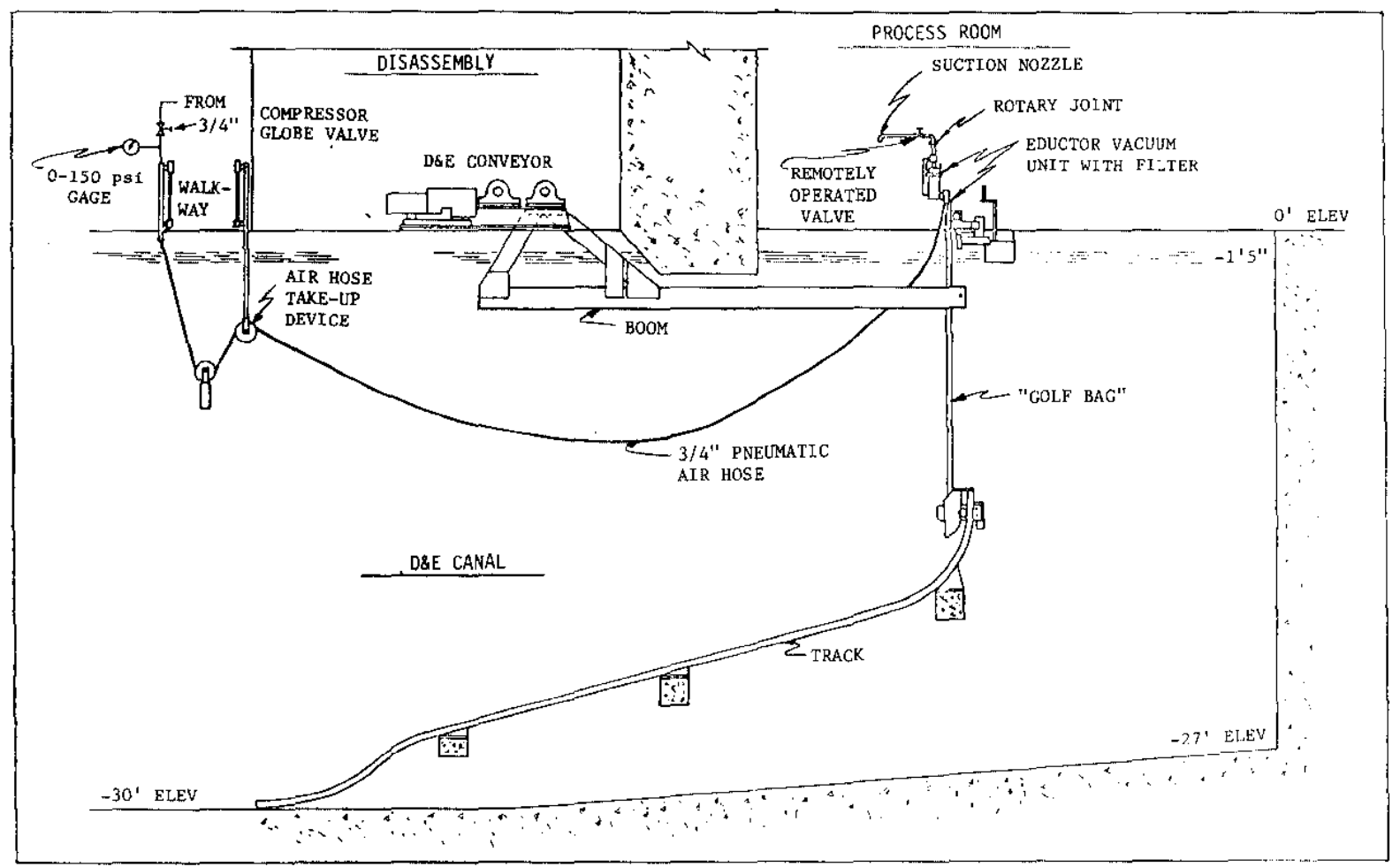

FIGURE 22. AIR EDUCTOR ON D\&E CONVEYOR 


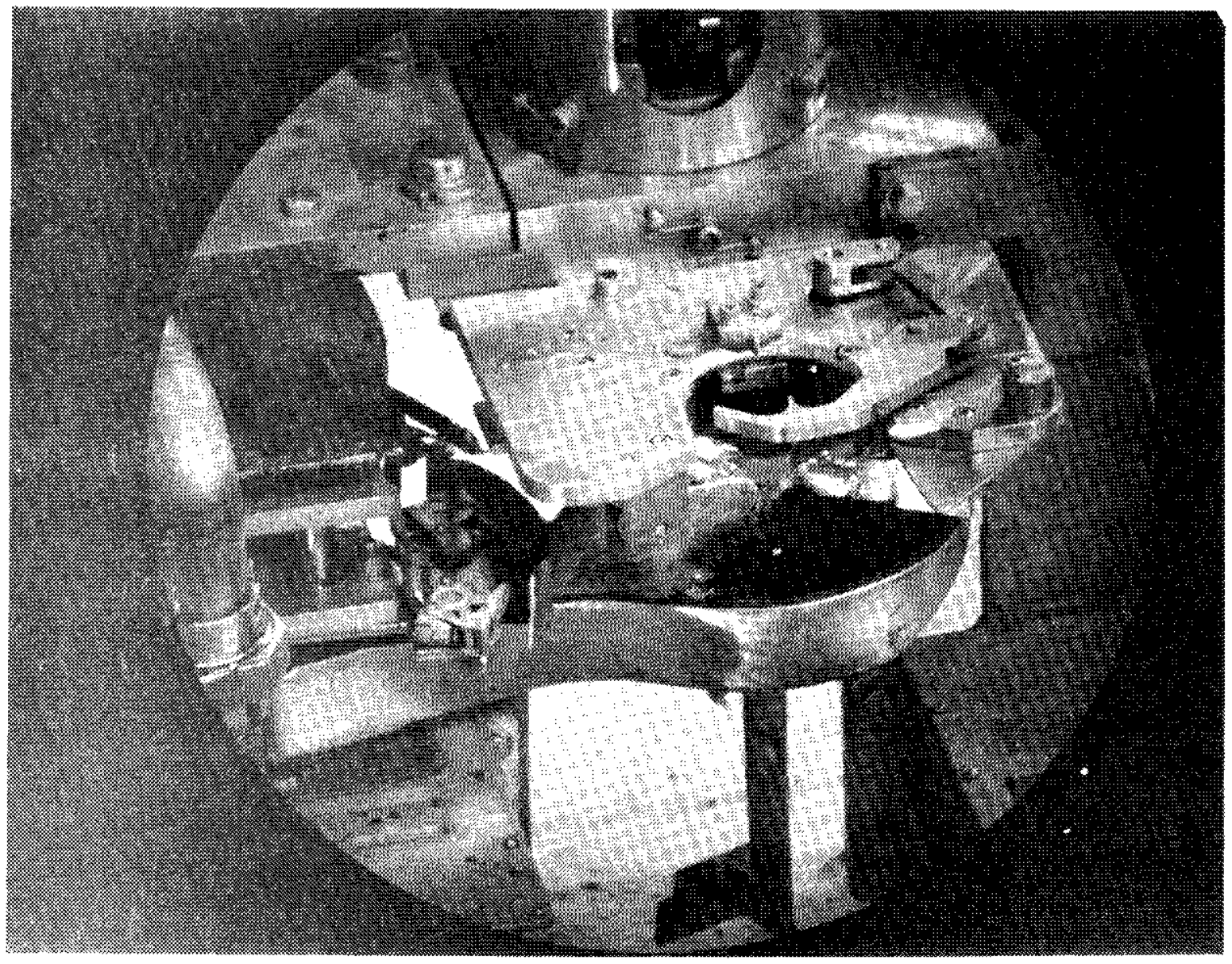

FOURE 23, DEBRS ON CLAMSHEL PLATE ANO IN WATERPAN ..

NOY 23 HEROR VACUUMING 


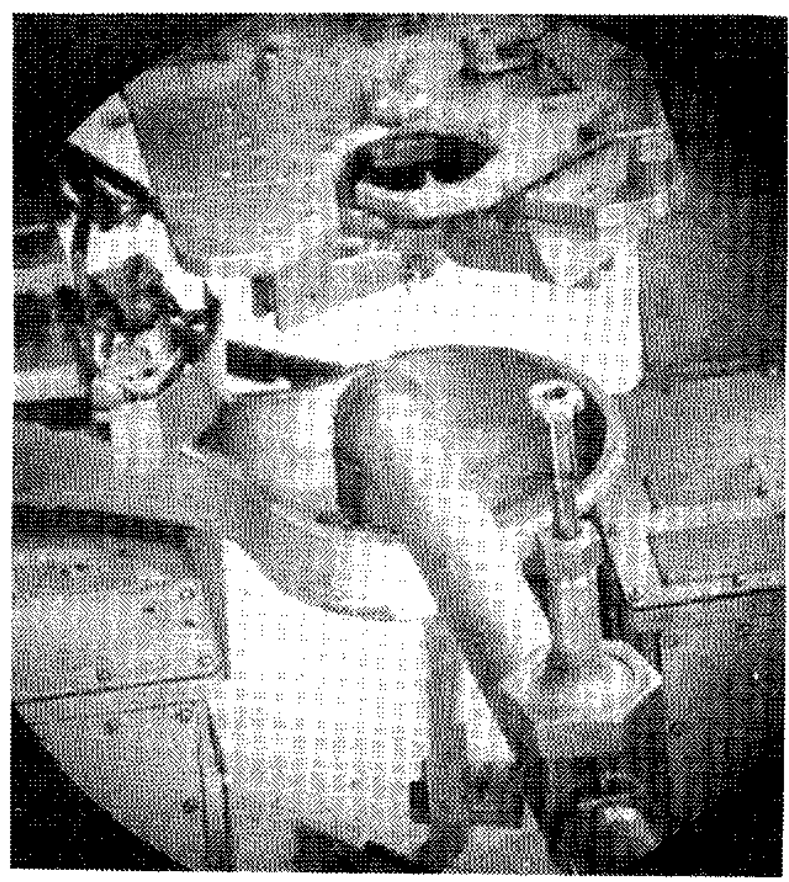

FIGURE 24. EDUCTOR MOZZLE IN WATERPAN (CANACHINE) ... NOVEMBER 23

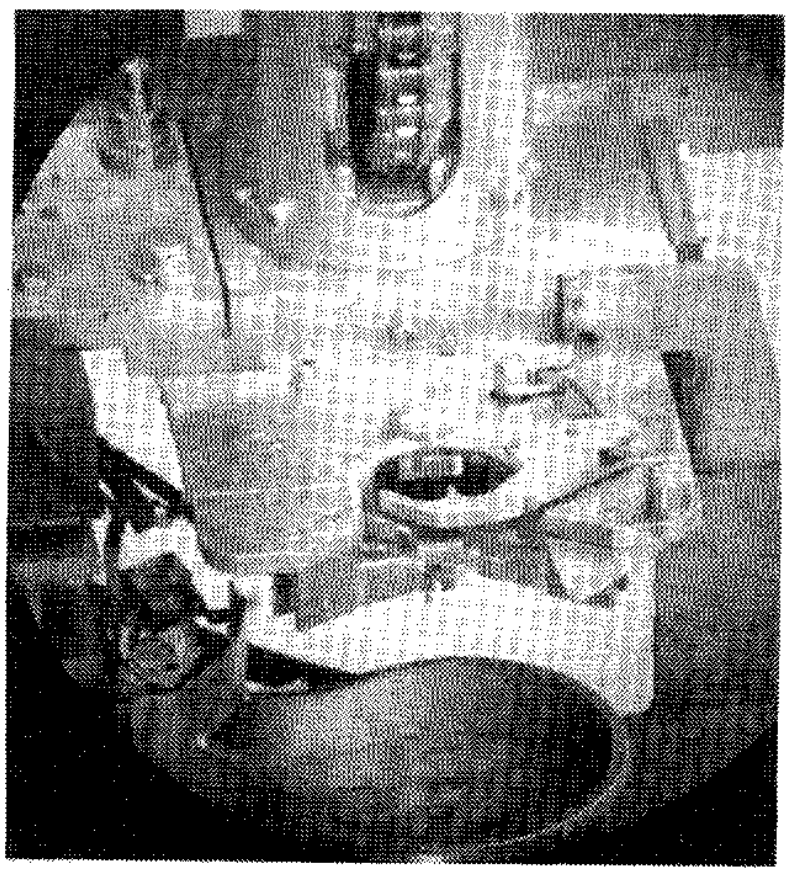

FIGURE 25. CXMACHINE CLAMSHELI. AND WATERPAN AFTER VACUUMING - NOVEMBER 23 
Y2/20 Bofore vecumba
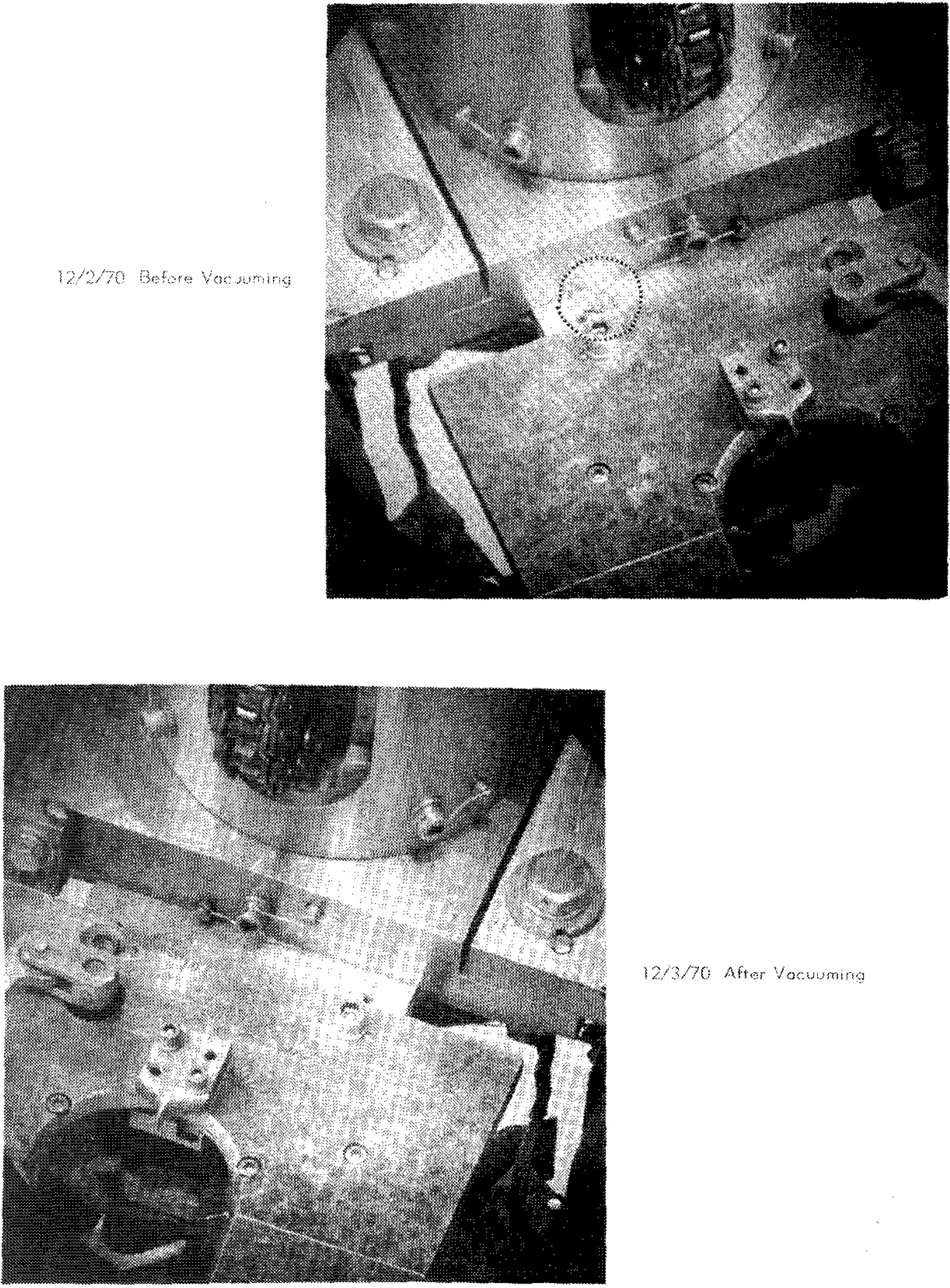

$12 / 3 / 70$ Afrer Vocumming

FIOURE 26. CHIF BEHINO CLAMSHELL PLATE

$-53 m$ 


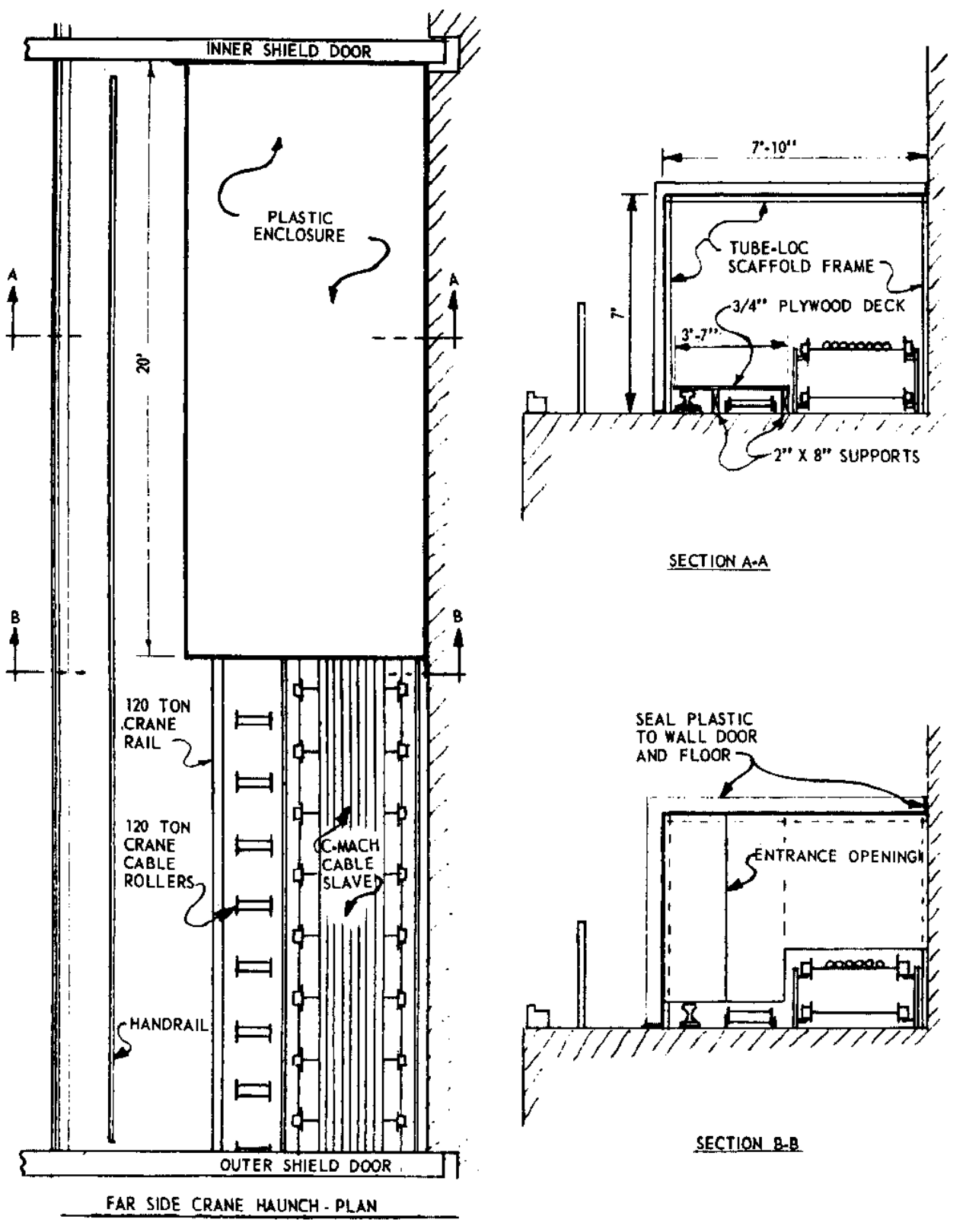

figure 27. Crane haunch plastic enclosure 

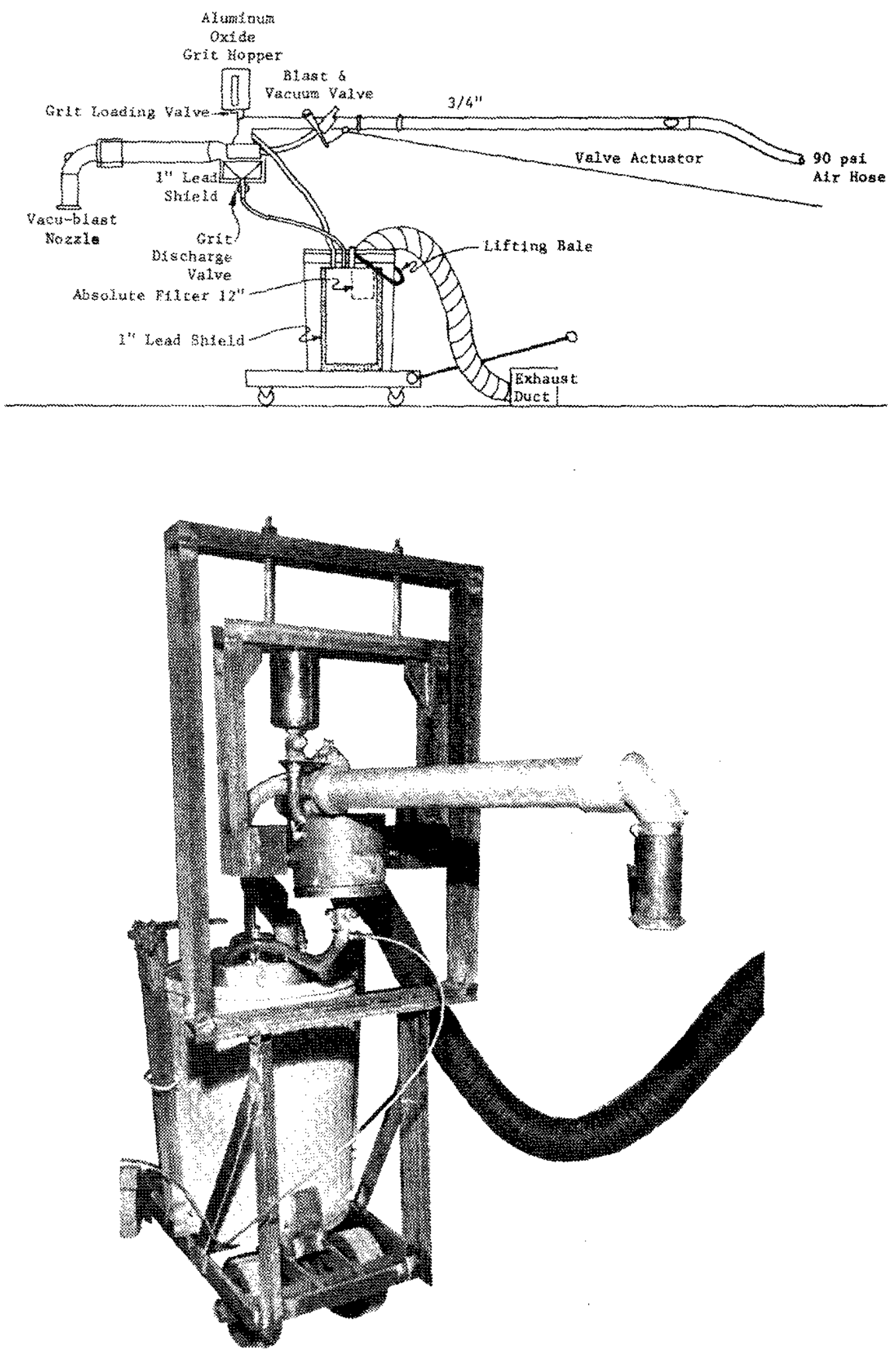

FIGUNE 28. SANOBLAST EQUIPMENT 


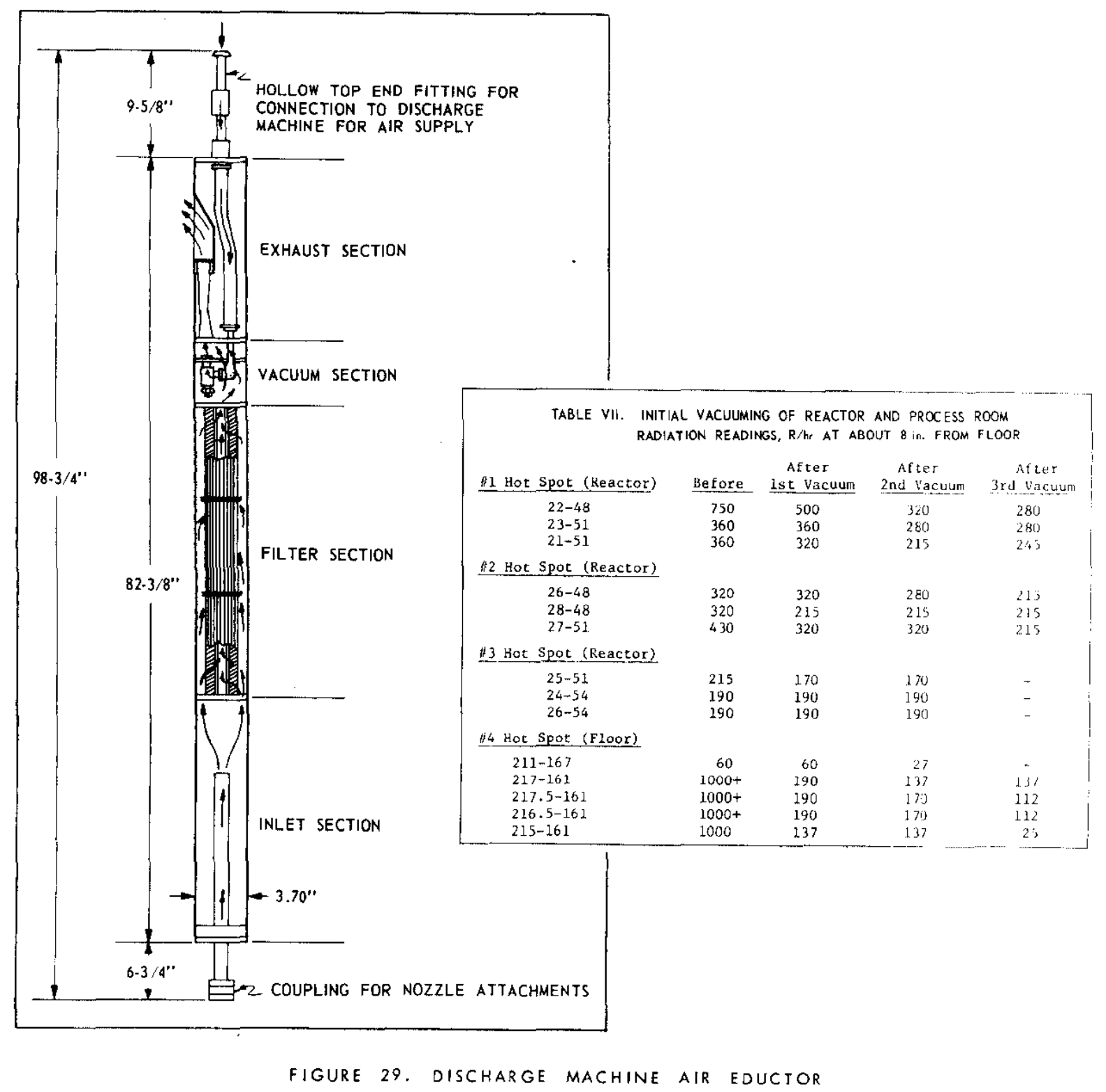




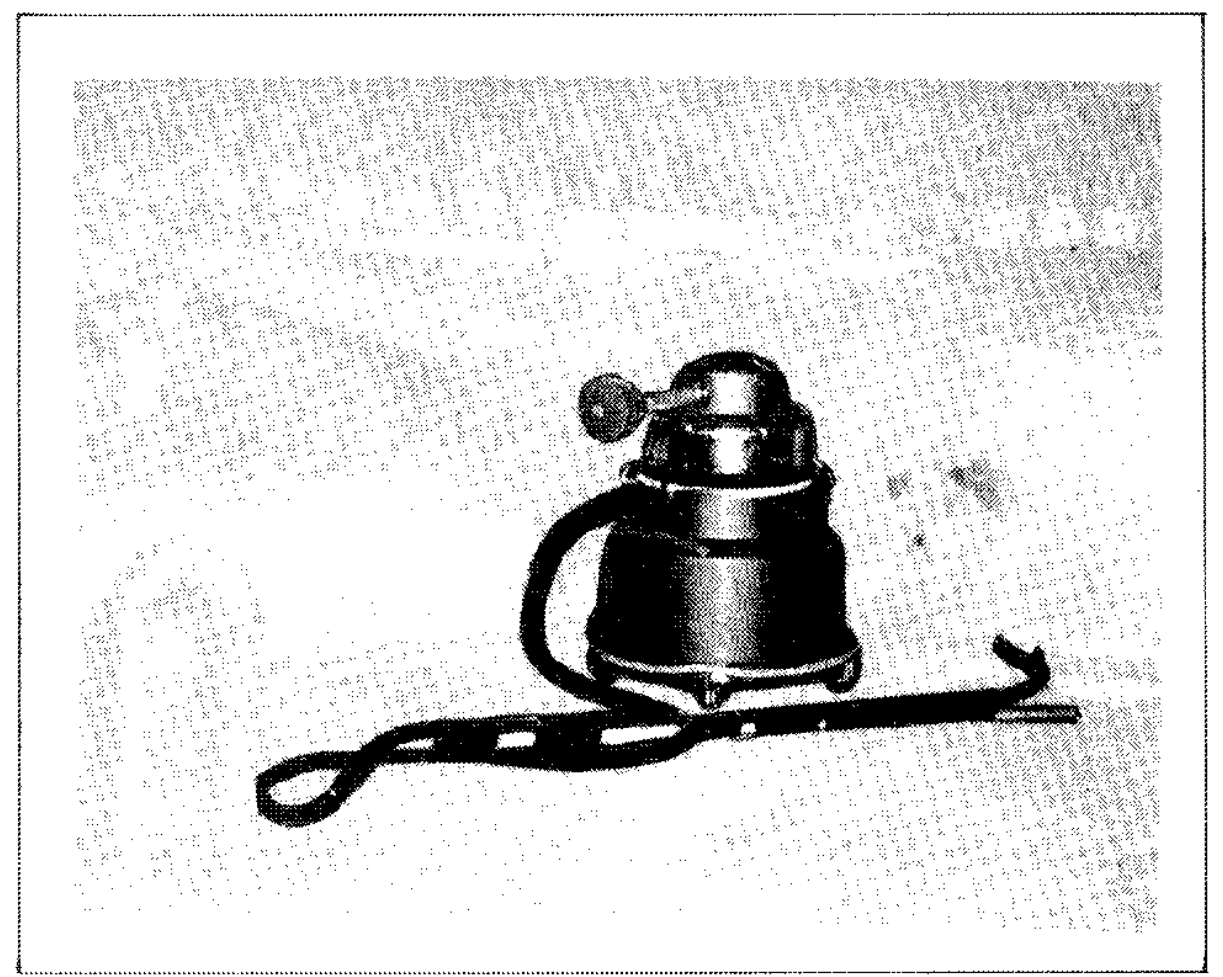

FGURE 30. PROCESS ROOM MANUAL VACUUM CLEANER UNote exhousthiter, wand axtension rod) 


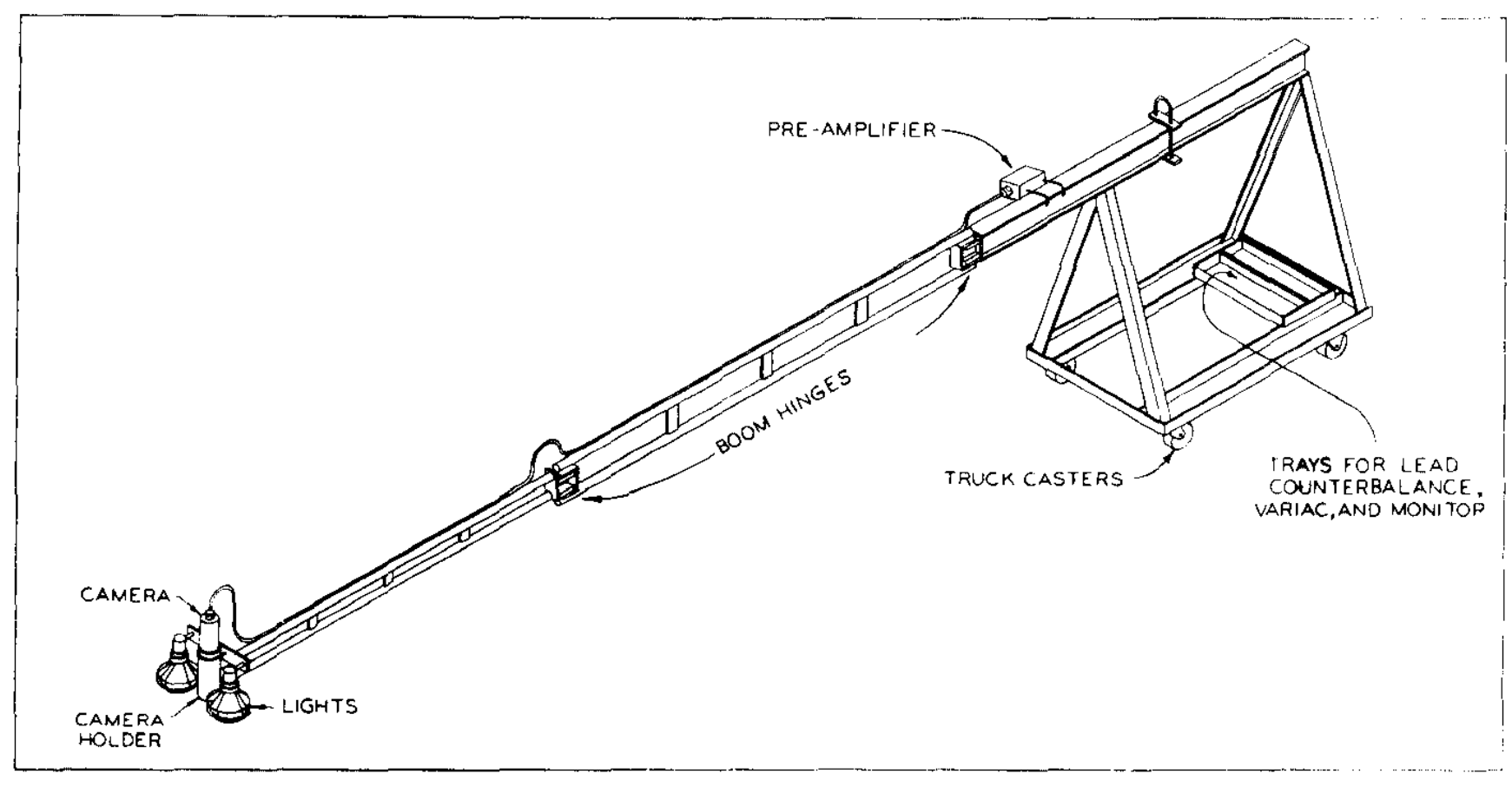

FIGURE 31. PROCESS ROOM TV CAMERA DOLLY 


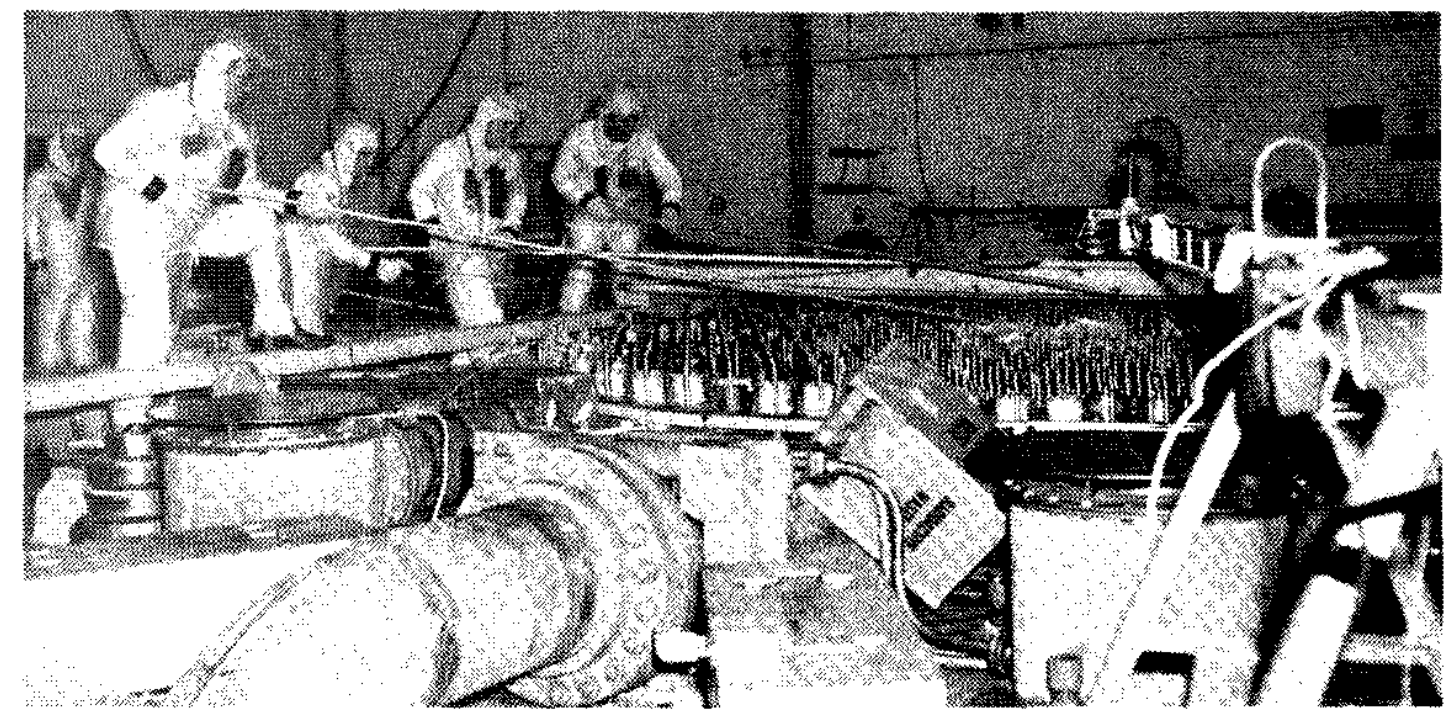

FGURE 32. PLACING SAGS OF LEAD SHOT ON TANK TOP



FGURE 33. COMPOSIE PHOTOGRAPH OF REACTOR TANK TOP

Used os guide in stripoing wires from tonk top 

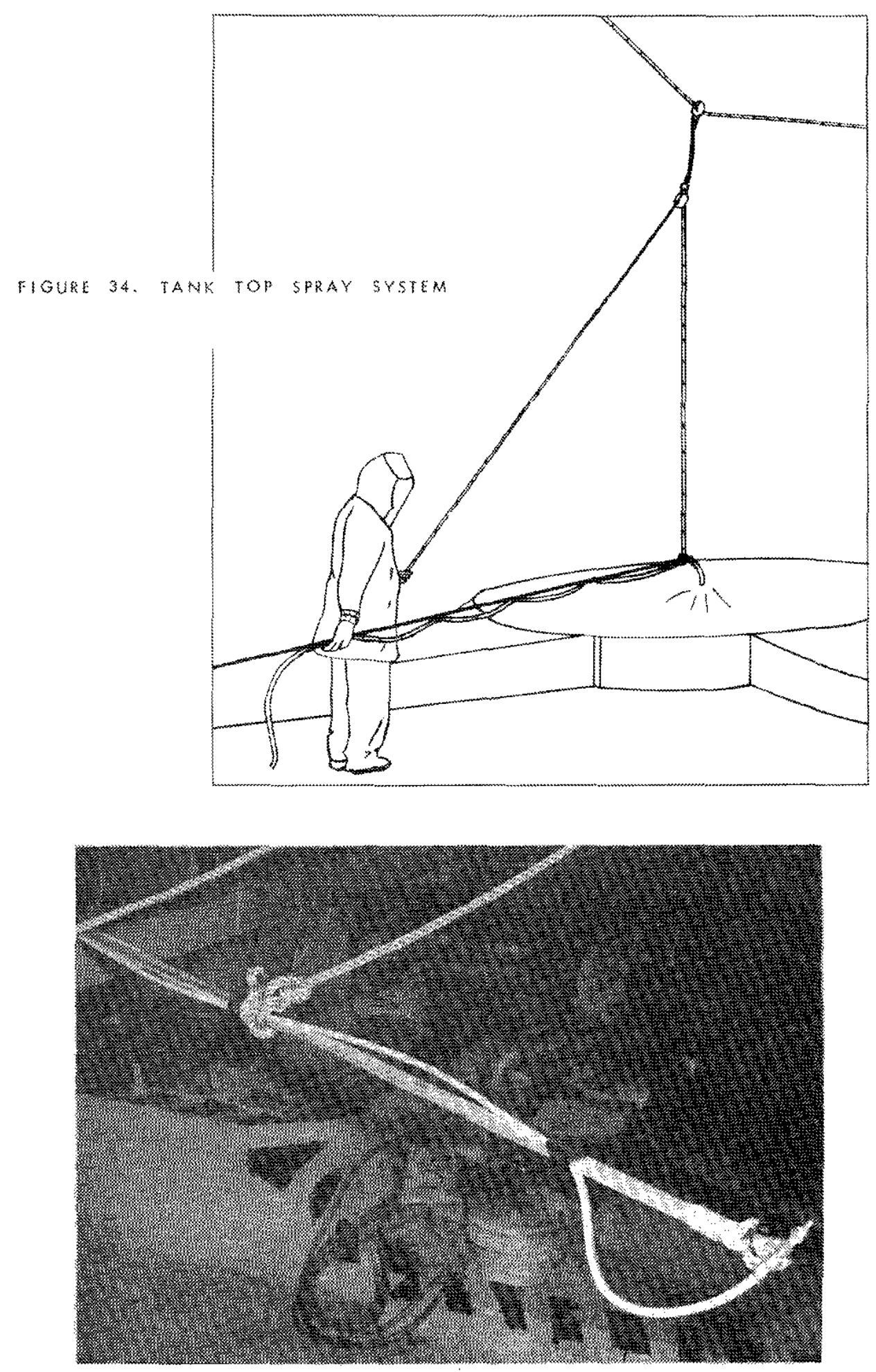

FIGURE 35. TANK TOF SPRAY NOZZLE 


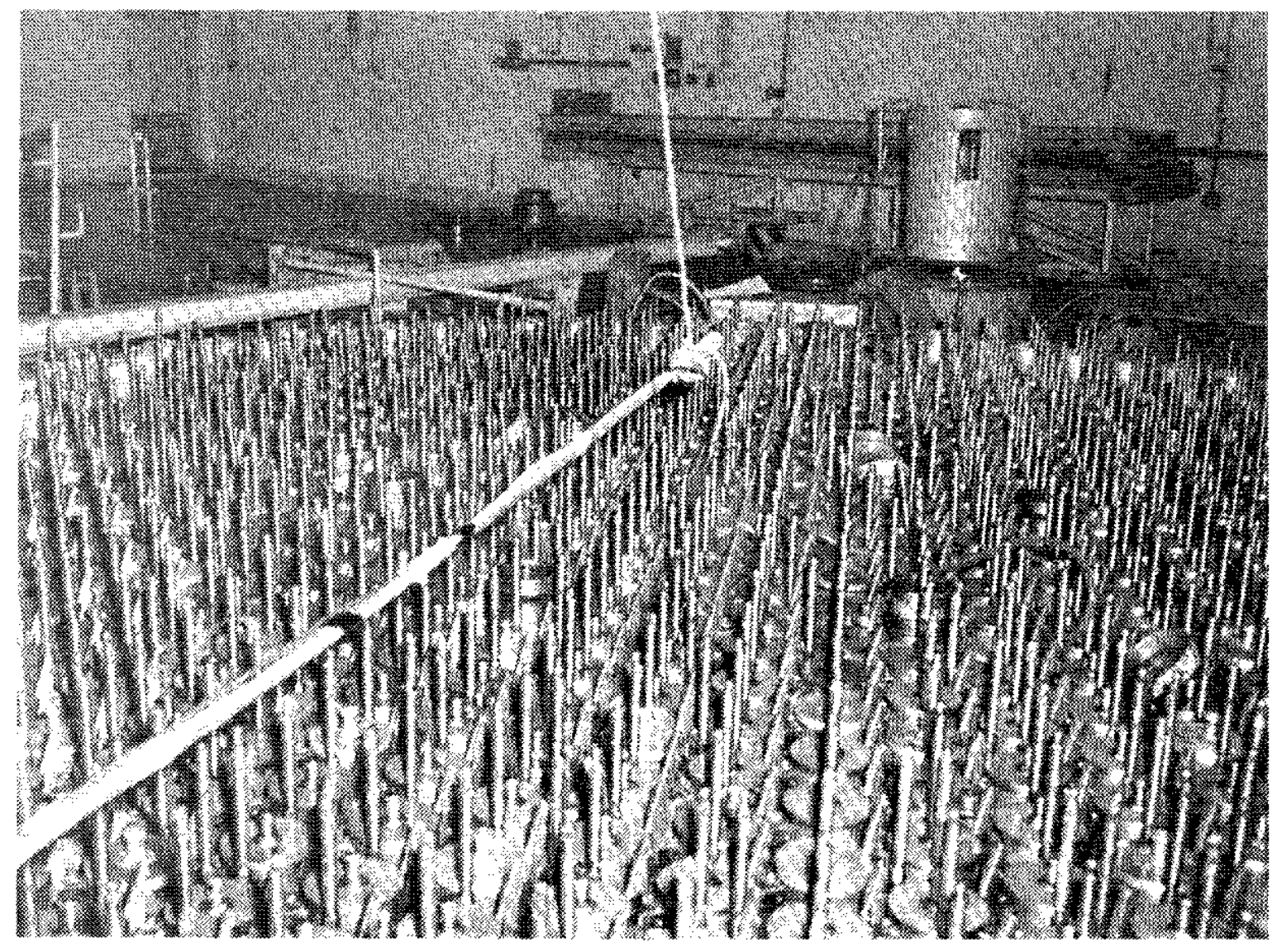

FIGURE 36. TANK TOP SPRAYING 


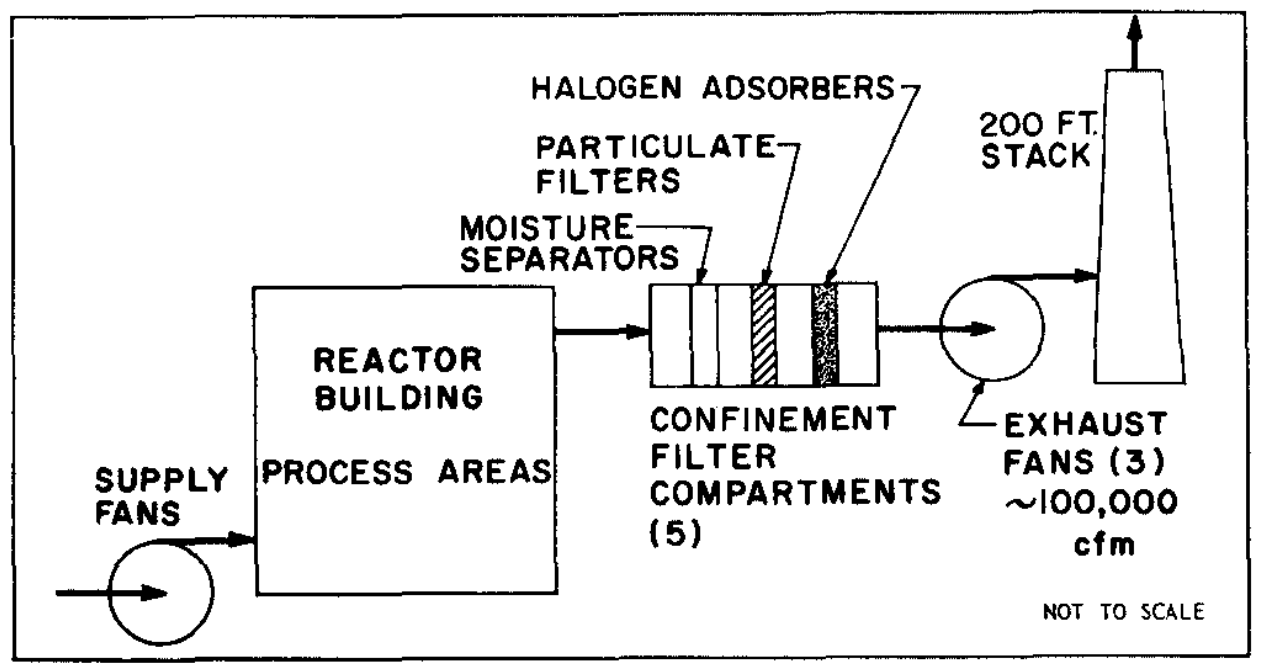

FIGURE 37. SCHEMATIC OF VENTILATION SYSTEM

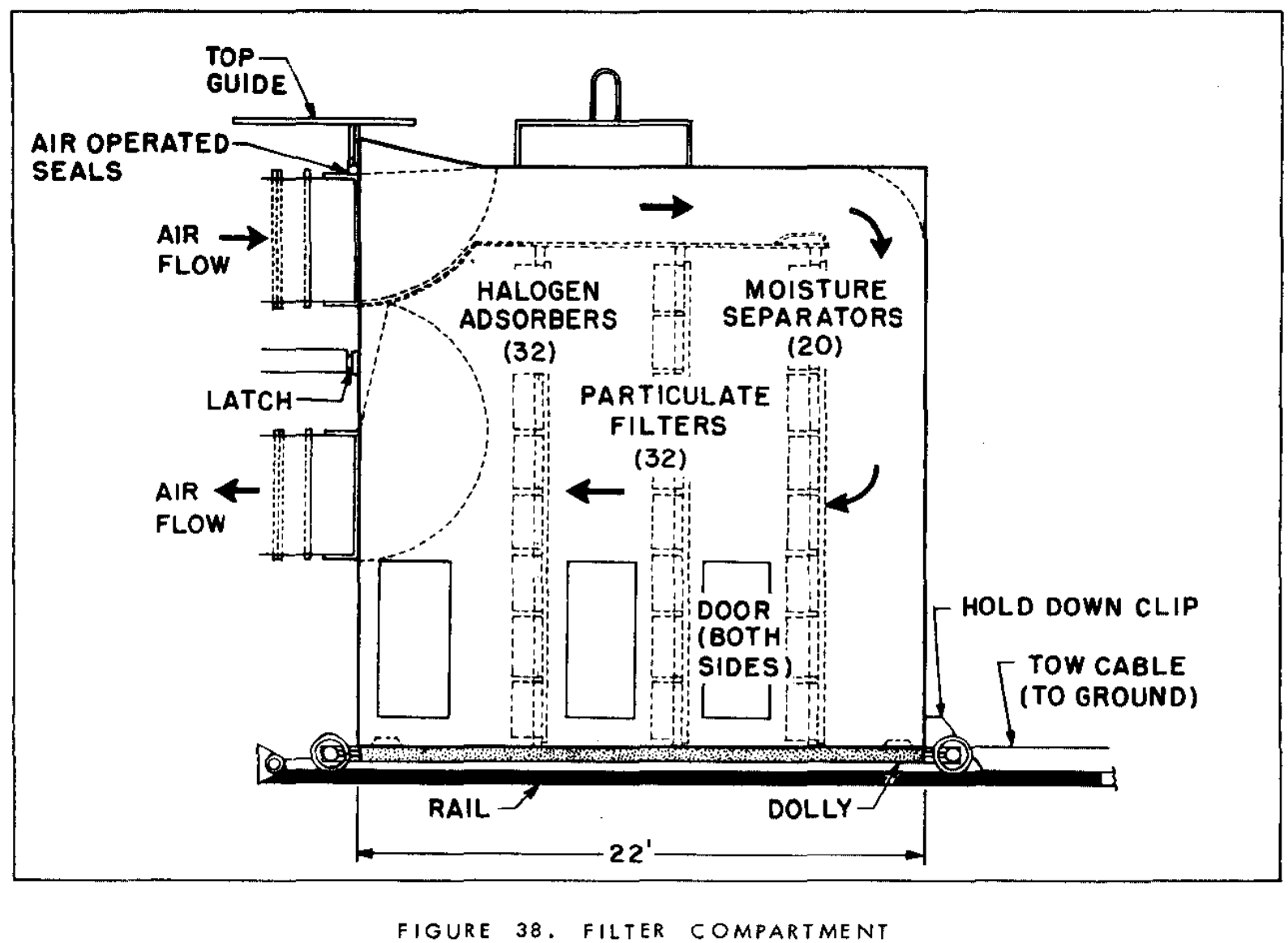




\begin{tabular}{|c|c|c|c|c|c|c|}
\hline \multirow[b]{3}{*}{ Comprtment } & \multirow{2}{*}{\multicolumn{2}{|c|}{ TABLE VIt: }} & \multicolumn{4}{|c|}{ FILYER DEYAVIOR } \\
\hline & & & \multicolumn{2}{|c|}{ stiparecoss } & \multicolumn{2}{|c|}{ Partarulate } \\
\hline & Prist & At Berova & $p_{n+0}$ & AE KRemioval & Erior & Af Bemoval \\
\hline$x-2$ & 20,600 & 15,200 & 2.22 & 4.39 & 0.66 & 1.04 \\
\hline $3-3$ & 28,400 & 18,700 & 1.04 & 3.40 & 0.62 & 0.84 \\
\hline $3-3$ & 37.600 & 10,900 & 2.28 & 6.36 & 1.26 & 2.98 \\
\hline $\ln$ & 20.4049 & 16,200 & 2.0 & 3.31 & 2.14 & a. 5. \\
\hline
\end{tabular}

\begin{tabular}{|c|c|c|c|c|c|}
\hline \multirow[b]{2}{*}{ Gomptement } & \multirow{2}{*}{ 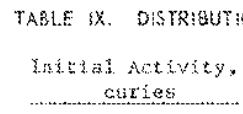 } & \multirow{2}{*}{$\begin{array}{l}\text { OF ACT: } \\
\text { Jof of } \\
\text { Sors }\end{array}$} & \multicolumn{3}{|c|}{ 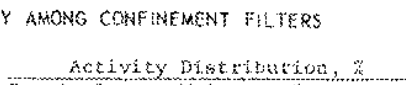 } \\
\hline & & & Marticulaze & Moisture & Esporates \\
\hline $\mathrm{k} \cdots 2$ & 032 & 26 & 24 & & 86 \\
\hline$x-3$ & 672 & 48 & 34 & & 76 \\
\hline$x-5$ & 64 & 4.7 & 0 & & 100 \\
\hline \multirow[t]{2}{*}{$k-6$} & 4 & 0.3 & 0 & & 100 \\
\hline & $\operatorname{lotal} \rightarrow 133$ & & & & \\
\hline
\end{tabular}



FIOURE 39. NOVING FILTER COMPARTMENTS (FROM L AREA) UNDER POWER (.) $3 E$ 


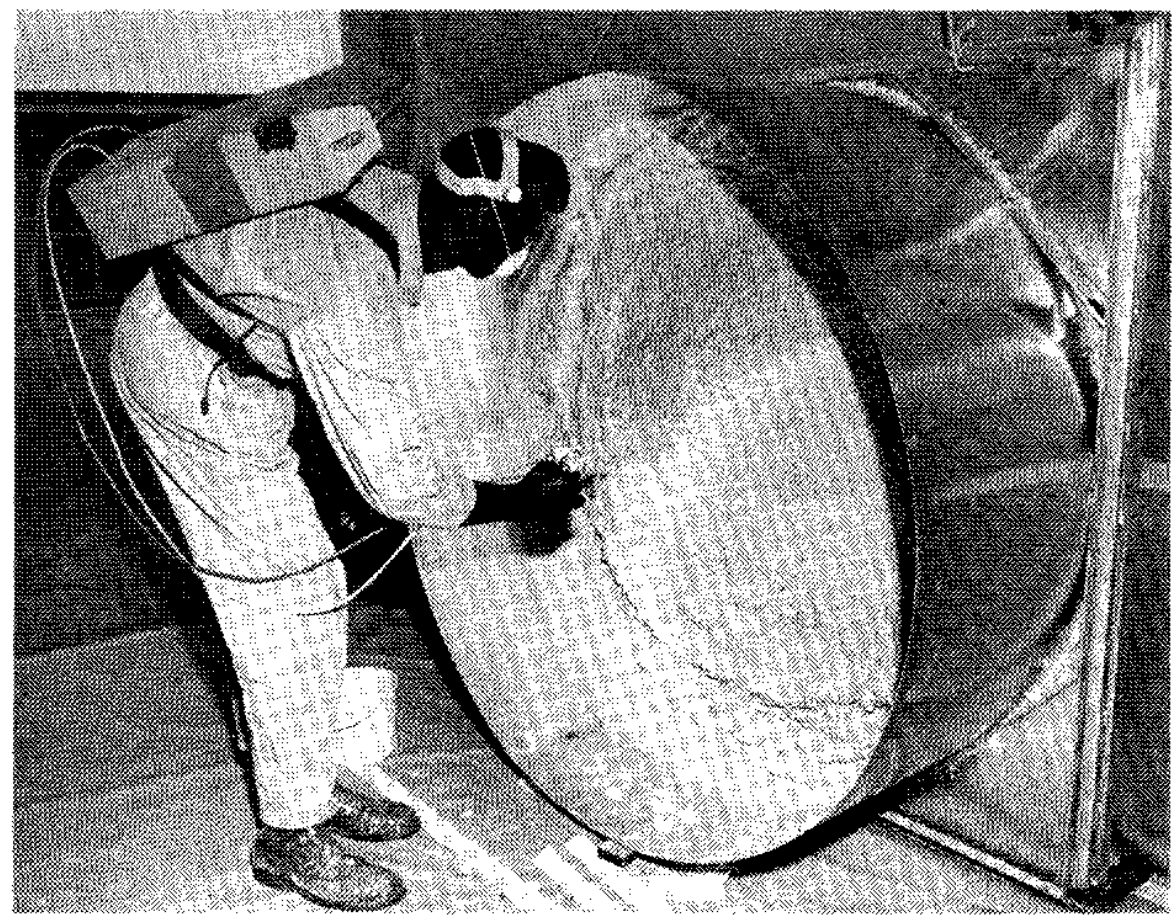

FlgURE 40. SEAIING FILTE COMPARTMENT WITH URETHANE FOAM (Prefiminary rext)

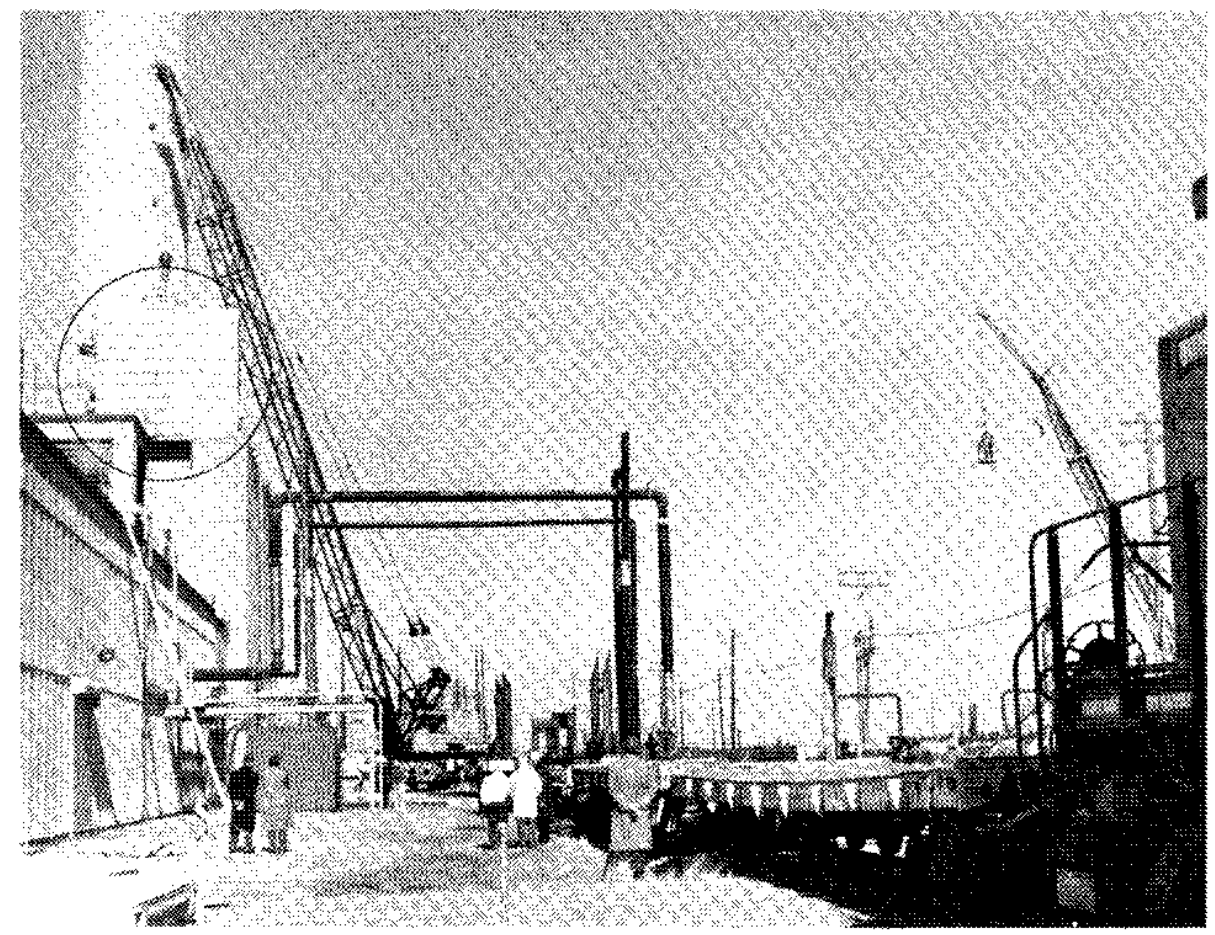

FIGURE AI. LIFTING FUTER COMPARTMENT FROM ROOF 


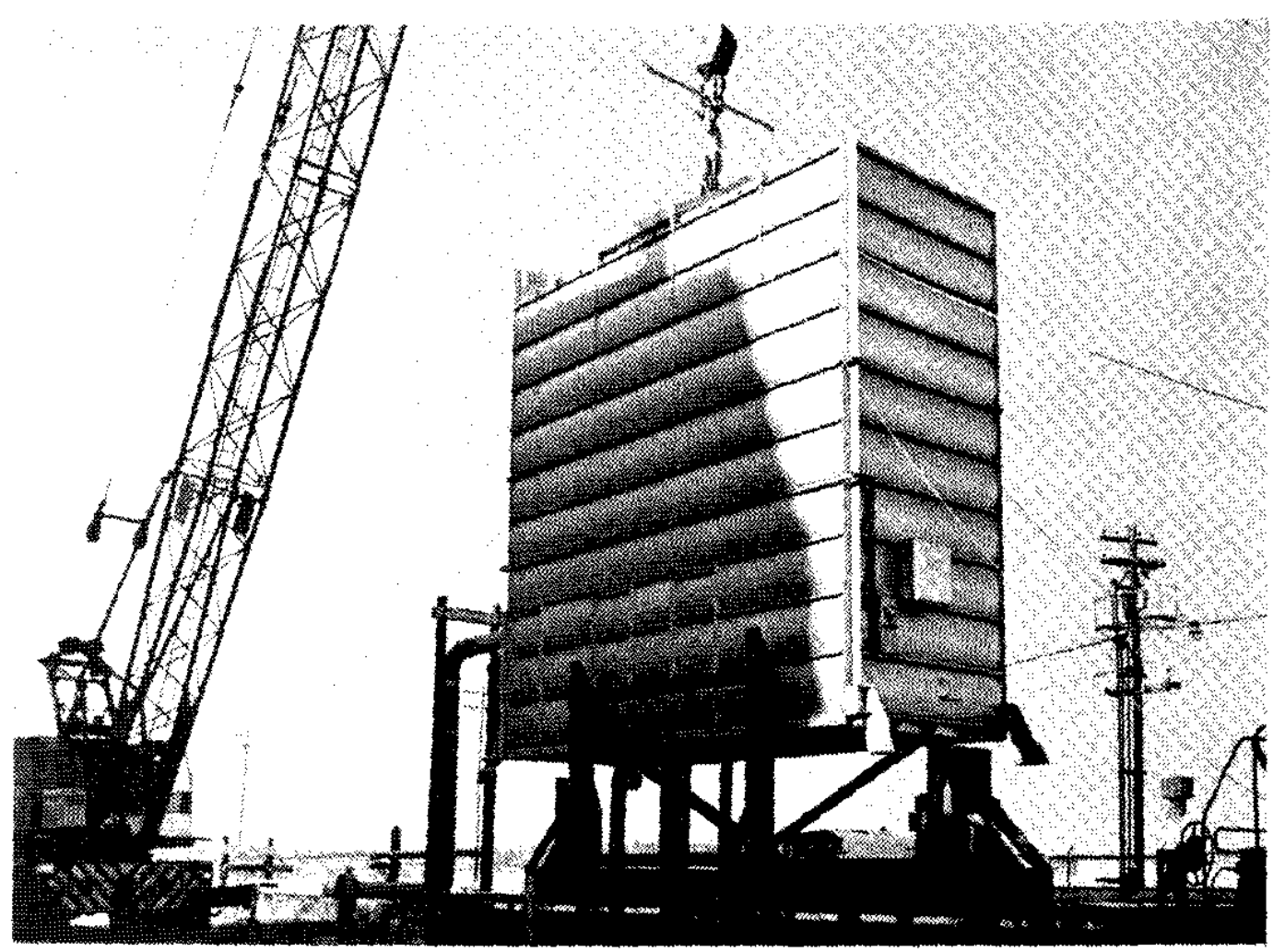

FGURE 42. FILTE COMPARTMENT GEING LOWERED ONTO FLATCAR

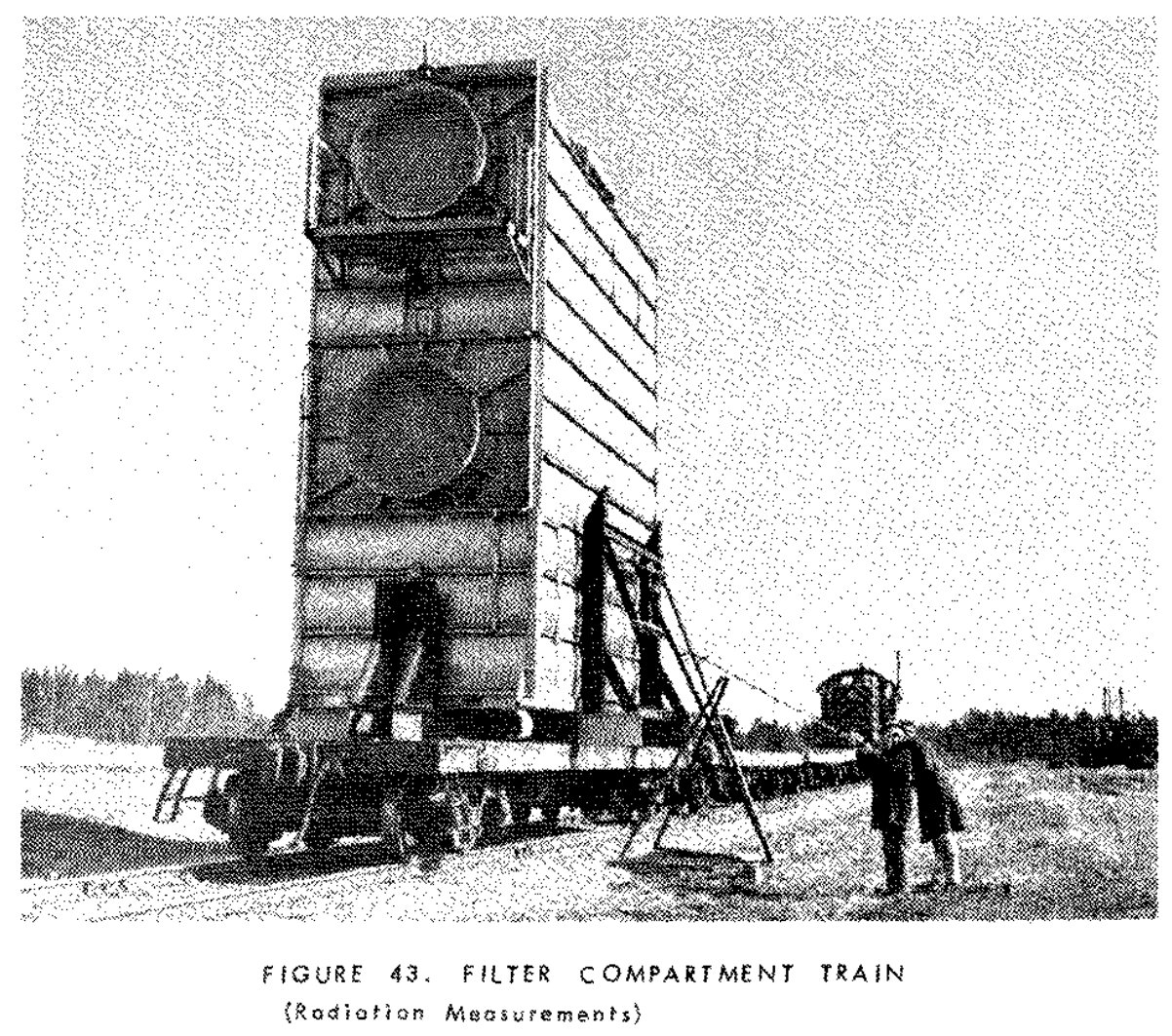




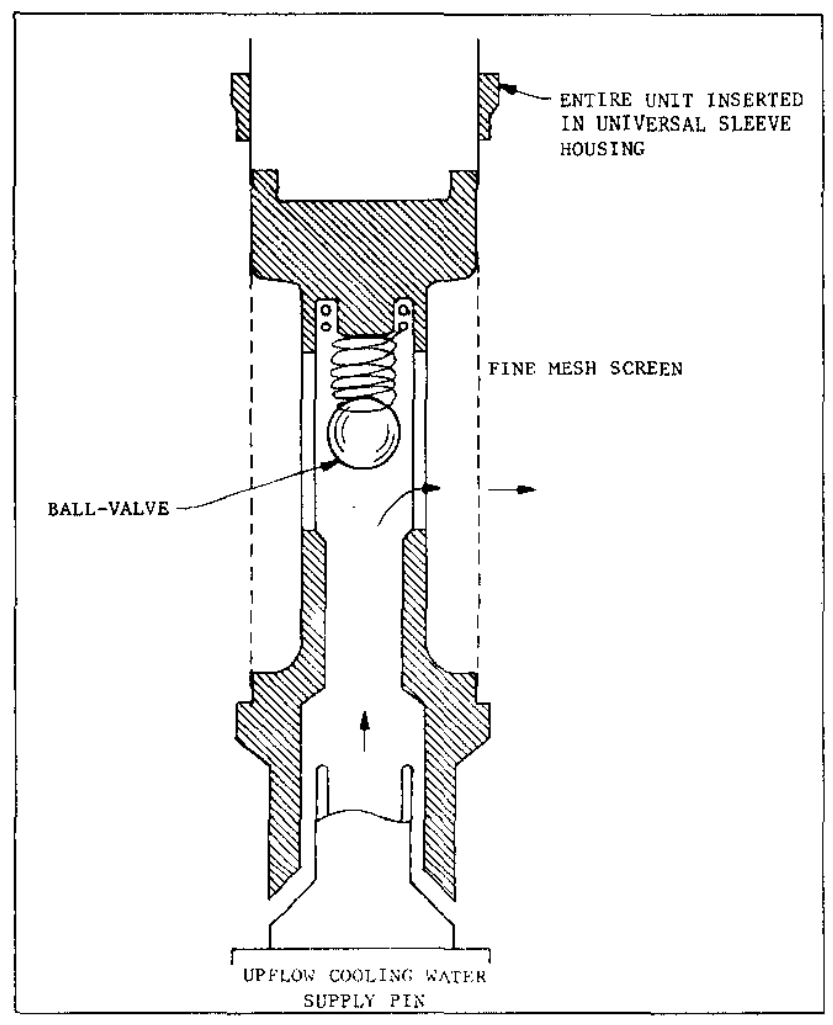

FIGURE 44. FILTER TRAP INSERT FOR "GOOSENECK" FLUSHING (Schematic) 


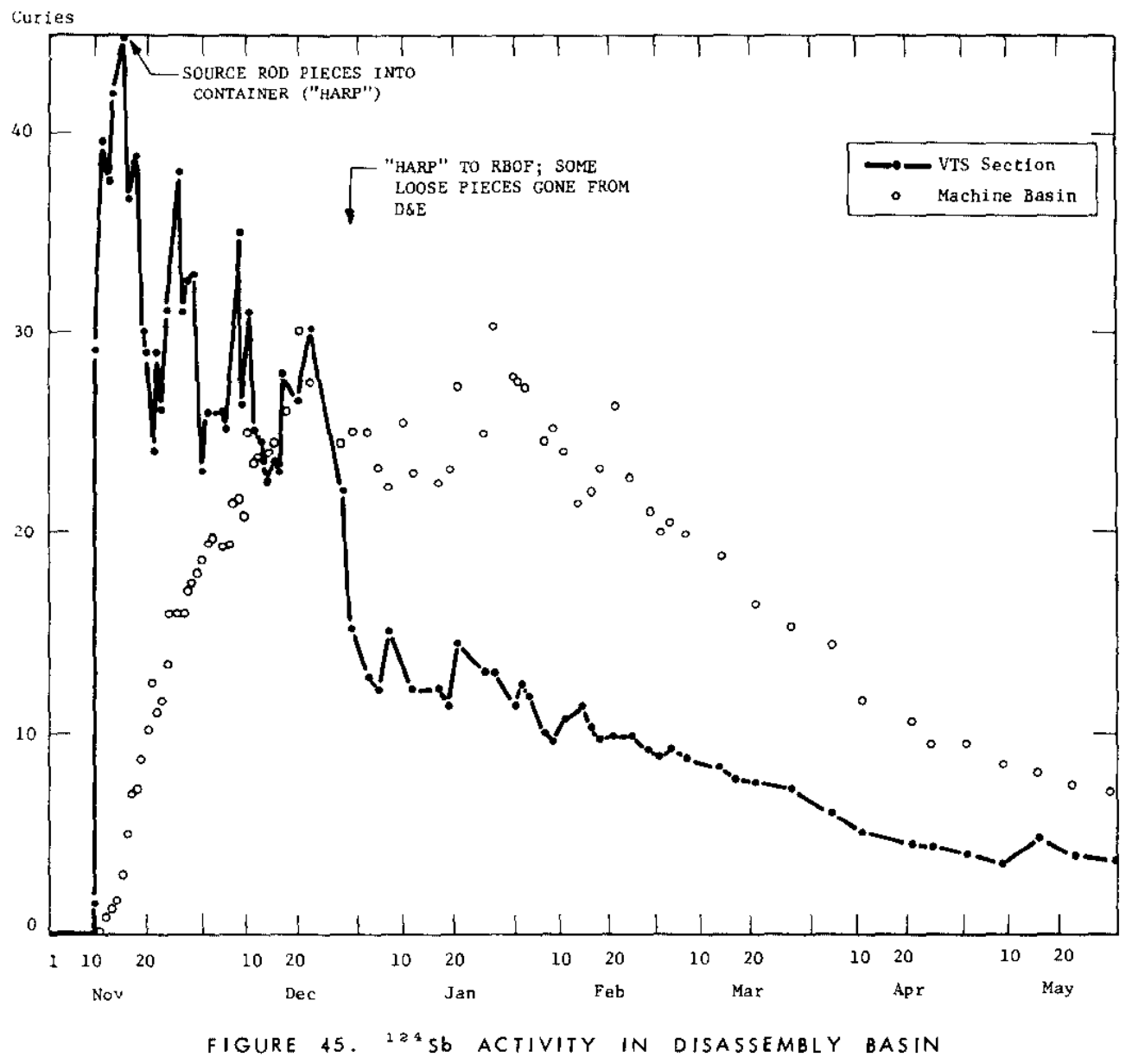



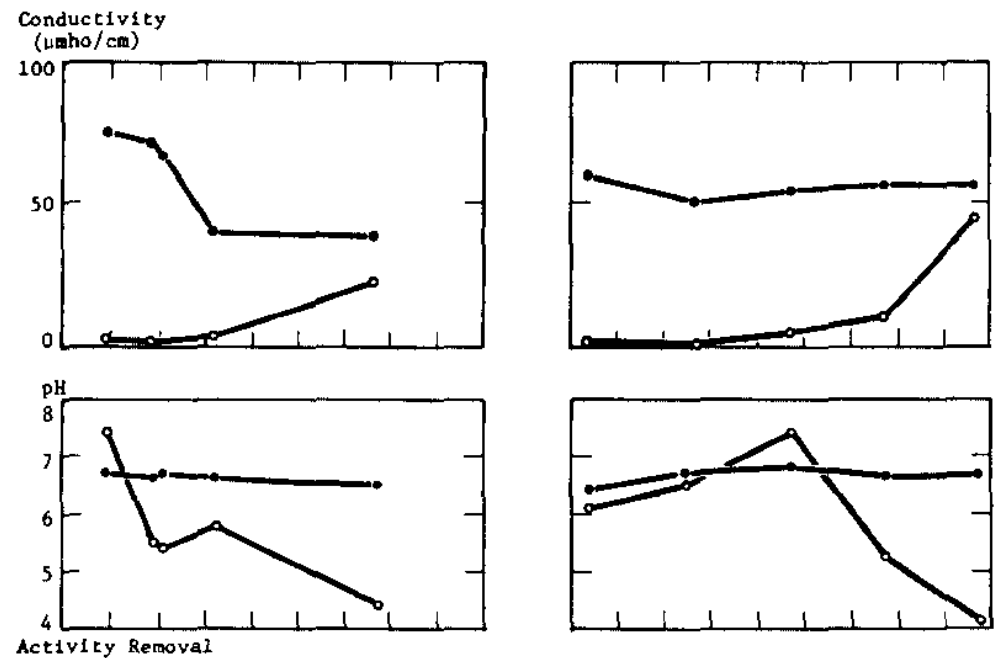

( 2 of input)
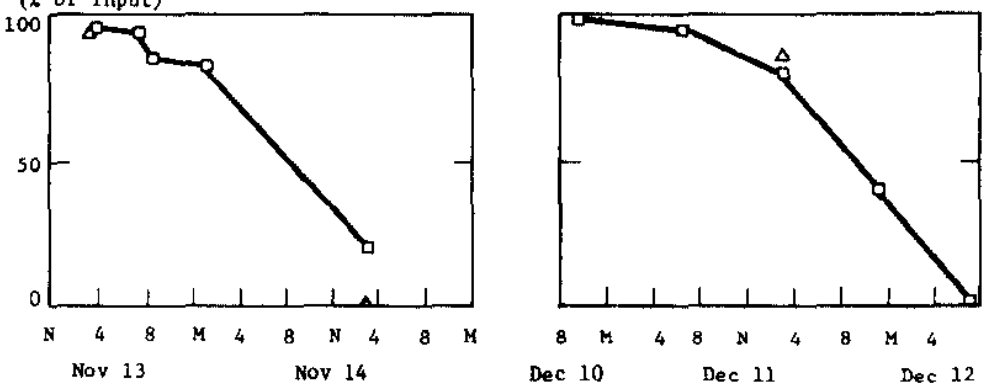

TABLE X. PERSONNEL EXPOSURE DISTRIBUTION

Exposure Range, Number of People*

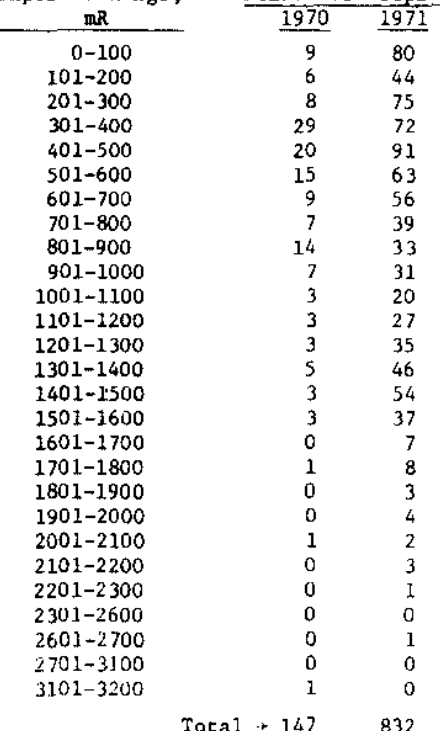

Total Exposure

(Approximate)

$93.8 \mathrm{~K} \quad 601.2 \mathrm{R}$

* Some of tine same people are included 10 boch 1970 and 1971.

NOTE: The data for 1971 represent total exposures accumulated by these people, including work othex than the $\mathrm{K}$-Area work othex than the $k-A x$ estimate of total exposure for cleanup work alone in 1971 18 $495 \mathrm{R}$, rather than 601.2 .

- Input to detonjzer

- Outlet from Delonizer

D F removal of gross $B-\gamma$ activity

$\Delta z$ removal of antimony activity 


\section{GLOSSARY}

Term

Assembly Area

B-Mast

C.Area

C-Machine

C-Mast

Canal, D \& E

Clamshell

Clamshell Plate

Compartment

Confinement Filter

Control Rod Cluster

Control Cluster Cap

Crane

Crane Control Room

Crane Wash Area

D\& E Canal

D \& E Conveyor

D-Machine

Disassembly Basin

Final Storage Section

GPR
Significance

Area where fuel assemblies are processed and stored before charging to the reactor

(See "Mast")

Area housing the $\mathrm{C}$-reactor

Reactor charging machine

(See "Mast")

Point of underwater entry of discharged fuel into the Disassembly Basin

Mechanism to guide control rods (or other reactor components) during charging; mounted under clamshell plate (See figure 24)

Mounting plate at bottom of C- or D-machine mast (See figure 26)

See figure 38,39

Retains radioactivity from ventilating system air (See "compartment")

Group of control rods housed in one septifoil (q.v.)

Cap to close the plenum tube in to which a control rod cluster is normally charged

See "C-Machine" or "D-Machine"

Located at +15 , elevation above the floor at the Disassembly end of the Process Room (behind Observation Window, figure 2)

Enclosed, shielded area for decontamination of cranes on removal from Process Room (See figure 2)

Discharge and Exit Canal (See "Canal")

See figure 22. This machine receives discharged reactor components from the $D$-machine and carries them underwater into the Disassembly Basin.

Reactor discharging machine (a duplicate of the "C-machine")

Area for underwater storage and disassembly of discharged reactor components

Section of the Assembly Area in which reactor components are stored ready for charging to the reactor

General Purpose Robot. Remotely operated electric powered robot for emergency retrieval of aropped objects from the Process Room floor or emergency discharging of reactor components. 
Term

Harp

HM Chambers

Latches

Mast

\section{Observation Window \\ Periscope \\ Peter's Tongs \\ Plenum \\ Plenum Tubes \\ Presentation Point}

Probe Pins

Process Room

RBOF

Reactor Room

Reactor Charging Room

Robot

Second Sb-Be Source Rod

Septifoil

Universal Sleeve-

housing
Container for storage of failed fuel in the Disassembly Basin. Its configuration resembles a harp.

Permanently installed ion chambers for monitoring Process Room radiation levels

Mechanism to restrain motion of certain reactor components (visible in figure 36 between rows of probe pins).

Each charge or discharge machine carries three vertical "masts." Each mast handles one class of reactor components, providing support and vertical motion. The $\mathrm{C}$-mast handles control clusters (see figure 1).

Window in Crane Control Room for observation of Process Room

Located in Crane Control Room adjacent to Observation Window, for telescopic observation

SRP design extension tool for underwater gripping

Top unit of reactor structure (See figure 1)

Tubes protruding through the plenum, which accept dischargeable reactor components

Point at which fuel assemblies are presented to the $\mathrm{C}$ machine for charging to the reactor: located in front of the Presentation Slot (figure 2)

Pins protruding vertically from the plenum to aid in positioning the $\mathrm{C} \& \mathrm{D}$ machines over the plenum tubes (See figure 36)

Reactor charging room (figures 1 and 2)

Receiving Basin for Off-Site fuel, located in the Savannah River "200 Area."

See Process Room

\section{See GPR}

Two source rods (in different clusters) were removed from the reactor to permit charging fresh septifoils. In point of time, this was the first to be removed. It was recharged without mishap.

Aluminum housing for a control rod cluster in the reactor

Special type of fuel housing 
Term

Significance

Upper Plug

VTS

Vertical Tube Storage

Waterpan

Wild Level Hole

$X$

Y

Z
A type of closure for plenum tubes

See Vertical Tube Storage

Section of the Disassembly Basin into which discharged reactor components are first placed in storage, awaiting the disassembly operation.

It can be isolated from the rest of the basin.

Pan to catch $\mathrm{D}_{2} \mathrm{O}$ drainage from discharged reactor components. It swings aside to permit charging (See figure 24).

A channel through the concrete wall for sighting with a surveying instrument (See figure 2)

Motion coordinates of the C \& D machines. $\mathrm{X}$ is lengthwise of the Process Room, $\mathrm{Y}$ is crosswise and $\mathrm{Z}$ is vertical. 


\section{REFERENCES}

1. Joseph, J. W., J. W. Little, "Activity Confinement and Decontamination After Failure of an Antimony-Beryllium Source Rod," DPSPU 71-30-10, June 1971. (To be published in Nuclear Safety, 1973).

2. Ayres, J. A. (editor), "Decontamination of Nuclear Reactors and Equipment," The Ronald Press Co., New York (1970).

3. Meservey, A. B., "Peroxide Inhibited Decontamination Solutions," USAEC report ORNL-3308, January 2, 1963.

4. Little, J. W., J. W. Joseph, "Confinement of Airborne Activity from Melted Antimony Slugs," DPSPU 71-30-20X, December 1971. (presented at the 12th AEC Air Cleaning Conference, August 28-31, 1972.

5. List, J. A., "The SRP Production Reactor Containment Program," Eighth USAEC Air Cleaning Conference, TID-7677, pp 273-279, October 1963.

6. Durant, W. S., "Performance of Airborne Activity Confinement Systems in Savannah River Plant. Reactor Buildings," Ninth AEC Air Cleaning Conference, CONF-660904, pp 348-367, January 1967. 